JEFFREY R. SHAFER

Federal Reserve Bank of New York

BONNIE E. LOOPESKO

Federal Reserve Bank of New York

\title{
Floating Exchange Rates after Ten Years
}

Ten years AGo, in March 1973, the United States and other nations abandoned efforts to maintain the Bretton Woods system of fixed exchange rates among the major currencies. The period of largely marketdetermined (floating) exchange rates between the dollar and other major currencies began. ${ }^{1}$ This fundamental change in the international monetary system was ratified by the Rambouillet Summit in 1975 and the Second Amendment of the International Monetary Fund's Articles of Agreement in 1978.

The debate about whether exchange rates among the major currencies ought to be fixed, freely floating, or somewhere in between has continued with considerable intensity. Strongly held but sharply contrasting views on how exchange rates behave and interact with other economic variables have been central to the debate, but differing interests and values regarding the proper role of governments in financial markets have also

We gratefully acknowledge the excellent assistance of Peter Borish and the help of Catherine Crosby with the data base. We are also indebted to the members of the Brookings Panel and to Maurice Obstfeld and Kenneth S. Rogoff for insightful and helpful comments and suggestions. The views expressed here are those of the authors and are not the official views of the Federal Reserve Bank of New York or the Federal Reserve System.

1. The Canadian dollar had been floating since May 1970; the pound sterling, since June 1972; and the yen, since February 1973. Transitional floats were permitted on several occasions in the later years of the Bretton Woods period, but the change in U.S. policy in March 1973 marked the end of that period. 
been important. ${ }^{2}$ The strongest advocates of fixed exchange rates, proponents of the reestablishment of a gold standard, and the strongest advocates of a free float, the monetarists, tend to share a desire to eliminate any discretionary element in economic policy. Those who see a role for discretion generally take intermediate positions, but also vary widely in how much flexibility they would permit in exchange rates.

In this paper we review what the ten years of experience with a floating exchange rate can reveal about how exchange rates behave. We conclude that no simple existing theory explains the behavior of rates well enough to provide a strong case for any mechanical approach to exchange rate management. Uncertainty about how exchange rates behave over periods as long as several years is itself one of the most important facts to consider in choosing among alternative strategies for managing exchange rates and, more generally, in formulating macroeconomic policies in an interdependent world.

\section{The Transition from Fixed to Floating Exchange Rates}

During the late 1960s and early 1970s, the system of fixed exchange rates established at the Bretton Woods Conference in 1944 showed

2. The strong presumption underlying the Bretton Woods system, that free multilateral trade requires fixed exchange rates, was based in large part on the dislocations accompanying the interwar experiences with flexible rates. The classic indictment of the flexibility of exchange rates during that period is by Ragnar Nurkse in International Currency Experience: Lessons of the Inter-war Period (Geneva: League of Nations, 1944). Milton Friedman's influential article is a response to that indictment. See Friedman, "The Case for Flexible Exchange Rates," Essays in Positive Economics (University of Chicago Press, 1953), pp. 157-203. Notable later contributions to the debate are Egon Sohmen, Flexible Exchange Rates (University of Chicago Press, 1969); J. E. Meade, "The Case for Variable Exchange Rates," Three Banks Review, vol. 27 (September 1955), pp. 3-27; Harry G. Johnson, “The Case for Flexible Exchange Rates, 1969," Federal Reserve Bank of St. Louis Review, vol. 51 (June 1969), pp. 12-24; Charles P. Kindleberger, "The Case for Fixed Exchange Rates, 1969," in Federal Reserve Bank of Boston, The International Adjustment Mechanism, Conference Series 2 (FRBB, 1970), pp. 93-108; and Robert A. Mundell, "Uncommon Arguments for Common Currencies," in Harry G. Johnson and Alexander K. Swoboda, eds., The Economics of Common Currencies (London: Allen and Unwin Ltd., 1973), pp. 114-32. Recent assessments include Jacques R. Artus and John H. Young, "Fixed and Flexible Exchange Rates: A Renewal of the Debate," IMF Staff Papers, vol. 26 (December 1979), pp. 654-98; and Morris Goldstein, Have Flexible Exchange Rates Handicapped Macroeconomic Policy? Special Papers in International Economics, 14 (Princeton University, International Finance Section, June 1980). 
increasing signs of stress. Despite widespread capital controls, capital flows and consequent intervention requirements expanded to levels that alarmed policymakers. Imbalances in the current account seemed to be giving off signals of fundamental disequilibrium with growing frequency. Monetary authorities increasingly observed situations in which the monetary policy they believed was appropriate from a domestic standpoint and the policy that would bring about external balance were in conflict. Par value changes and periods during which countries permitted their currencies to float became more common. Two currency realignments in December 1971 and February 1973, involving a net depreciation of the dollar, failed to stem mounting pressure on the dollar.

It was against this background that the decision to float the exchange rate was made in March 1973. For nearly a year afterward the United States continued to advocate the establishment of a modified Bretton Woods system of fixed but adjustable par values in the Committee of Twenty on the Reform of the International Monetary System. The turbulence in international money markets following the first oil shock then persuaded officials in the United States and other countries that Humpty Dumpty could not be put back together again-at least for the time being. U.S. negotiating efforts shifted to legitimizing and establishing rules for conducting a float. These efforts culminated in the agreement at the Rambouillet Summit in November 1975.

A growing number of economists, particularly in the United States, had been advocating a shift to flexible rates for some time. Expediency in the face of an increasingly uncontrollable situation, rather than economic theory, was apparently the strongest consideration in the initial decision to float; but the theoretical arguments did influence the decisions to continue support of floating rates.

The advocates of floating exchange rates made four principal claims. First, price-adjusted or real exchange rates would be maintained at relatively constant values by stabilizing speculation and would change mainly in response to shifts or trends in the equilibrium terms of trade between economies. Second, external balance would be better maintained than under fixed rates. Imbalances in the overall balance of payments (the official settlements balance) would not arise by definition; and current accounts would be kept roughly in line with the fundamental positions of countries as net suppliers or demanders of capital, determined by wealth accumulation and investment potential. Third, econ- 
omies would be relatively insulated against macroeconomic shocks from abroad, and authorities would enjoy greater independence of monetary policies to pursue domestic stabilization goals. And fourth, national policymakers would find it unnecessary to impose restrictions on trade and capital flows for macroeconomic reasons, and existing restrictions could be discarded, thus enhancing the efficiency of resource allocation in the world economy.

Policymakers in the United States and abroad each saw an additional advantage from floating rates. For both, a floating dollar was seen as a way of escaping the asymmetry in the role of the dollar under the Bretton Woods system-the so-called "n-plus first" currency problem. This asymmetry was evident in two aspects of the way the system worked. Under the Bretton Woods system, other countries bore the principal obligation to maintain their currencies within fixed margins vis à vis the dollar through the purchase and sale of dollar assets. But they also enjoyed greater freedom to choose par values against the dollar and to change them from time to time; and the effective or weighted-average par value of the dollar resulted from the par values chosen by others.

Foreign authorities had become increasingly concerned about the consequences of the first aspect of the asymmetry: the privilege that they felt the system bestowed on the United States to follow expansionary policies unconstrained by reserve losses, particularly as U.S. fiscal deficits and monetary expansion began to be associated with the unpopular war in Vietnam. These foreign authorities saw themselves as facing an unpleasant choice between accepting indefinitely large accumulations of dollar reserves or getting in step with U.S. policy. ${ }^{3}$ Foreign official holders of dollars were paid interest and sometimes were given an exchange rate guarantee on their dollar investments, but they did not see this as balancing the scales.

At about the same time there was growing distress among U.S. authorities about the consequences of the second aspect of the asymmetry-the difficulty of achieving an appropriate effective value of the dollar. Changing the value of the dollar entailed a systemic negotiation,

3. One statement of this view appears in Otmar Emminger, The D-Mark in the Conflict between Internal and External Equilibrium, 1948-75, Essays in International Finance, 122 (Princeton University, International Finance Section, June 1977). 
which had proven difficult and tedious when undertaken at the Smithsonian in December 1971 and again in February 1973. Moreover, because of its special role as a reserve currency, devaluation of the dollar was thought to threaten the stability of the system.

Not all economists were enthusiastic about the move to floating exchange rates, and many, if not most, policymakers had reservations. Skeptics were most numerous outside the United States, where there was less confidence in the self-equilibration of markets. They had several

areas of concern: (1) Speculative capital movements would be destabilizing and would lead to wide swings in exchange rates. (2) National policies, once freed of the discipline of fixed rates, would be less stable and, on the whole, more inclined to accommodate inflation. Policies, together with frequent speculative disturbances to rates, would tend to result in greater divergence and higher average levels of inflation rates. (3) Exchange rates that were not associated with underlying fundamental developments would induce undesirable fluctuations in current accounts, domestic output, employment, and inflation. (4) False signals from exchange rates and exchange rate uncertainty, per se, were thought to distort and inhibit trade and investment with adverse consequences for the allocation of resources in the world economy. (5) Trade barriers and restrictions on capital flows would proliferate as officials sought to protect their economies from the destabilizing effects of exchange rate changes.

\section{Problems in Evaluating the Period of Floating Rates}

The period of floating exchange rates has been marked by great instability in the world economy and relatively poor economic performance when compared with the 1960s, and even when compared with the 1970-72 period when the Bretton Woods system was becoming unworkable. Table 1 highlights the general decline in economic performance. But one cannot decide the argument in favor of the opponents of floating on the basis of such casual observations. On the one hand, one must keep in mind the problems with the Bretton Woods system that led to its abandonment. On the other, the past ten years are distinguished from the 1960s in a number of respects other than the 
Table 1. Economic Performance of the OECD Economies, Selected Periods, 1960-82

Percent

\begin{tabular}{cccc}
\hline Measure & $1960-69$ & $1970-72$ & $1973-82$ \\
\hline Average real GNP growth rate & 4.95 & 4.12 & 2.45 \\
Average inflation rate & 2.84 & 5.20 & 9.88 \\
Average unemployment rate & 2.73 & 3.40 & 5.34 \\
\hline
\end{tabular}

Source: Organization for Economic Cooperation and Development, OECD Economic Outlook, various issues. a. Data on total OECD unemployment commences in 1964.

exchange rate regime. These differences include the following: (1) It is unlikely that growth in the economies of continental Europe and Japan could have been sustained at the rapid pace of the 1950s and 1960s, a period that showed in part a catching up after the Second World War. (2) The period of floating rates inherited the international disequilibrium and inflationary tendencies that had built up gradually during the 1960s. (3) International trade grew in relative importance and Eurocurrency markets were developing that were relatively free of direct control by authorities. Consequently the exposure of all economies to economic and financial disturbances from abroad was potentially greater in the 1970s. (4) The major oil market shocks of 1973-74 and 1979 disturbed the world economy much more than any events that occurred in the 1960s.

Still another complication arises because the domestic monetary policies and exchange rate policies that have been pursued have changed from time to time and have often departed from the strict prescription of the advocates of floating. The unsatisfactory performance of national economies and the adjustment to the needs and possibilities of floating exchange rates led to considerable experimentation with monetary policy strategies in the 1970s, especially attempts to use monetary targets more or less stringently.

Moreover, exchange rates have not been permitted to float cleanly since March 1973, nor have exchange rate policies in any country remained settled for any extended period. Intervention strategies have differed among countries and over time, ranging from free floating, to short-run smoothing, to rather heavy intervention directed toward achieving a specified exchange rate. Capital controls have been a factor influencing exchange rates on at least some occasions, although controls 
have been a lesser influence as time has passed. ${ }^{4}$ Domestic monetary policies have ranged from benign neglect of exchange rates to giving exchange rates considerable weight in setting interest rates or monetary growth rates, and European countries have gone through several stages of experimentation with maintaining narrow margins among their currencies.

Thus, sorting out how harsh a judgment the floating rate regime deserves and whether there is a better way is difficult, even after ten years. What can be done, however, is to take stock of what has been learned about how floating exchange rates behave. Differing views on whether floating exchange rates are beneficial, what domestic policies are appropriate with a floating exchange rate, and whether exchange rates can and should be managed more tightly, independent of domestic policies, follow from different models of exchange rate determination.

The theory of exchange rate determination has undergone considerable development over the past ten years as simple models were found to explain current experience poorly and the lengthening time series introduced new phenomena for theorists to explain. One important question is how the predictions and policy prescriptions of the early advocates of floating should be modified, given the evolution of theoretical understanding of exchange rate determination. A second important question is how complacent economists should be about the current understanding of exchange rates and about any set of policy prescriptions that depends on a particular model.

The following section of this paper reviews the behavior of several important exchange rates (the dollar-deutsche mark, the dollar-yen, the dollar-pound sterling, and a weighted-average rate for the dollar against six major currencies), investigates the challenges that this behavior posed for theory, and describes the evolution of mainstream theoretical views during the ten years of floating exchange rates from 1973 to 1983. A subsequent section takes a statistical look at how much of the variance of these exchange rates can be related systematically to other variables

4. Capital controls were pervasive at the beginning of the floating rate period. The United States, Germany, and the United Kingdom have lifted their controls, and Japan has substantially liberalized capital flows; these actions support at least one prediction made by the advocates of floating rates. Only France and Italy, among the large industrial countries, now use capital controls as an important short-run policy tool, and these countries have accepted fixed parity obligations within the European Monetary System. 
that appear in the models. The central restrictions of the models from the standpoint of exchange rate policy are then examined. A concluding section presents an assessment of what economists do and do not know about exchange rates and what policies are defensible or indefensible in light of this knowledge.

\section{Exchange Rate Behavior and the Development of Exchange Rate Theory}

The theory of exchange rate determination has evolved largely from an asset view of exchange markets; that is, models have been built around the determinants of net outside supplies of stocks of assets denominated in different currencies and the demands for them. Prices in asset markets are viewed as adjusting freely, and hence stock equilibrium is assumed to be achieved very quickly, if not instantaneously, following a disturbance. Expectations are seen to play a central role in the determination of equilibrium and, reflecting the fashion in macroeconomics more generally, the rational expectations hypothesis is the norm. Goods markets are important in varying degrees, although they are generally kept in the background. At a minimum, they tie down long-run expectations and influence the demands for assets.

\section{THE FLEXIBLE-PRICE MONETARY MODEL}

The model that provides the strongest case for the advantages of the system of floating exchange rates, the flexible-price monetary model, is also the simplest model..$^{5}$ It presents the exchange rate, $S$, as the relative

5. For some early contributions to the monetary approach see Rudiger Dornbusch, "The Theory of Flexible Exchange Rate Regimes and Macroeconomic Policy," Scandinavian Journal of Economics, vol. 78, no. 2 (1976), pp. 255-75; Jacob A. Frenkel, "A Monetary Approach to the Exchange Rate: Doctrinal Aspects and Empirical Evidence," Scandinavian Journal of Economics, vol. 78, no. 2(1976), pp. 200-24; and Michael Mussa, "The Exchange Rate, The Balance of Payments and Monetary and Fiscal Policy under a Regime of Controlled Floating," Scandinavian Journal of Economics, vol. 78, no. 2(1976), pp. 229-48. Early empirical evidence was provided by Lance Girton and Don Roper, "A Monetary Model of Exchange Market Pressure Applied to the Postwar Canadian Experience," American Economic Review, vol. 67 (September 1977), pp. 537-48; John F. O. Bilson, "The Monetary Approach to the Exchange Rate: Some Empirical Evidence," IMF Staff Papers, vol. 25 (March 1978), pp. 48-75; and Robert J. Hodrick, "An Empirical Analysis of the Monetary Approach to the Determination of the Exchange Rate, " in Jacob A. Frenkel and Harry G. Johnson, eds., The Economics of Exchange Rates: Selected Studies (Addison-Wesley, 1978), pp. 97-116. 
price of two monies, $M$ and $M^{*}$ (an asterisk indicating a foreign country), each supplied as the liability of a central bank and demanded by the residents of one country. The condition for zero excess demands in money markets determines price levels in the two respective countries, $P$ and $P^{*}$. The assumption of one tradable good in the world implies a constant real exchange rate reflecting purchasing power parity, and hence a path for the nominal exchange rate determined by the paths of money supplies and outputs, $Y$ and $Y^{*}$, in the two economies. The model has an equation for domestic monetary equilibrium,

$$
M_{t}=m\left(r_{t}\right) P_{t} Y_{t}
$$

for purchasing power parity,

$$
P_{t}=S_{t} P_{t}^{*}
$$

and for uncovered interest rate parity,

$$
s_{t}^{e}=r_{t}-r_{t}^{*},
$$

where $r$ is the nominal interest rate, $e$ denotes an expected value, and a lowercase rendering of a level variable denotes its percentage change, computed as the difference in natural logarithms. In a small-country model the foreign price level and nominal interest rate, $P^{*}$ and $r^{*}$, respectively, are taken as exogenously given.

The uncovered interest-rate parity condition implies that assets denominated in different currencies are viewed by international investors as perfect substitutes in portfolios. With perfect asset substitutability and rational expectations, the fundamental behavior of exchange rates is governed by purchasing power parity. If one country has a higher expected monetary growth rate and consequently a higher expected inflation rate, assets denominated in its currency will carry a higher interest rate that is exactly offset by an expected depreciation of its exchange rate. So uncovered interest rate parity implies that expected rates of return on interest-bearing assets denominated in different currencies are equalized. ${ }^{6}$ Since in this model the rate of exchange

6. One related proposition that was settled rather early and has stood the test of time is that covered interest arbitrage (the equality of the annualized forward premium or discount and the interest differential) holds extremely well for assets having the same characteristics except for currency of denomination (for example, Eurocurrency deposits). This implies that forward markets need not be modeled explicitly. It also implies that the uncovered interest arbitrage condition is equivalent to the condition that the forward 
depreciation is just the difference in inflation rates between the two countries, this proposition holds whether returns are measured in either country's currency or in real terms. The real interest rate in the domestic economy is tied to the exogenous real rate in the foreign economy.

Although the current account does not appear explicitly in this model, the model is not inconsistent with surpluses and deficits in the current account financed by net accumulation of cross-border claims and liabilities of a nonmonetary character. However, imbalances in the current account would reflect differences in propensities to save and investment opportunities-considerations that are kept in the background and are assumed not to be influenced by exchange market developments. They would influence exchange rates only to the extent that they altered the expected future path of output.

The diagram opposite illustrates the characteristic responses of the nominal and real exchange rates to a one-time increase in the money supply and to a permanent increase in the growth rate of the money supply for the flexible-price monetary model. Prices and interest rates in the rest of the world are taken as given. The time paths for variables in the diagram assume perfect foresight by economic agents, except that the two policy changes are unanticipated. A one-time increase in the domestic money stock occurs at time $t 1$, resulting in a jump in the price level and a rise in the price of foreign exchange (a depreciation of the home currency) to new equilibrium values. The real exchange rate is unaffected. An increase in the rate of growth of the money supply occurs at time $t 2$. The rate of price increase rises immediately by the same amount as the increase in the growth rate of the money supply, and the exchange rate begins rising at the same rate, that is, the home currency

exchange rate is equal to the expected future spot rate, which provides an alternative and essentially equivalent way of testing the uncovered interest parity condition. These tests are discussed below. Interest rates in different national money markets have at times deviated from corresponding Eurocurrency market interest rates and hence from covered interest parity when capital controls have been tight. Tax requirements, reserve requirements, and risk considerations also influence covered interest parity deviations just as they lead to interest rate differentials within national markets, but for a wide range of instruments these differences are relatively small. For evidence on the covered interest arbitrage condition, see Jacob A. Frenkel and Richard M. Levich, "Covered Interest Arbitrage: Unexploited Profits?' Journal of Political Economy, vol. 83 (April 1975), pp. 325-38; Frank McCormick, “Comment," Journal of Political Economy, vol. 87 (April 1979), pp. 411-17; and Richard C. Marston, "Interest Arbitrage in the Euro-currency Markets," European Economic Review, vol. 7 (January 1976), pp. 1-13. 


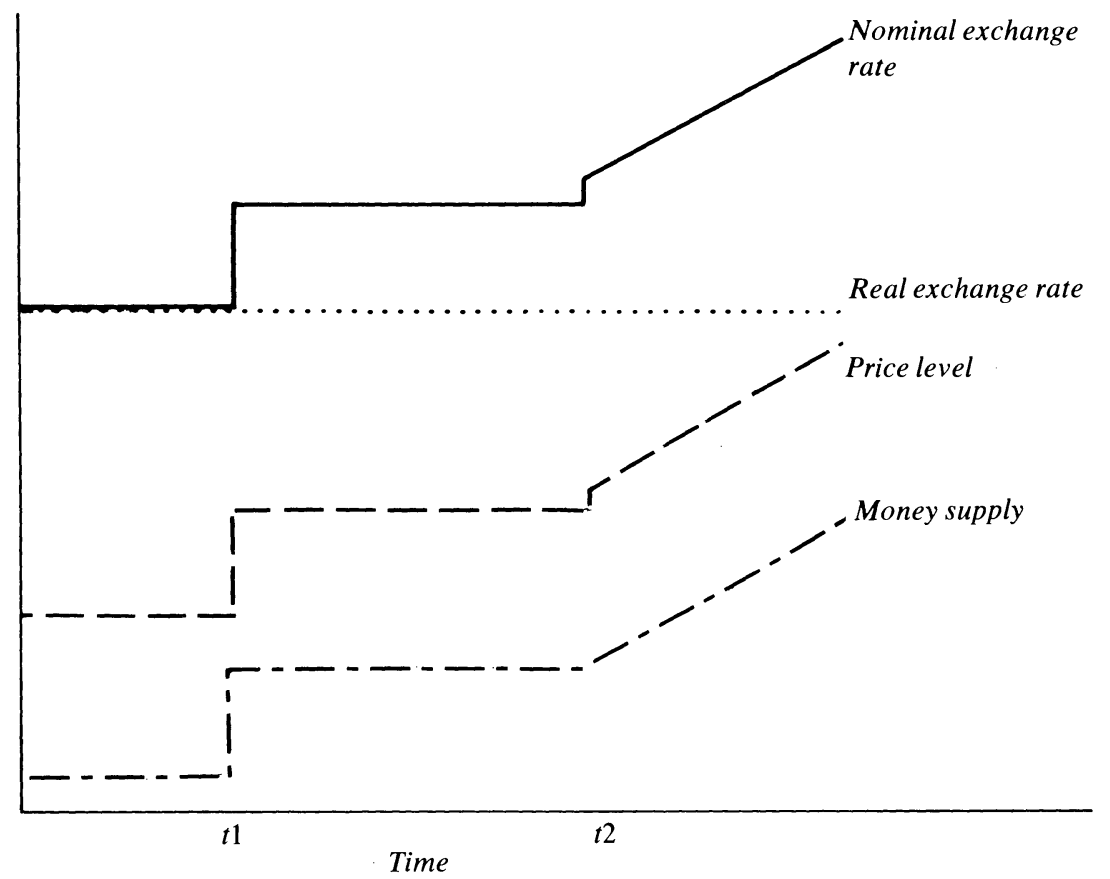

depreciates. The exchange rate and price level also jump at time $t 2$ because the demand for money depends on the nominal interest rate. But even so, the real exchange rate is unaffected.

\section{EXCHANGE RATE BEHAVIOR: MARCH I973 TO LATE I 975}

By late 1975 it was becoming clear that purchasing power parity was not well maintained and that changes over time in real exchange rates were much larger than those under fixed rates. ${ }^{7}$ Figure 1 shows the behavior of the nominal and real exchange rates over the fixed and

7. Econometric studies of purchasing power parity include Isard's study using disaggregated price data. See Peter Isard, "How Far Can We Push 'The Law of One Price?', American Economic Review, vol. 67 (December 1977), pp. 942-48. See also Paul R. Krugman, "Purchasing Power Parity and Exchange Rates: Another Look at the Evidence," Journal of International Economics, vol. 8 (August 1978), pp. 397-407; Hans Genberg, "Purchasing Power Parity Under Fixed and Flexible Exchange Rates,' Journal of International Economics, vol. 8 (May 1978), pp. 247-76; and Irving B. Kravis and Robert E. Lipsey, "Price Behavior in the Light of Balance of Payments Theories," Journal of International Economics, vol. 8 (May 1978), pp. 193-246. 


\section{Figure 1. Nominal and Real Exchange Rates ${ }^{\mathrm{a}}$}

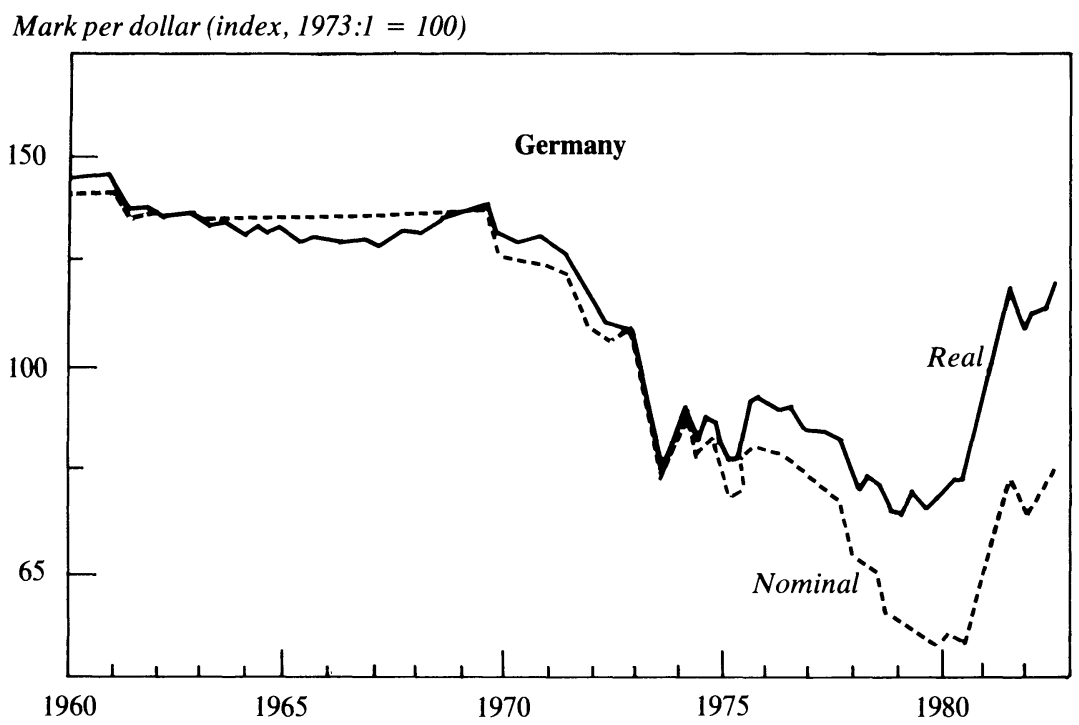

Yen per dollar (index, 1973:1 = 100)

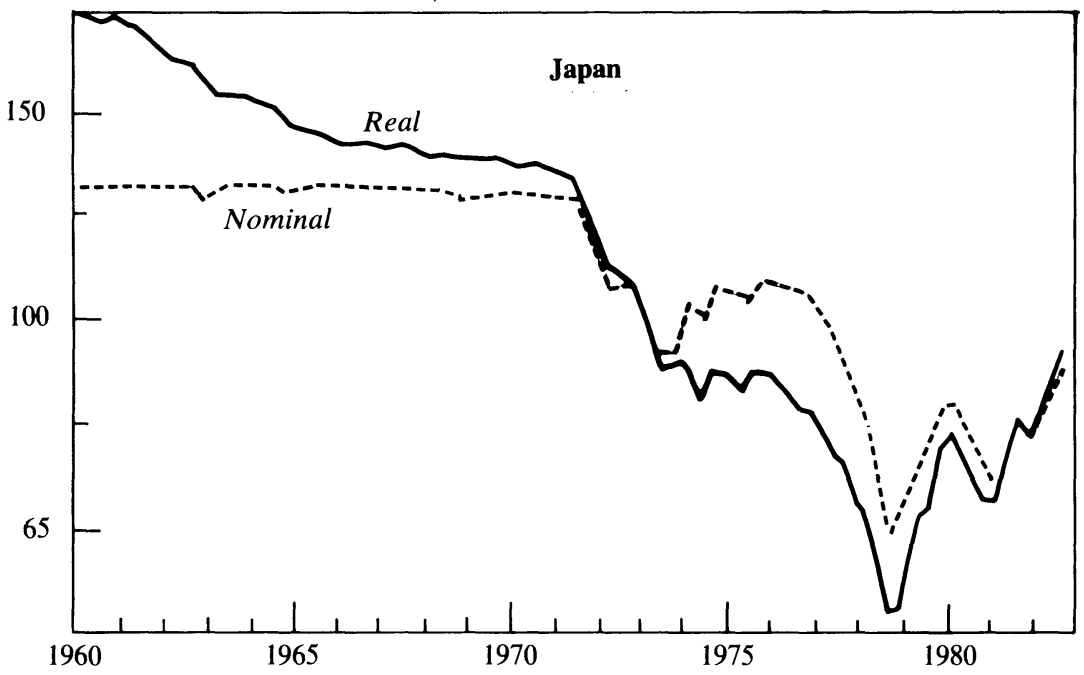

Source: Federal Reserve Bank of New York, international macro data base.

a. Quarterly data. Price adjustments use consumer price indexes. The effective U.S. dollar is the weighted average of six currencies-Canadian dollar, French franc, mark, lira, yen, and pound sterling (expressed in units of foreign 
Figure 1 (continued)

Pound per dollar (index, 1973:1 = 100)

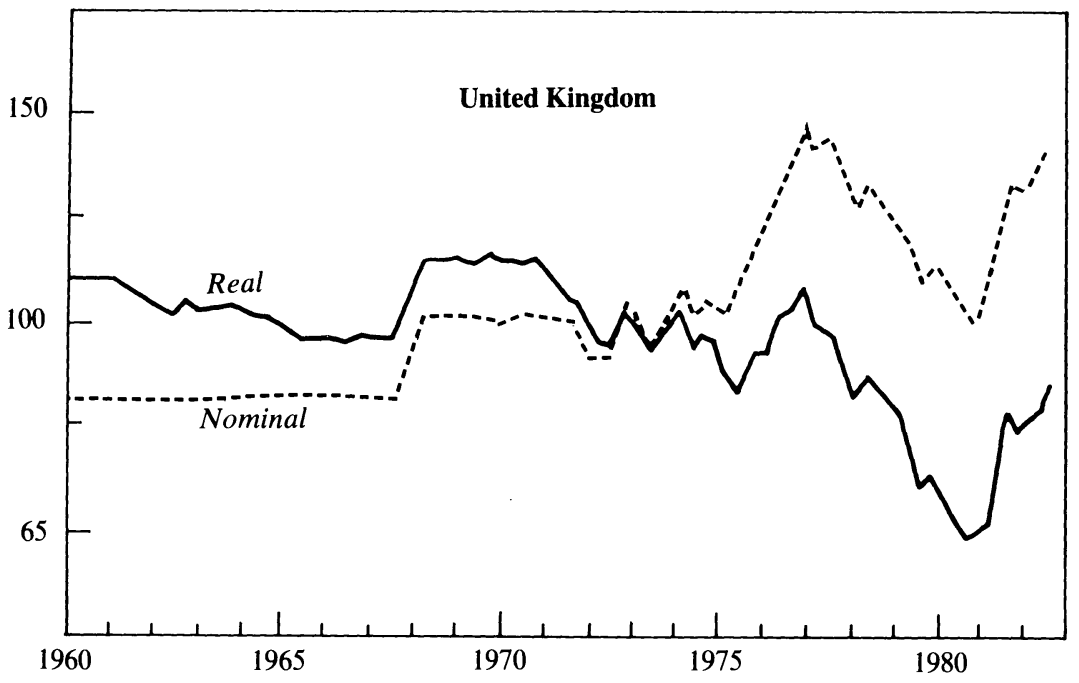

Effective U.S. dollar (index, 1973:1 = 100)

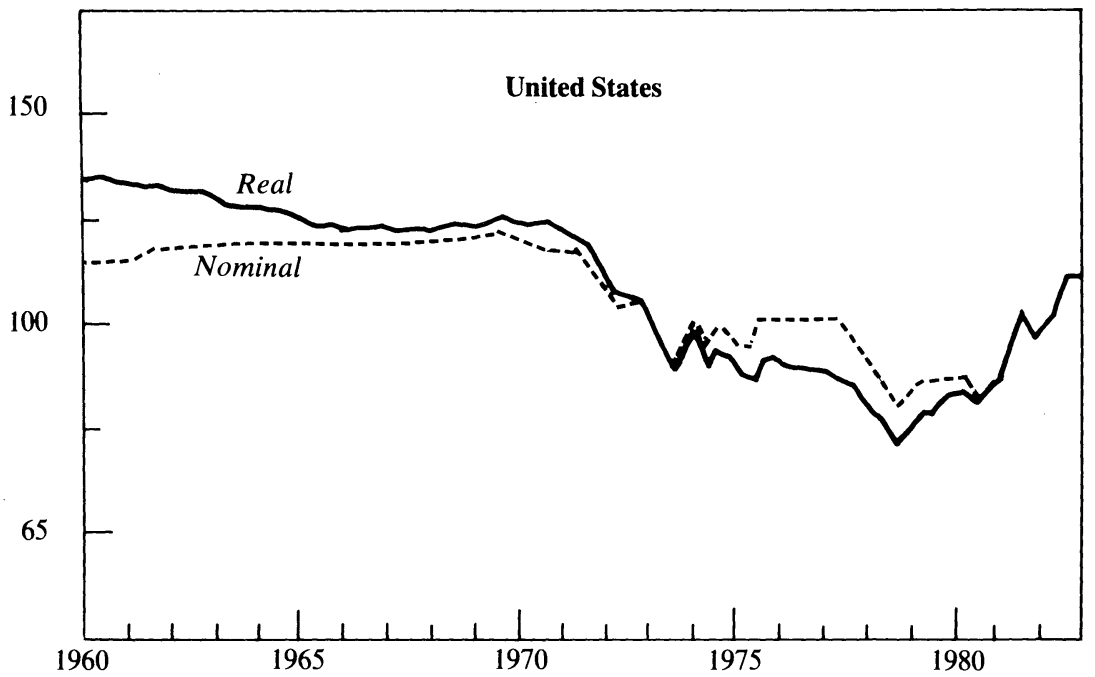

currency per dollar). Weights are from the International Monetary Fund's multilateral exchange rate model and are normalized for the six countries. 
floating rate periods for the mark, yen, and pound as measured against the dollar and a weighted-average value of the dollar against six major currencies. ${ }^{8}$

When inflation rates diverged widely, as they did between the United States and the United Kingdom from mid-1972 to 1977, the exchange rate showed some tendency to change over time so as to contain deviations from purchasing power parity. ${ }^{9}$ Nevertheless, most of the nominal exchange rate fluctuations in the period from March 1973 to September 1975 were reflected in movements of real exchange rates. These relatively short-term exchange rate swings were of great concern to many at the time, but they shriveled almost to insignificance when compared with the large sustained swings that came later.

Exchange rate movements have often been analyzed and their causes debated in terms of episodes that appear to be associated with specific events. Indeed, until a rather lengthy data record could be compiled, more formal statistical techniques were of little value. After the decision to float exchange rates, the dollar continued to depreciate for several months in both nominal and real terms, especially against the mark. This depreciation was widely explained as a continuation of the adjustment to the misalignment of the dollar and the mark that had built up during the Bretton Woods period, but some market observers expressed concern that speculation against the dollar was feeding on itself and was carrying the dollar to unrealistically low levels. The dollar ultimately stabilized and recovered somewhat after July 1973, but not before U.S. authorities had tempered their policy of benign neglect and intervened to resist the slide.

The dollar strengthened against most currencies following the Arab oil embargo of October 1973 and the quadrupling of oil prices at the end of the year. The pound was also remarkably strong in the wake of the oil shock, considering the sharp increase in wages and prices that had occurred in the United Kingdom. The yen weakened sharply.

8. The six currencies are the Canadian dollar, French franc, deutsche mark, lira, yen, and pound sterling.

9. While the tendency for nominal exchange rate changes to offset differential changes in price levels has been weak in the current period of floating rates, it has been more marked when nominal inflation differentials have been very large. See the evidence on the German hyperinflation in Jacob A. Frenkel, "Exchange Rates, Prices, and Money: Lessons from the 1920s," American Economic Review, vol. 70 (May 1980, Papers and Proceedings, 1979), pp. 235-42. 
Three reasons were advanced to explain these adjustments to the oil shock. First, the United States appeared to be following a relatively less accommodating course than other countries after the inflationary impetus of the increases in oil prices. An explosion of the money supply, wages, and prices in Japan stood out by contrast. Second, at that time the United States was relatively less dependent on imported oil than other countries. And third, the current account surpluses accumulated by OPEC members were expected to be invested predominantly in dollar and pound assets.

The first reason was roughly consistent with the flexible-price monetary model. The second could be reconciled with this model by recognizing that large real disturbances could permanently alter the purchasing power parity relation, even if monetary disturbances could not. Thus considerable effort was devoted to assessing how much the oil shock could be expected to alter permanently countries' competitive positions.

The final consideration-portfolio preferences of OPEC investors among nonmoney assets denominated in different currencies-was not allowed for in the monetary model. But the shock was unprecedented and therefore did not necessarily discredit the claim of the flexible-price monetary model to explain a majority of the persistent movements in nominal exchange rates. Broad capital controls had been inherited from the Bretton Woods period and could also be argued to have affected the range and relative attractiveness of various currencies for the investment of OPEC financial wealth. U.S. authorities took advantage of the strength of the dollar to lift all controls on capital flows out of the United States in January 1974. This represented a further step toward allowing rates to be determined by market forces. But Germany continued controls on inflows, the United Kingdom on outflows, and Japan on both.

In mid-1974 one could look back on the first fifteen months of floating and be somewhat complacent that the system of floating exchange rates would function roughly as predicted by the flexible-price monetary model despite the movements of real exchange rates that had occurred. The major developments seemed explainable by continued adjustment to the disequilibrium built up during the Bretton Woods period and by the unprecedented oil shock. Moreover, it was not surprising that markets were taking some time to adjust to the new environment. The continued prevalence of capital controls meant that the conditions prescribed by the advocates of floating had not been fully established. 
But the skeptics could note that the slide of the dollar in 1973 had only been reversed after concerted intervention by the central bank. In any event, the next episode posed a greater challenge to the theory.

The United States maintained a relatively restrictive policy stance through most of 1974 as the U.S. economy experienced a less marked drop in output than most other countries in the wake of the oil shock. Then in the fall of that year a sharp recession began in the United States. Short-term interest rates on dollar assets fell relative to average rates abroad and particularly relative to rates for the mark. The dollar weakened, declining by 10 percent against the mark and 5 percent on a weighted-average basis. Adjusting for prices, the weighted-average depreciation was even sharper, and against the mark it was nearly as large. The drop in the dollar ultimately drove U.S. authorities to intervene once again. Finally the slide came to an end and a sharp rebound occurred with the strong recovery in the United States in 1975:2. Short-term interest rates on dollar instruments rose relative to rates on the mark and yen counterparts while U.S. inflation was declining more rapidly than the lower inflation rate in Germany. By September the dollar had recovered from its earlier decline.

Figure 2 shows the three real bilateral exchange rates, together with the corresponding three-month interest differential and smoothed-out inflation rate differential. The association between changes in the interest rate and in the exchange rate in late 1974 and early 1975 is apparent for the mark-dollar rate. Some parallel movements can also be seen at other times and in other currencies, especially when interest rates move counter to inflation rates. But the relation is not close. Nevertheless, changes in the interest rate played a prominent role in day-to-day market commentary. And the tendency, evident in late 1974 and 1975, for a rising nominal interest rate to be associated with a strong currency, contrary to the prediction of the flexible-price monetary model, stimulated interest in finding a theoretical connection. The lack of a close correspondence between money growth and exchange rate movements in the early period of floating rates also suggested the need for a modification of the theory.

THE STICKY-PRICE MONETARY MODEL

The principal theoretical response to these observations was renewed recognition of the importance of price stickiness for understanding 
changes in the exchange rates among major currencies in the 1970s. This "Keynesian" assumption had fallen into disfavor in the inflationary environment of the early part of the decade, but it was revived as a central assumption of the dynamic sticky-price monetary model of exchange rate determination. As developed by Dornbusch, this model predicted that, following an unanticipated monetary disturbance, exchange rate expectations would deviate from purchasing power parity for as long as it took goods prices to adjust fully to the new monetary conditions and goods market clearing to be restored. ${ }^{10}$ Moreover, the exchange rate could (depending on the parameter values of the model) overshoot its long-run path.

The monetary equilibrium condition and perfect substitutability of nonmoney assets were retained from the flexible-price monetary model. Although goods markets might adjust slowly, asset markets were still assumed to clear continuously. Purchasing power parity became a longrun tendency since the equilibrium real exchange rate was unaffected by purely monetary factors. The new elements were an equation determining the inflation rate-a stylized expectations-augmented Phillips curveand an IS locus incorporating the relative price of foreign and home goods and the real interest rate. Work with this model has mainly focused on the case of perfectly foreseen changes in exchange rates.

A sticky-price monetary model, then, has an equation for the condition of monetary equilibrium,

$$
M_{t}=m\left(r_{t}\right) P_{t} Y_{t}
$$

for the IS locus,

$$
Y_{t}=y\left(S_{t} P_{t}^{*} / P_{t}, r_{t}-p_{t}^{e}\right)
$$

for the expectations-augmented Phillips curve,

$$
p_{t}=g\left(Y_{t}-\bar{Y}\right)+v
$$

and for uncovered interest parity,

$$
s_{t}^{e}=r_{t}-r_{t}^{*},
$$

10. The Dornbusch model presented in "Expectations and Exchange Rate Dynamics," Journal of Political Economy, vol. 84 (December 1976), pp. 1161-76, extended earlier work by Robert A. Mundell, International Economics (Macmillan, 1968) and J. Marcus Fleming, "Domestic Financial Policies under Fixed and Floating Exchange Rates," IMF Staff Papers, vol. 9 (November 1962), pp. 369-80. Other important work in the stickyprice tradition includes Michael Mussa, "A Model of Exchange Rate Dynamics, " Journal of Political Economy, vol. 90 (February 1982), pp. 74-104. 
Figure 2. Real Exchange Rates, Short-Term Interest Rates, and Inflation ${ }^{\mathrm{a}}$

Mark per dollar

Interest and inflation differential

(index, March $1973=100$ )

(percent)

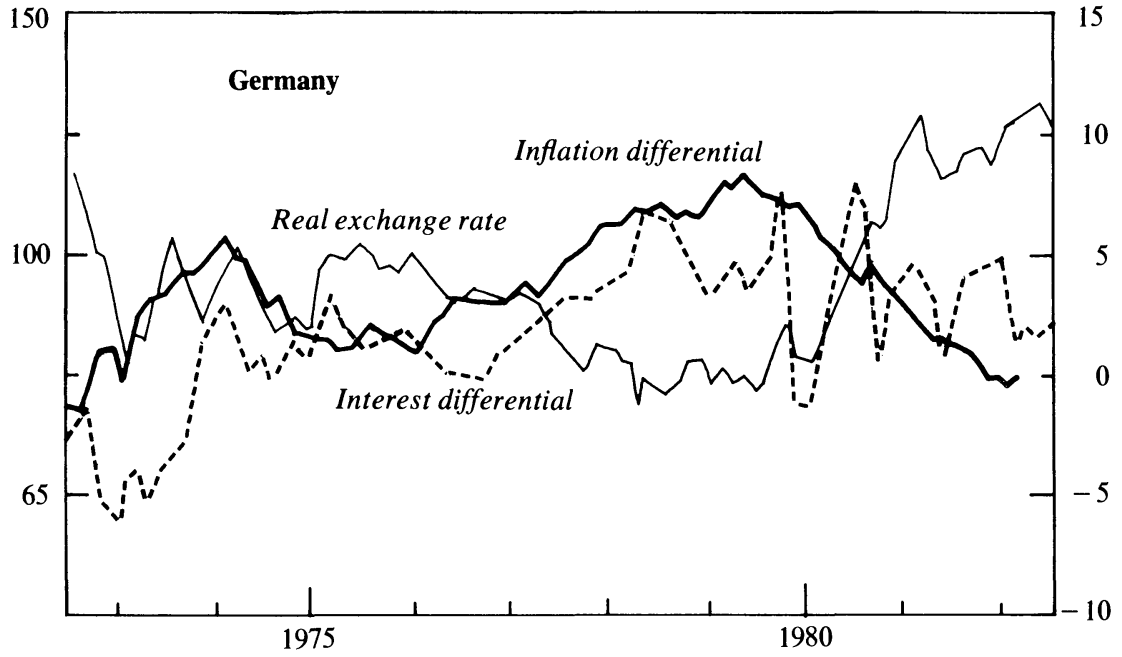

Yen per dollar

Interest and inflation differential

(index, March $1973=100$ )

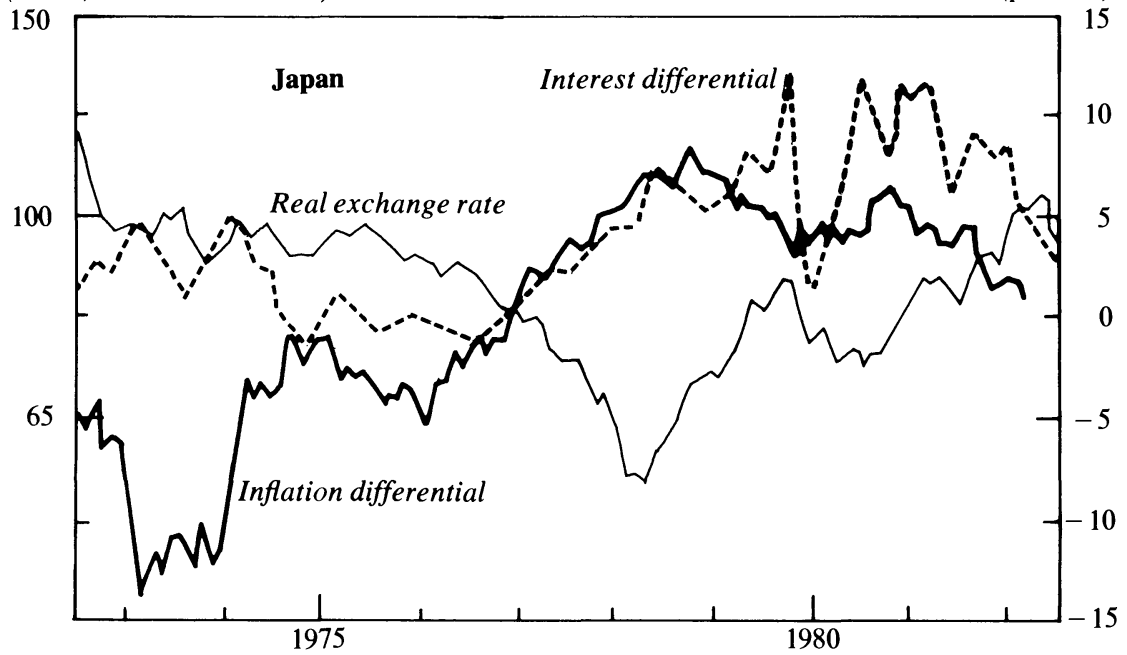


Figure 2 (continued)

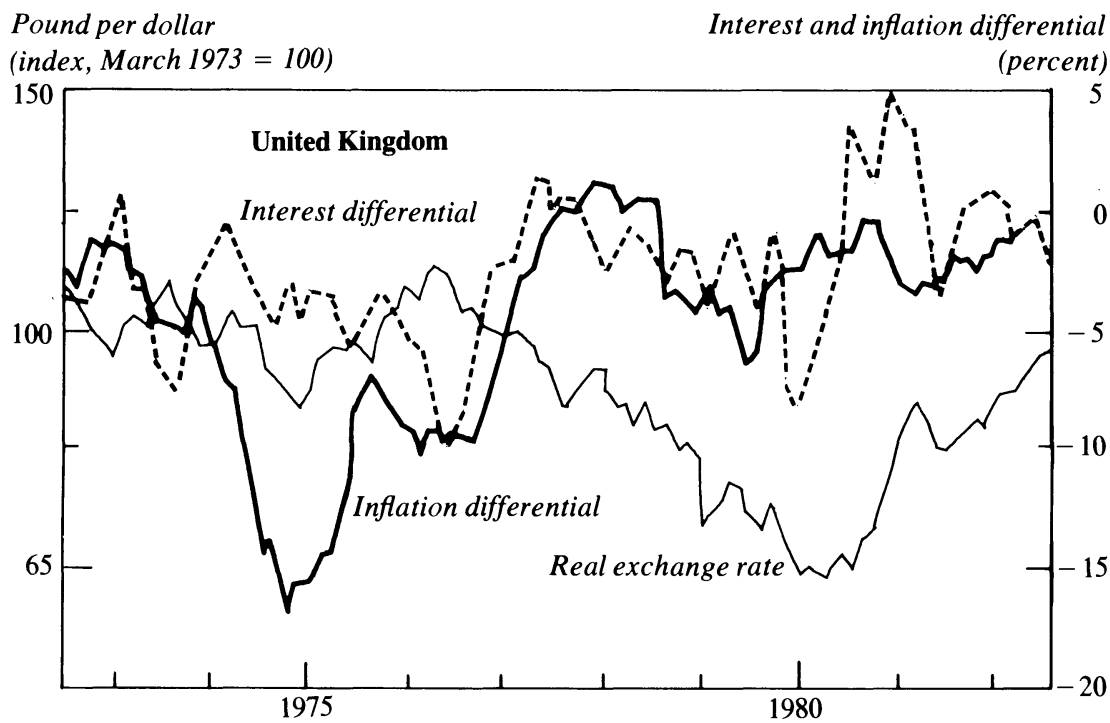

Source: Monthly data. Federal Reserve Bank of New York, international macro date base.

a. The interest rates are based on the three-month interbank rate for Germany, the sixty-day Treasury bill for Japan, the ninety-one-day Treasury bill for the United Kingdom, and ninety-day bankers' acceptances for the United States. The inflation rate is measured as a twelve-month centered moving average of consumer price changes. Differentials are calculated as U.S. rates minus foreign rates.

where the rest of the world is taken as exogenous. The actual and expected rates of change in the exchange rate are the same, except at the instant when an unanticipated disturbance occurs. Then the exchange rate jumps to a new path. Note that the Phillips curve equation requires that, for a stable long-run equilibrium, $Y_{t}$ converge to $\bar{Y}$. Long-run purchasing power parity is then implied by the IS locus. The $v$ parameter is the expected equilibrium inflation rate, which equals the expected growth rate of the money supply (from the monetary equilibrium condition).

The diagram below illustrates for the sticky-price monetary model the response of nominal and real exchange rates and of prices to a onetime increase in the money supply at time $t 1$ and to a permanent increase in the growth rate of the money supply at time $t 2$. As in the first diagram above, perfect foresight is assumed, except for the disturbances, which are unanticipated. Following a monetary disturbance, the variables 


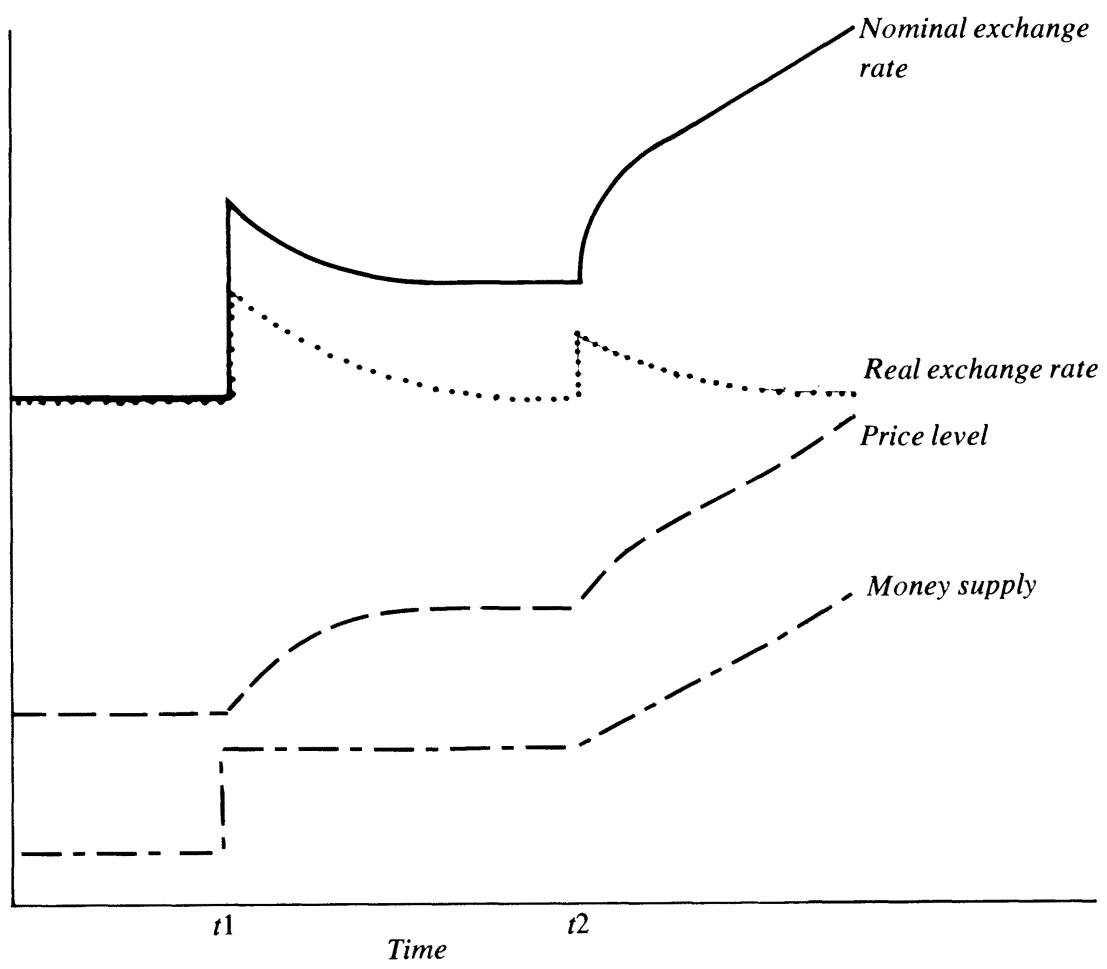

ultimately converge to the same paths as in the flexible-price monetary model. ${ }^{11}$ But for some time the real exchange rate is deflected from its equilibrium value. For example, an unanticipated monetary expansion at time $t 1$ leads to a transitory rise in the real exchange rate (a real depreciation of the home currency). The nominal exchange rate may overshoot its long-run level or path, as illustrated in the diagram, but this result depends on the parameter values of the model.

The sticky-price monetary model was consistent with several stylized facts that did not fit with the flexible-price model. Not only did it admit deviations from purchasing power parity, but it provided an explanation for periods when a rising nominal interest rate was associated with a

11. Monetary disturbances may include unanticipated changes in monetary policy or changes in money demand that are expected to persist while monetary policy is expected to pursue an unchanged monetary target. Changes in the IS locus, including modifications in fiscal policy, can give rise to the same kind of exchange rate effects if they do not alter the long-run terms of trade. 
strong currency. In the flexible-price monetary model, a rise in the interest rate was always associated with an increase in the rate of inflation and more rapid depreciation (or less rapid appreciation) of the currency. In the sticky-price monetary model a persistently higher level of the interest rate would reflect higher inflation and be associated with a weaker currency. But an increase in the interest rate and declining inflationary expectations may be produced by a shift to tighter monetary policy, and then the currency will strengthen.

The model suggests that changes in the exchange rate may not have a simple relation to monetary aggregates even when money supply disturbances are the underlying cause. Expectations concerning the future behavior of money supplies may be much more important than their current behavior in determining the exchange rate. Thus poor correlation between contemporaneous changes in monetary aggregates and exchange rates can be explained. (This is also true of the rational expectations version of the flexible-price monetary model.) The overshooting of the exchange rate associated with sticky prices also seems to account for a widespread perception that rates tend to move too far in one direction and then reverse themselves.

With sticky prices, the assumption that assets denominated in different currencies must provide the same expected rate of return to a particular investor (uncovered interest parity) does not mean that real interest rates must be the same for residents of different countries, as it does with flexible prices. Indeed, differences in real interest rates across residents of different countries must match expectations of real appreciation or depreciation of currencies. This point is discussed further below.

Looking back over the first three years of floating, it appears that sustained exchange rate swings occurred over periods of three months to a year. Thus the convergence to equilibrium was assumed to be relatively rapid. In empirical work real interest rate differentials were sought in short-term rates, while changes in long-term interest rates were viewed as indicative of changing inflation expectations. Frankel achieved some success in interpreting the model this way for explaining the behavior of the mark-dollar rate. ${ }^{12}$ Although allowances had to be

12. Jeffrey A. Frankel, "On the Mark: A Theory of Floating Exchange Rates Based on Real Interest Differentials," American Economic Review, vol. 69 (September 1979), pp. 610-22. 
made for the initial adjustment to floating rates and the oil shock, the sticky-price monetary model showed promise.

EXCHANGE MARKET DEVELOPMENTS:

LATE I975 TO EARLY I 979

Developments in 1976 did not seriously challenge the sticky-price monetary model. It was the most tranquil year for the weighted-average exchange rate of the dollar of the entire ten years of floating. But there were major adjustments among foreign currencies. Authorities in Italy and France were forced to abandon intra-European narrow-margin commitments, and their currencies depreciated sharply. The downward pressure then shifted to the pound. Some saw the weakness of this currency as reflecting a structural shift away from the pound by OPEC and other investors. The pound stabilized only after a standby agreement calling for more restrictive policies was concluded between the United Kingdom and the International Monetary Fund at the end of the year.

The weakness of the lira, franc, and pound and subsequent acceleration of inflation in Italy, France, and the United Kingdom revived and sharpened the debate about whether floating exchange rates tend to destabilize inflation. There was considerable discussion of "vicious and virtuous cycles" in which high inflation and currency depreciation or low inflation and currency appreciation reinforce one another. ${ }^{13}$ At least some who saw such a process at work seemed to have in mind a perpetual cycle that was touched off by an exogenous disturbance to exchange rates. At the other pole were those who believed the source of such apparent cycles was the different monetary policy choices of national

13. For more detail on various aspects of the vicious circle hypothesis, see Rudiger Dornbusch and Paul Krugman, "Flexible Exchange Rates in the Short Run," BPEA, 3:1976, pp. 537-75; Giorgio Basevi and Paul De Grauwe, "Vicious and Virtuous Circles: A Theoretical Analysis and a Policy Proposal for Managing Exchange Rates," European Economic Review, vol. 10 (December 1977), pp. 277-301; Maurice Obstfeld, "Relative Prices, Employment, and the Exchange Rate in an Economy with Foresight," Econometrica, vol. 50 (September 1982), pp. 1219-42; and John F. O. Bilson, "The 'Vicious Circle' Hypothesis," IMF Staff Papers, vol. 26 (March 1979), pp. 1-37. For a sorting out of the theoretical issues, see Henry Wallich and Jo Anna Gray, "Stabilization Policy and Vicious and Virtuous Circles," in John S. Chipman and Charles P. Kindleberger, eds., Flexible Exchange Rates and the Balance of Payments: Essays in Memory of Egon Sohmen (Amsterdam: North Holland, 1980), pp. 49-65. 
authorities. They used the sticky-price monetary model to demonstrate that an actual or expected shift toward a more expansionary monetary policy would be reflected more rapidly in currency weakness than in higher inflation. Thus to infer causality from the observation that changes in exchange rates sometimes preceded changes in inflation was to commit the fallacy of post hoc ergo propter hoc. In the middle were some who believed that disturbances could originate in foreign exchange markets as well as in domestic monetary policy, but that these disturbances would be self-limiting unless accommodated by monetary policy.

After 1976, evidence less favorable to the sticky-price monetary model began to emerge. One anomaly was that the model did not provide a role for shifts in investors' preferences among currencies. Market commentary increasingly associated exchange rate movements with such portfolio shifts; and evidence began to accumulate as early as late 1976 that the uncovered interest parity condition might not hold or that the expectations for which it held were not rational. Put another way, there appeared to be systematic differences in the rates of return achievable from holding open positions in different currencies if no allowance was made for risk.

Early research supporting this result was not conclusive and used daily data, hence allowing for the possibility that the anomaly might be a very short-run phenomenon. ${ }^{14}$ The apparent profit opportunities could also be dismissed as a temporary phenomenon that would dissipate once market participants learned to operate in the new regime. Moreover, the results had to be viewed as tentative until out-of-sample tests could be conducted. But evidence has continued to accumulate that casts strong doubt on the joint hypotheses embedded in tests of uncovered interest rate parity-that is, the hypotheses that otherwise identical nonmoney assets denominated in different currencies are viewed as perfect substitutes (and hence bear the same expected rates of return) and that expectations are rational. ${ }^{15}$ Earlier tests have been redone with

14. See Michael P. Dooley and Jeffrey R. Shafer, "Analysis of Short-Run Exchange Rate Behavior: March 1973 to September 1975," International Finance Discussion Paper 123 (Board of Governors of the Federal Reserve System, 1976).

15. Tests of this joint hypotheses are alternatively referred to as tests of foreignexchange market efficiency or as tests for time-varying risk premiums, depending mainly on which part of the joint hypothesis the researcher is most prepared to interpret as the source of the rejection. Little progress has been made toward empirically resolving the question of which hypothesis can be rejected. 
new data confirming the existence of systematic profit opportunities. ${ }^{16}$ Moreover, with a lengthening period of floating rates to examine and new econometric techniques, tests on weekly, monthly, and even quarterly changes in exchange rates have become more powerful, and these tests tend to give qualitatively similar results. ${ }^{17}$

Beginning in June 1977, the dollar began a steep slide against most currencies that continued until November 1, 1978, when a major effort was undertaken to stabilize its foreign exchange value. The weightedaverage dollar dropped more than 15 percent during this period-and 13 percent in real terms. The depreciation against the yen was about twice as large. In these years the U.S. inflation rate rose relative to that abroad, but U.S. short-term nominal interest rates rose relative to rates abroad by about as much. Although inflationary expectations may have contributed to the nominal depreciation of the dollar, the combination of price and interest rate developments in this period did not appear to explain such large changes in the real exchange rate.

Fellner provides a case for understanding the slide of the dollar during this period in terms of the sticky-price monetary model. He argues that differentials in real interest rates among countries might be expected by market participants to be much more persistent than assumed earlier. ${ }^{18}$ Frankel in his work on the mark-dollar rate and others assume that changes in long-term nominal interest rates are a measure of changes in inflation expectations. ${ }^{19}$ According to this line of thought, only shortterm interest rates are viewed as moving somewhat independently of inflation. By extending the hypothetical duration of disequilibrium,

16. See Michael P. Dooley and Jeffrey R. Shafer, "Analysis of Short-Run Exchange Rate Behavior: March 1973 to November 1981," in David Bigman and Teizo Taya, eds., Exchange Rate and Trade Instability: Causes, Consequences and Remedies (Ballinger, 1983), pp. 43-69.

17. Recent econometric studies include Lars Peter Hansen and Robert J. Hodrick, "Forward Exchange Rates As Optimal Predictors of Future Spot Rates: An Econometric Analysis," Journal of Political Economy, vol. 88 (October 1980), pp. 829-53; Robert E. Cumby and Maurice Obstfeld, "A Note on Exchange-Rate Expectations and Nominal Interest Differentials: A Test of the Fisher Hypothesis," Journal of Finance, vol. 36 (June 1981), pp. 697-703; and John F. O. Bilson, "The 'Speculative Efficiency' Hypothesis," Journal of Business, vol. 54 (July 1981), pp. 435-51.

18. See William Fellner, "The Bearing of Risk Aversion on Movements of Spot and Forward Exchange Relative to the Dollar," in John S. Chipman and Charles P. Kindleberger, eds., Flexible Exchange Rates and the Balance of Payments: Essays in Memory of Egon Sohmen (Amsterdam: North Holland, 1980), pp. 113-26.

19. Frankel, "On the Mark." 
Fellner associates much larger changes in the real exchange rate with the effects of divergent monetary policies on real interest differentials. ${ }^{20}$ But having dropped the long-term interest rate as a measure of long-run inflationary expectations, Fellner's argument rests on the plausibility of particular values for inflationary expectations rather than hypothesis tests. We return to the Fellner hypothesis below.

Many observers began to view the 1977-78 slide of the dollar as primarily an adjustment to the large and growing deficit in the U.S. current account and surpluses in Germany and Japan. This constituted a second phenomenon that was not directly explainable in the context of the sticky-price monetary model. Figure 3 shows the real weightedaverage exchange rates for these three countries and the United Kingdom, together with their cumulative current account positions from the first quarter of 1973 to the end of 1982. (The change in the cumulative measure is the current account for each period.) Note that current account imbalances have been larger and more volatile from the outset of the floating rate period than they had been during the Bretton Woods period. The extenuating factors discussed above-greater trade interdependence, inherited disequilibrium, and the two oil shocks-allowed the advocates of floating rates to remain unconcerned. But those who had made strong claims for the self-equilibrating properties of floating exchange rates had certainly overstated the case.

The events of 1977-78 had their origins several years before. In early 1975 the U.S. current account surged into surplus as the sharp U.S. recession reduced imports. But with recovery in the economy and in the dollar, the current account began to decline rapidly. At the same time, Germany and Japan were in substantial current account surplus. Yet the markets reacted only after Secretary of the Treasury Blumenthal made a statement in June 1977 calling attention to the imbalances. (The statement was widely interpreted as a desire on the part of the Carter administration to see the dollar decline.)

One source of the current account imbalances and exchange market pressures was the relatively more growth-oriented policies of the United

20. To illustrate this point, assume full adjustment takes five years and a real rate of return differential of 2 percent is expected to prevail, on average, in the interim. Then a displacement of the exchange rate from purchasing power parity of more than 10 percent would be warranted. Thus the model could be consistent with rather large changes in the exchange rate in response to moderate changes in long-term nominal interest rates relative to inflation rates. 
Figure 3. Real Effective Exchange Rates and Cumulative Current Account Positions ${ }^{\mathrm{a}}$

Real effective exchange rate, mark

Cumulative

(index, 1973:1 = 100)

current account

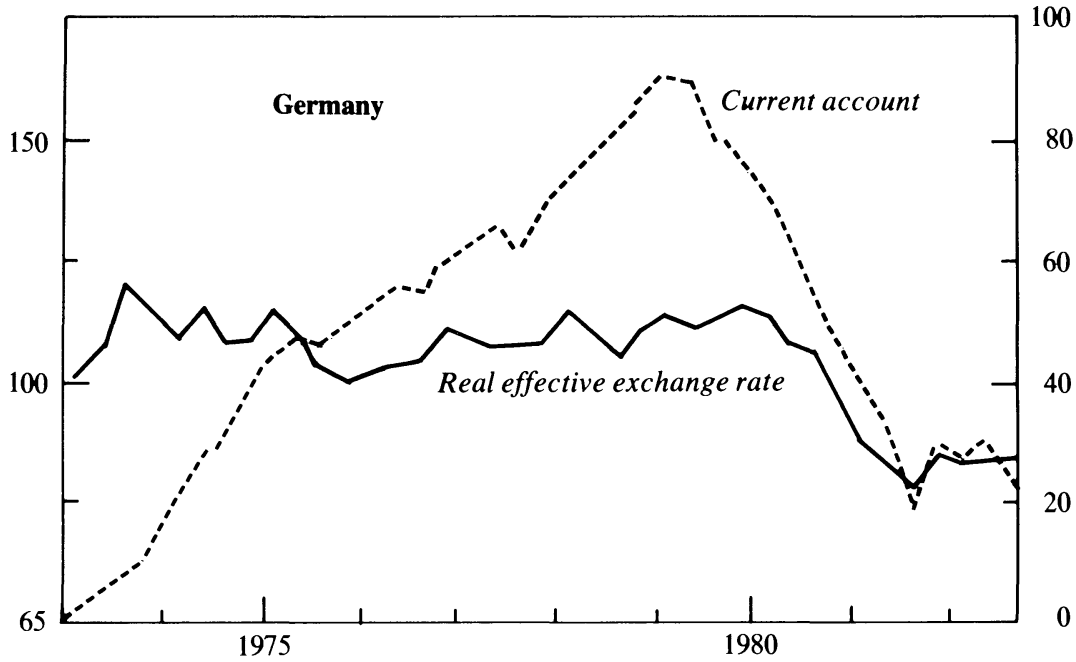

Real effective exchange rate, yen

Cumulative (index, 1973:1 = 100) current account

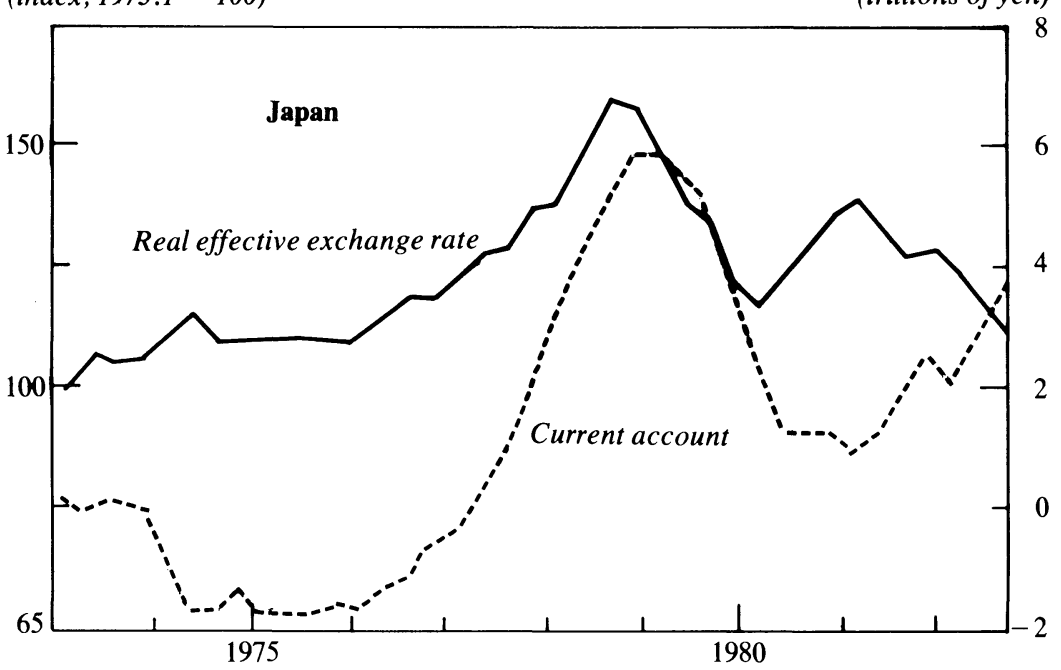

Source: Quarterly data. Federal Reserve Bank of New York, international macro data base.

a. Effective rates are weighted averages of each currency against six others (expressed in units of foreign currency per unit of domestic currency). The seven currencies are the U.S. dollar, mark, yen, pound sterling, lira, Canadian 
Figure 3 (continued)

Real effective exchange rate, pound

Cumulative

(index, 1973:1 = 100)

current account

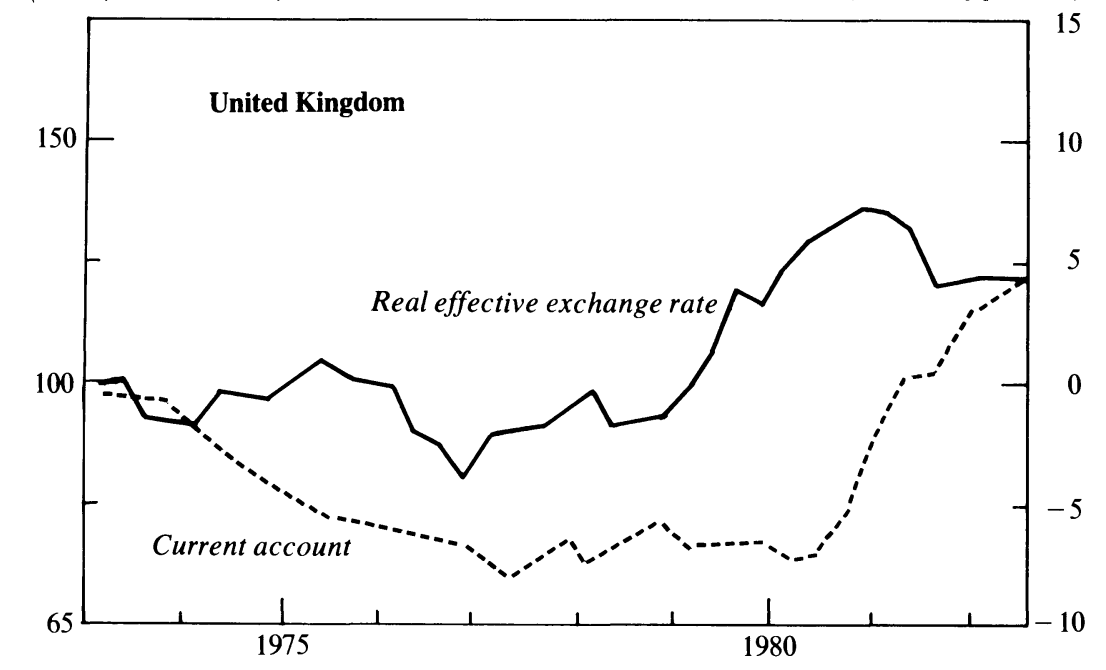

(billions of pounds)

Real effective exchange rate, U.S. dollar

Cumulative (index, 1973:1 = 100)

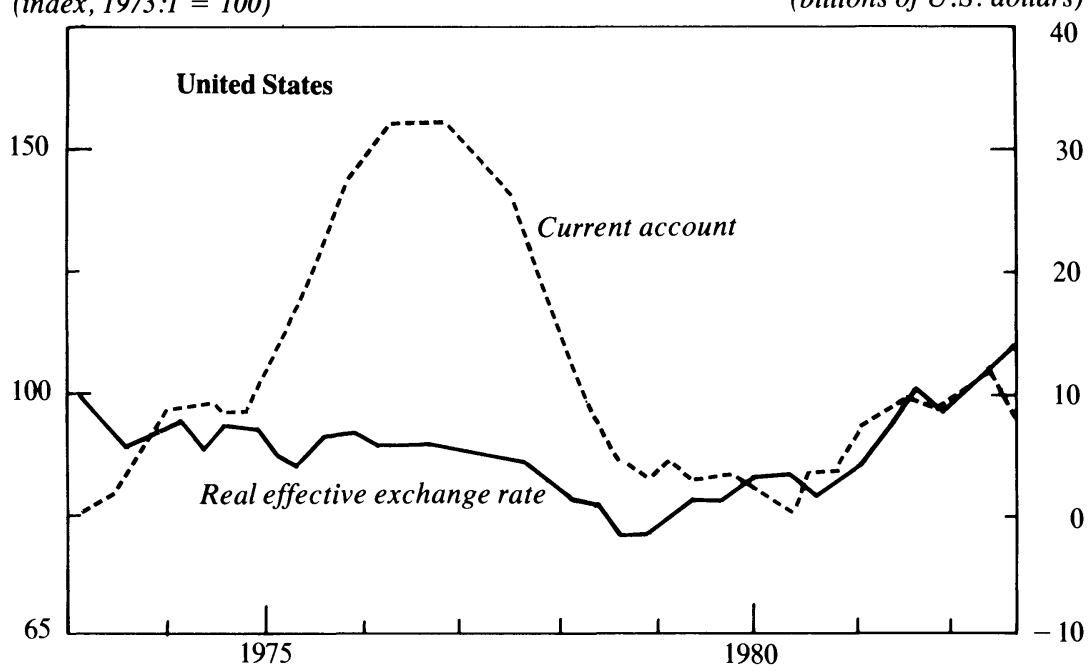

dollar, and French franc. Weights are normalized according to the International Monetary Fund's multilateral exchange rate model for the seven currencies. The cumulative current account is the algebraic sum of current surpluses and deficits from 1973:1. 
States and the more anti-inflation emphasis of policies in Germany and Japan. Another source was U.S. energy policy, which discouraged domestic oil production by keeping oil prices below world market levels, thereby increasing already expanding oil imports. At the Bonn Summit in July 1978 these considerations lay behind a package that included commitments to fiscal stimulus by Germany and Japan, where inflation had dropped to low levels, and commitments to energy price decontrol and stronger anti-inflation policies by the United States. The slide of the dollar continued, however, and even steepened. ${ }^{21}$

On November 1, 1978, U.S. authorities announced their determination to correct what they termed an excessive depreciation of the dollar. ${ }^{22}$ The dollar was driven up sharply, but it was not until early 1979 that it showed some strength on its own, and intervention could begin to be unwound. By then, signs of current account convergence were appearing.

Market commentary in 1977-78 also focused on international diversification of asset portfolios as an additional source of dollar weakness. Exchange rate risk as well as expected return received more attention as potential forces in exchange markets. ${ }^{23}$ Evidence on how much currency diversification occurred is skimpy. But even the data that are available are hard to interpret because changing shares of currencies in portfolios were dominated by changing currency values rather than by changes in the relative quantities of dollars and other currencies. ${ }^{24}$

21. A number of efforts were made to moderate the slide. Initially intervention operations were undertaken mainly by German and Japanese authorities; but as time went on, there was increased intervention by U.S. authorities using foreign currencies obtained from swap drawings with foreign central banks.

22. The measures announced included stepped up intervention backed by greatly expanded resources and a tightening of monetary policy underscored by a hike of 200 basis points in the Federal Reserve discount rate.

23. It was thought that Middle Eastern countries and some others were increasingly spreading their foreign currency reserves over a number of currencies rather than holding only or mostly dollar assets in order to reduce exposure to exchange rate fluctuations. Private investors were thought to be responding to the same incentives.

24. These valuation effects could be interpreted as the results of attempts to diversify leading to exchange rate changes that brought actual portfolio shares into line with desired shares without large net changes in currency holdings. Indeed, in a pure floating exchange rate regime (with no intervention) this is the only way diversification could occur in the aggregate because net supplies of assets denominated in various currencies would be determined solely by fiscal deficits. The evidence is also difficult to evaluate because changes in exchange rates from other causes would lead to the same valuation-induced changes in portfolio shares if investors were passive. Moreover, even if holders of dollars 


\section{THE PORTFOLIO-BALANCE MODEL}

The development of various theoretical formulations of the portfoliobalance model was stimulated by evidence that the uncovered interest arbitrage condition might not hold, the casual observation that exchange rates seemed to be influenced by cumulative changes in the current account, and the expressed interest of official and private portfolio managers in exchange risk as well as the expected rate of return on currencies. The portfolio-balance model has been around for some time and has antecedents in both the theory of fixed exchange rates and domestic financial theory. ${ }^{25}$ Its distinguishing feature is the assumption that interest-bearing assets denominated in different currencies are not perfect substitutes in portfolios, presumably because portfolio managers are risk averse and because exchange risk cannot be completely eliminated by diversification.

In a simple static portfolio-balance model, money market equilibrium is expressed as

$$
M_{t}=m\left(r_{t}\right) P_{t} Y_{t}
$$

were able to shift into other currencies or alter the relative distribution of additions to reserves because authorities in the key financial centers were intervening, the shifts could be interpreted as a response to expectations of dollar depreciations-behavior consistent with the monetary models.

25. The portfolio-balance approach has been pursued by a number of authors. See Lance Girton and Dale W. Henderson, "Central Bank Operations in Foreign and Domestic Assets under Fixed and Flexible Exchange Rates," in Peter B. Clark and others, eds., The Effects of Exchange Rate Adjustments (U.S. Government Printing Office, 1977), pp. 15179; Pentti J. K. Kouri, "Monetary Policy, the Balance of Payments and the Exchange Rate," in David Bigman and Teizo Taya, eds., The Functioning of Floating Exchange Rates: Theory, Evidence and Policy Implications (Ballinger, 1980), pp. 79-111; William H. Branson, "Asset Markets and Relative Prices in Exchange Rate Determination," Sozialwissenschaftliche Annalen des Instituts für Höhere Studien, vol. 1 (1977), pp. 6989; and Jeffrey R. Shafer, "The Macroeconomic Behavior of a Large Open Economy with a Floating Exchange Rate" (Ph.D. dissertation, Yale University, 1976). Antecedents in the fixed exchange rate literature include William H. Branson, "Monetary Policy and the New View of International Capital Movements," BPEA, 2:1970, pp. 235-62; Lance Girton and Dale W. Henderson, "Financial Capital Movements and Central Bank Behavior in a Two-Country, Short-Run Portfolio Balance Model," Journal of Monetary Economics, vol. 2 (January 1976), pp. 33-61; and Pentti J. K. Kouri and Michael G. Porter, "International Capital Flows and Portfolio Equilibrium," Journal of Political Economy, vol. 82 (May-June 1974), pp. 443-67. The framework was developed in a domestic context in William C. Brainard and James Tobin, "Pitfalls in Financial Model Building," American Economic Review, vol. 58 (May 1968, Papers and Proceedings, 1967), pp. 99-122. 
equilibrium in the market for assets denominated in home currency as

$$
B_{t}=b\left(r_{t}-r_{t}^{*}-s_{t}^{e}\right)\left(B_{t}+S_{t} B_{t}^{*}\right)
$$

equilibrium in the market for assets denominated in foreign currency as

$$
S_{t} B_{t}^{*}=\left[1-b\left(r_{t}-r_{t}^{*}-s_{t}^{e}\right)\right]\left(B_{t}+S_{t} B_{t}^{*}\right) ;
$$

and the IS locus, including net foreign investment income as an argument, as

$$
Y_{t}=f\left(S_{t} P_{t}^{*} / P_{t}, r_{t}-p_{t}^{e}, S_{t} r_{t}^{*} B_{t}^{*} / P_{t}, W_{t} / P_{t}\right),
$$

where $W$ denotes wealth, and $W \equiv M+B+S B^{*}$.

In this model, foreigners do not demand assets denominated in domestic currency, and money demand depends only on the domestic interest rate and nominal income. The rest of the world is large so that its interest rates, prices, and incomes are taken as exogenously given. One asset market equation is redundant by Walras's law. Thus, with home prices and exchange rate expectations given at a point in time, three equations determine real output, the home interest rate, and the spot exchange rate. ${ }^{26}$ What distinguishes the model from monetary models is that the expected rate of change of the exchange rate, $s^{e}$, is not constrained to correspond exactly to the interest differential, that is, uncovered interest parity will not hold in general. The expression $(r-$ $\left.r^{*}-s^{e}\right)$ is the deviation from uncovered interest parity. If this expression is positive, the home currency is said to carry a risk premium.

A dynamic version of the portfolio-balance model provides a mechanism for cumulative imbalances in the current account to influence the real exchange rate. Over time, wealth is transferred from countries in deficit to countries in surplus. Assuming that residents have a relative preference for assets denominated in their own currency, this redistribution of wealth alters the relative demands for assets. The currency of a country in deficit falls to a point from which it can subsequently be expected to appreciate, thus establishing the risk premium. Beyond this common feature, this model and variants of it can exhibit a range of

26. More general formulations of asset demands and endogenous adjustment of foreign variables can be found in the references cited above. But at least some of the simplifying assumptions or alternative ones are normally employed to keep the model tractable. The model presented in the text is intended merely to illustrate the approach as an extension of the sticky-price monetary model. 
dynamic properties depending on the degree of asset substitutability and the specific properties of the real side of the model-the determinants and speed of adjustment of goods prices, aggregate demands, and the distribution of demand among goods produced in different countries. Hence characteristic adjustment paths like those shown for the more restrictive models are not given.

One formulation of the dynamic portfolio-balance model incorporates the equations of the static model and the following equations of motion: evolution of net supply of assets denominated in home currency is given by

$$
\left(B_{t}-B_{t-1}\right)=D_{t}-\left(M_{t}-M_{t-1}\right)-I_{t},
$$

evolution of net domestic private holdings of assets denominated in foreign currency by

$$
S_{t}\left(B_{t}^{*}-B_{t-1}^{*}\right)=P_{t} C_{t}+I_{t},
$$

the expectations-augmented Phillips curve by

$$
p_{t}=g\left(Y_{t}-\bar{Y}\right)+v,
$$

and the current account by

$$
C_{t}=h\left(Y_{t}-\bar{Y}, S_{t} P_{t}^{*} / P_{t}, W_{t} / P_{t}\right)+S_{t} r^{*} B_{t}^{*} / P_{t},
$$

where $D$ is the domestic government deficit, $I$ is the central bank intervention (the sale of foreign currency reserves), and $C$ is the real current account balance. In this dynamic form of the model the evolution of stocks of assets is governed by the fiscal deficit, the current account, and monetary policy. A role for exchange market intervention, even when sterilized so as to have no effect on money supplies, is also introduced. ${ }^{27}$

27. The usual formulations of this model ignore the role of government deficits as a determinant of the supply of domestic outside assets. Their implications for the exchange rate, through the influence on the IS locus, has long been recognized. For a small net initial position in foreign currency, the effects of a current account deficit on portfolio equilibrium will be large relative to the effects of a budget deficit of the same size because the latter alters the supply of assets as well as wealth with a partially offsetting effect. Ignoring the effects of budget deficits on asset stocks may then have some justification beyond just keeping the model tractable. But with the growing attention that fiscal deficits are attracting in market commentary on interest rate and even exchange rate developments, their theoretical implications are worthy of more attention than they have received. 
EXCHANGE RATE DEVELOPMENTS:

EARLY I 979 TO MARCH I 983

In the period from 1979 to 1982 the positions of the dollar and pound as weak currencies and the positions of the mark and yen as strong currencies were reversed. After stabilizing in early 1979, the dollar began a climb that, by any measure, dwarfed all its earlier swings. By late 1982 the real weighted-average value of the dollar was at a higher level than at the beginning of the float almost ten years earlier or at any time in between. The mark was near its all-time low on a real weighted-average basis and the yen, measured the same way, fell to the level that prevailed in the early part of the float. The pound appreciated even more drastically than the dollar in 1979-80 but had fallen back somewhat in 1981. In late 1982 the pound dropped sharply and the dollar declined slightly from its highs measured against the mark and yen.

The factors that have appeared in market commentary to explain rates since 1979 have been the same as those identified in earlier periods, including those that had been incorporated into the progressively more general asset market models. One might say that, after the first six years of floating, we had seen it all. But the large swings in interest rates relative to inflation received by far the most attention.

In retrospect, 1979 appears to have been a relatively good year for the dollar. But the sense at the time was one of apprehension. Nonmonetary as well as monetary factors received considerable attention. The dollar dropped against European currencies as the second round of large increases in oil prices began at mid-year. In contrast to 1974, the United States was much more dependent on imported oil, and there was no longer a presumption that OPEC reserve accumulations would be invested mainly in dollars. Developments in the oil market and the election of the Thatcher government, which promised stronger monetary control in the United Kingdom, were associated with a sharp upswing of the pound. The mark generally moved upward against the dollar, along with the European currencies included in the European Monetary System, which was launched in March 1979. The yen was the most markedly weak currency in 1979; a declining trend of the current account became clear, and Japan, once again, was expected to be a major loser as a result of higher oil prices. 
Since late 1979, monetary developments-notably erratic movements in U.S. interest rates-seem to have been by far the most important influence on exchange rates. In September the weakness of the dollar against the mark reappeared as earlier expectations of a recession in the United States gave way to heightened concern about inflation. On October 6, 1979, the Federal Reserve adopted its new reserve targeting procedures designed to gain closer control over M1. The dollar recovered against the mark as interest rates rose initially, then sagged as expectations of further increases in the U.S. interest rate were not fulfilled.

In 1980 U.S. interest rates and exchange rates moved in tandem, first rising through April, then falling until late summer, then rising again through the end of the year. In 1981 the dollar continued to climb to still higher levels even though interest rates did not surpass their earlier peaks and interest rates in Germany and many other countries also rose. But by then a surplus in the U.S. current account had emerged that contrasted with deficits in Germany and Japan. Declining U.S. inflation was also seen as a positive factor for the dollar. While the shorter-run movements of the dollar continued to be related to changes in the interest rate in 1982, the strength of the trend could no longer be explained solely by movements of short-term rates. And the real value of the dollar, relative to earlier periods, appeared to point toward substantial deficits in the current account down the road. A drop in U.S. interest rates and the emergence of a current account deficit brought only a small reversal of the cumulative rise in the dollar. Some observers argue that portfolio preferences shifted toward the dollar as a safe haven, given the earlier election of a Socialist government in France, turmoil in Poland, and political uncertainty in Germany.

Meanwhile the strength of the pound in 1979 and 1980 has been largely reversed since the end of 1981 . It is easy to point to qualitative factors that would account for this-moderately lower interest rates and weakening of the world oil market. But inflation in the United Kingdom has finally slowed decisively; growth of the money supply was slower in 1982 than earlier, and the current account has remained in surplus.

Although the qualitative behavior of exchange markets in recent years seems consistent with the earlier years of floating, many would question whether relations that are stable over the entire period of floating rates can be identified and whether these relations are quantitatively consistent with the theory as it now stands. Without such relations, one cannot 
offer general, as opposed to ad hoc, explanations of the behavior of exchange rates. In the next section we look for such systematic relations and explore some specific questions concerning the quantitative consistency of exchange rate behavior using the predictions of the various models of the asset market.

\section{Empirical Evaluation of Exchange Rate Models}

During the past decade the development of the theory of exchange rate determination has been heavily influenced by the events of the floating rate period. Models have been continually modified to incorporate important new stylized facts. Yet empirical confirmation of the evolving theories has proven more elusive. When judged by the criterion of out-of-sample fit, the structural models surveyed above fail at all forecasting horizons to outperform a simple random-walk model. ${ }^{28}$

When judged from the standpoint of a weaker criterion-consistency with historical experience-various models have proven successful in terms of tests of significance and predicting directions of effects, although often for only a particular currency and subsample period. ${ }^{29}$ This section

28. Richard A. Meese and Kenneth S. Rogoff compared the out-of-sample fit (using actual values of the exogenous variables) of several popular structural and time-series models of exchange rate determination for the dollar-mark, dollar-pound, and dollar-yen exchange rates. They conclude that a random-walk model, which takes today's exchange rate as the best predictor for all future rates, performs as well as the structural and timeseries models over the sample period from December 1976 to June 1981. See Meese and Rogoff, "Empirical Exchange Rate Models of the Seventies: Do They Fit Out-of-Sample?" Journal of International Economics, vol. 14 (February 1983), pp. 3-24.

29. Early evidence in support of the flexible-price monetary models include Bilson, "The Monetary Approach," and Hodrick, "An Empirical Analysis." Frankel in "On the Mark" presented evidence favorable to the sticky-price model. Later, less favorable results were provided by Rudiger Dornbusch, "Exchange Rate Economics: Where Do We Stand?" BPEA, 1:1980, pp. 143-85; and Jeffrey A. Frankel, "On the Mark: Reply," American Economic Review, vol. 71 (December 1981), pp. 1075-82. For the portfoliobalance approach, William Branson, Hannu Halttunen, and Paul Masson, "Exchange Rates in the Short-Run: The Dollar-Deutschemark Rate," European Economic Review, vol. 10 (December 1977), pp. 303-24, provide mildly supportive evidence that was later qualified in their "Exchange Rates in the Short-Run: Some Further Results," European Economic Review, vol. 12 (October 1979), pp. 395-402. Obstfeld estimates a structural portfolio-balance model of the dollar-mark rate and finds little empirical support for the model's key policy implication-the ability of sterilized intervention to affect the exchange rate. See Maurice Obstfeld, "Exchange Rates, Inflation, and the Sterilization Problem: Germany, 1975-1981," European Economic Review, vol. 21 (March-April 1983), pp. 161-89. 
focuses on the short-run volatility of exchange rates and evaluates models of exchange rate determination on the basis of the less stringent criterion of in-sample ability to track the facts.

One of the hallmarks of the period following the Bretton Woods era has been the high volatility of both real and nominal exchange rates. The evidence in figure 1 reveals that, even using quarterly average data that smooth over much of the short-run volatility, there have been wide and sustained swings in exchange rates over the 1970s. Table 2 reports estimates of standard deviations of daily, weekly, four-week, and twelve-week percentage changes in nominal exchange rates over four subperiods of the past decade. Volatility of the dollar-mark and dollaryen rates was generally relatively high in the early years of flexible exchange rates, a consequence of the inevitable learning period and the severe oil and other commodity price shocks that accompanied it. There followed a period of relative calm in foreign exchange markets lasting several years, but the past five years have been characterized by a rising trend in exchange rate volatility. For the dollar-pound exchange rate, the second subperiod was punctuated by a weakening of the pound in 1976, which culminated in an International Monetary Fund stabilization program for the United Kingdom in January 1977 . Volatility rose steadily for the dollar-pound rate during the 1970s with no respite in these middle years.

The observation that nominal exchange rates have been volatile, and, in some cases, increasingly volatile, does not in itself constitute a condemnation of the floating rate regime. In an efficiently functioning foreign exchange market, the exchange rate will respond immediately and fully to new information received by market participants. In this respect, a high degree of exchange rate volatility is implied by the asset price characterization of the exchange rate that serves as the common denominator of all the major theories. In this view, a high degree of exchange rate volatility would be predicted if expectations of the future course of variables influencing the exchange rate were uncertain and subject to large revisions. Indeed, if all exchange rate changes were related solely to the advent of new and unanticipated information on the market, the exchange rate would follow a random walk-today's exchange rate would be the best predictor of all expected future exchange rates. If exchange rate changes were caused by new information about the future path of economic variables, superior to that contained in the 
Table 2. Volatility of Exchange Rates, Selected Periods, April 1973 to February $1983^{a}$

Percent

\begin{tabular}{|c|c|c|c|c|c|c|}
\hline \multirow[b]{3}{*}{ Period } & \multicolumn{6}{|c|}{ Standard deviation of change in exchange rate } \\
\hline & \multicolumn{2}{|c|}{ Dollar-mark } & \multicolumn{2}{|c|}{ Dollar-yen } & \multicolumn{2}{|c|}{ Dollar-pound } \\
\hline & Actual & $\begin{array}{l}\text { Nor- } \\
\text { malized }\end{array}$ & Actual & $\begin{array}{l}\text { Nor- } \\
\text { malized }\end{array}$ & Actual & $\begin{array}{l}\text { Nor- } \\
\text { malized }\end{array}$ \\
\hline \multicolumn{7}{|c|}{$\begin{array}{l}\text { April 1973-September } 1974 \\
\text { (transition to floating } \\
\text { rates and first oil shock) }\end{array}$} \\
\hline Daily & 0.86 & 0.86 & 0.52 & 0.52 & 0.42 & 0.42 \\
\hline Weekly & 1.65 & 0.74 & 1.12 & 0.50 & 0.98 & 0.44 \\
\hline Four-week intervals & 4.52 & 1.01 & 2.73 & 0.61 & 2.19 & 0.49 \\
\hline Twelve-week intervals & 6.89 & 0.89 & 4.26 & 0.55 & 3.95 & 0.51 \\
\hline \multicolumn{7}{|l|}{$\begin{array}{l}\text { October 1974-May } 1977 \\
\text { (relative calm) }\end{array}$} \\
\hline Daily & 0.43 & 0.43 & 0.23 & 0.23 & 0.49 & 0.49 \\
\hline Weekly & 0.89 & 0.40 & 0.56 & 0.25 & 1.05 & 0.47 \\
\hline Four-week intervals & 2.24 & 0.50 & 1.30 & 0.29 & 2.15 & 0.48 \\
\hline Twelve-week intervals & 3.49 & 0.45 & 2.56 & 0.33 & 4.49 & 0.58 \\
\hline \multicolumn{7}{|c|}{$\begin{array}{l}\text { June } 1977-\text { October } 5,1979 \\
\text { (weakness of the dollar) }\end{array}$} \\
\hline Daily & 0.61 & 0.61 & 0.64 & 0.64 & 0.57 & 0.57 \\
\hline Weekly & 1.25 & 0.56 & 1.50 & 0.67 & 1.14 & 0.51 \\
\hline Four-week intervals & 2.91 & 0.65 & 3.53 & 0.79 & 2.68 & 0.60 \\
\hline Twelve-week intervals & 3.80 & 0.49 & 6.12 & 0.79 & 4.26 & 0.55 \\
\hline \multicolumn{7}{|l|}{$\begin{array}{l}\text { October } 6,1979-F e b r u a r y \\
1983 \text { (resurgence of the } \\
\text { dollar) }\end{array}$} \\
\hline Daily & 0.76 & 0.76 & 0.81 & 0.81 & 0.72 & 0.72 \\
\hline Weekly & 1.52 & 0.68 & 1.68 & 0.75 & 1.41 & 0.63 \\
\hline Four-week intervals & 3.18 & 0.71 & 3.67 & 0.82 & 2.95 & 0.66 \\
\hline Twelve-week intervals & 4.65 & 0.68 & 5.89 & 0.76 & 5.73 & 0.74 \\
\hline
\end{tabular}

Source: Authors' calculations based on New York noon bid rates, Board of Governors of the Federal Reserve System, international macro data base.

a. Standard deviations of changes in the logarithms of three bilateral exchange rates, calculated for daily and weekly changes and changes at intervals of four and twelve weeks. The normalized standard deviations are the actuals divided by the square root of the number of days in the change calculated-that is, by the square roots of 5 for the weekly changes, 20 for changes every four weeks, and 60 for changes every twelve weeks. Use of this normalization implies that, if the exchange rate exactly followed a random walk, the normalized entries for each subperiod would be equal in large samples.

current values of those variables themselves, then the exchange rate would be a good predictor of other variables but would itself be poorly explained even by current values of other variables.

In fact, evidence has been found that is consistent with the view that 
nominal exchange rates follow approximately a random walk. ${ }^{30}$ The results in table 2 provide some further evidence of the near random-walk pattern of exchange rate movements, based on the pattern of exchange rate variability across varying time horizons. If the exchange rate follows a random walk, the variance of the five-day, or one-trading-week, change in the exchange rate will be five times that of the one-day change, and the standard deviation of the five-day change will be the square root of five times that of the one-day change. Normalized standard deviations are reported in table 2; the standard deviations of one-week, four-week, and twelve-week changes in that table are divided by the square roots of five, twenty, and sixty, respectively. For each subperiod the four normalized standard deviations would all be equal in large samples if the exchange rate exactly followed a random walk. The normalized measures, while not identical, are generally close in value, so that the pattern of volatility across the four time aggregations for each subsample period suggests random-walk behavior. There is no clear tendency for frequently occurring changes in exchange rates to either reinforce or offset one another over longer time intervals (positive or negative serial correlation).

\section{SHORT-RUN EXCHANGE RATE VOLATILITY}

An assessment of whether exchange rates have been too volatile during the 1970s should include three considerations. First, attainment of greater exchange rate stability could entail sacrificing domestic monetary policy objectives. For example, the decision by the United

30. Interest in exploring whether exchange rates follow a random walk dates back more than fifteen years to work by Poole. See William Poole, "Speculative Prices as Random Walks: An Analysis of Ten Time Series of Flexible Exchange Rates," Southern Economic Journal, vol. 33 (April 1967), pp. 468-78. For a more recent analysis see Michael Mussa, "Empirical Regularities in the Behavior of Exchange Rates and Theories of the Foreign Exchange Market," in Karl Brunner and Allan H. Meltzer, eds., Policies for Employment, Prices, and Exchange Rates, Carnegie-Rochester Conference Series on Public Policy, vol. 11 (Amsterdam: North Holland, 1979), pp. 9-57. Mussa claims that recent exchange rate behavior has conformed closely to the random-walk hypothesis. Econometric evidence consistent with (but not directly proving) the random-walk hypothesis is provided by Richard A. Meese and Kenneth J. Singleton, "On Unit Roots and the Empirical Modeling of Exchange Rates," Journal of Finance, vol. 37 (September 1982), pp. 1029-35. In the forecasting context, Meese and Rogoff in their "Empirical Exchange Rate Models" show that a random-walk model of exchange rates generally yields a better out-of-sample fit than the forward rate or any of the structural models. 
States authorities in October 1979 to abandon operating procedures focusing on the federal funds rate in favor of reserve targeting led to higher interest rate volatility. Asset market models indicate that exchange rate changes will be closely related to interest rate developments. Thus the change in domestic operating procedures of monetary policy may have heightened exchange rate volatility in the recent period.

A second consideration is whether nominal exchange rate volatility has a detrimental effect on the real macroeconomy. It is evident in figure 1 that nominal exchange rate volatility has been closely associated with, and perhaps often the source of, real exchange rate volatility. These real exchange rate changes may serve as a conduit for transmitting the effect of nominal exchange rate volatility to the real economy. For the dollarmark and dollar-yen rates during the past decade the contemporaneous correlation between the nominal and real exchange rates has been high0.61 and 0.84 , respectively. For the dollar-pound rate, the correlation is lower, 0.30 , at least partly because rapid price inflation in the United Kingdom during much of the past decade has often roughly kept pace with changes in exchange rates over time. The high correlation between nominal and real exchange rates in the cases of the dollar-mark and dollar-yen rates is consistent with the notion that prices are sticky so that purchasing power parity will not hold in the short run. ${ }^{31}$

At the microeconomic level it has been argued that nominal and associated real exchange rate volatility may deter international trade and investment by greatly complicating the profit-maximizing calculations of firms. The uncertainty created by real exchange rate volatility could lead to misallocation of resources. Little statistical evidence exists to date, however, that exchange rate volatility has had negative effects of this sort. ${ }^{32}$

31. Sluggish price adjustment is not, however, a necessary condition for a strong correlation between nominal and real exchange rate movements. For example, the exchange rate may respond to real shocks that require a change in the equilibrium relative price of national outputs. For an example of this type of model, see Alan C. Stockman, "A Theory of Exchange Rate Determination," Journal of Political Economy, vol. 88 (August 1980), pp. 673-98.

32. See, for example, Peter Hooper and S. W. Kohlhagen, "The Effects of Exchange Rate Uncertainty on the Prices and Volume of International Trade," Journal of International Economics, vol. 8 (November 1978), pp. 483-511. They find little evidence of a significant effect of unanticipated variability in the nominal exchange rate (measured as the absolute difference between the lagged forward and current spot rates) on export volumes, but identify some influence on export prices for the period from 1965:1 to 1975:4. There are few empirical studies for the more recent period. 
The final and probably most important consideration in assessing if nominal rates have been overly volatile is whether exchange rates move principally in response to new and unanticipated developments in socalled fundamentals - variables suggested by theory as important determinants of the exchange rate- and whether they react to an appropriate degree. In other words, does this volatility appear to serve a clear economic purpose? This issue is not readily resolved because any assessment of whether exchange rates are too volatile is necessarily rooted in an underlying model of exchange rate determination and its prediction of what a warranted response to changes in the determinants would be. Therefore, each model of exchange rate determination may imply a different measure of excess volatility. Moreover, some important economic variables are empirically unmeasurable, or at best measurable with substantial error given existing statistical techniques and data sources. How can one accurately quantify the effect of a Thatcher, Reagan, or Mitterrand election on expected future monetary growth and inflation? Or the impact of the Iranian revolution, the rise and decline of OPEC wealth, or the international debt crisis on portfolio preferences? Clearly the overwhelming importance of expectations in asset market models and the inherent difficulty of empirically measuring expectational variables imply that some significant sources of exchange rate volatility remain unquantifiable.

\section{EXCHANGE RATE VOLATILITY AND FUNDAMENTALS}

It is nonetheless useful to see just how much of exchange rate volatility can be related to past and contemporaneous changes in the variables suggested as determinants of the exchange rate by asset market models. Of course, if the exchange rate anticipates these variables, as Sims has suggested for the interest rate, then its movements will appear poorly explained..$^{33}$ But it is worth trying to discover how important such problems seem to be, using an atheoretical methodology. Previous attempts at structural modeling of exchange rates have met with little success, and this failure is not restricted to the simpler, single-equation models. Even large structural models that take explicit account of the

33. Christopher A. Sims, "Comparison of Interwar and Postwar Business Cycles: Monetarism Reconsidered," American Economic Review (May 1980, Papers and Proceedings, 1979), pp. 250-57. 
multicountry general equilibrium nature of exchange rate determination, such as the multicountry model (MCM) developed over the past decade at the Board of Governors of the Federal Reserve System, have met with limited success in tracking and forecasting short-run exchange rate fluctuations. ${ }^{34}$

For this reason, an alternative empirical strategy is adopted below. No a priori assumptions are imposed about speeds of adjustment. Although the econometric approach employed is nonstructural in nature, it is possible (under assumptions equivalent to those used in singleequation models) to draw some qualitative conclusions about the ability of fundamentals to explain short-run exchange rate volatility.

In the reduced-form model developed below the change in the logarithm of the bilateral (dollar-foreign currency) exchange rate is related to changes in the logarithm of relative (U.S. to foreign) money supplies, M1; changes in the logarithm of relative output (industrial production); changes in the logarithm of relative prices (consumer price index); changes in the short-term (three-month) nominal interest rate differential; and the level of the two countries' current accounts (or trade balances, when monthly current account data are unavailable). ${ }^{35}$ All raw data are seasonally unadjusted and seasonal dummies are incorporated in estimation.

The exchange rate equation is derived and estimated as part of a vector autoregressive (VAR) system of equations in which each of the seven variables - the exchange rate and its six predicted determinantsis regressed on its own lagged values and on lagged values of all the other

34. A summary of the various approaches to exchange determination attempted within the context of the MCM is described in Peter Hooper and others, "Alternative Approaches to General Equilibrium Modeling of Exchange Rates and Capital Flows: The MCM Experience," International Finance Discussion Paper 213 (Board of Governors of the Federal Reserve System, 1982).

35. Much of the data used in the following simulations was provided by Richard Meese and Kenneth Rogoff. The exchange rates, interest rates, and money supplies are aligned at end-of-month dates. This alignment of the data helps to capture some of the announcement effects of money and interest rates on exchange rates. Because joint stationarity of the regressors is a key assumption underlying the existence of a VAR representation, most variables appear as first differences of logarithms. See Thomas J. Sargent, Macroeconomic Theory (Academic Press, 1979), for a discussion of the conditions required for the existence of VAR and MA representations of a vector time series. Trade balances and current accounts appear in level form because the portfolio-balance model predicts an association between the change in the exchange rate and the change in private sector holdings of foreign assets. 
variables. ${ }^{36}$ Lag length was selected using the likelihood ratio criterion. Then, to focus attention on the importance of unanticipated movements in the determinants, the estimated VAR system is expressed in terms of its associated Wold or moving average (MA) representation. In the MA system, the change in the exchange rate is expressed as a linear combination of current and past unanticipated movements (disturbances or innovations) in the explanatory variables, and disturbances further in the past are given progressively less weight. An unanticipated movement in a variable in this context is defined as the forecast error from the VAR equation for that variable. ${ }^{37}$

The disturbance terms in the moving average representation are typically contemporaneously correlated, which makes it difficult to provide a meaningful definition of a disturbance to any single VAR equation. As is standard in the VAR methodology, the MA representation is transformed before the simulations are performed in order to obtain uncorrelated disturbances. Since we wish to place an upper bound on the component of exchange rate movements that can be explained by innovations in other variables, the particular transformation employed assumes that all contemporaneous correlation between the exchange rate and its determinants reflects causation from the latter to the former. This assumption is also commonly used in the single-equation exchange rate models that abound in the literature, which assume that the regressors are econometrically exogenous. ${ }^{38}$

To impose this assumption during the simulations that are used to decompose the variance of the exchange rate change, several steps are required. First, before simulation the system of estimated VAR equations is ordered so that the exchange rate equation appears last. The ordering selected for the six remaining variables is (from top to bottom): relative output, relative prices, relative money, the U.S. trade balance, the

36. Significance tests for the variables in the VAR exchange rate equation are reported in the appendix. They indicate the importance only of lagged values of the variables because contemporaneous effects are contained in the disturbance terms. These contemporaneous effects are incorporated in the simulation results reported in the text.

37. These disturbances include the possible effects of omitted variables that operate directly on the exchange rate and not through the other regressors, including the political or confidence factors that are often said to influence portfolio preferences.

38. The exogeneity specification of popular exchange rate models has been critically evaluated by Glaessner. See Thomas Glaessner, "A Test of the Exogeneity Specifications of Models of Exchange Rate Determination"' (Board of Governors of the Federal Reserve System, 1979). 
other country's current account (or trade balance for the United Kingdom), and the nominal interest rate differential. ${ }^{39}$ The covariance matrix of the estimated residuals is then used to transform the system so that, during simulations, innovations in variables placed higher in the ordering of equations are allowed to influence contemporaneously those below them, but not vice versa. This transformation is tantamount to incorporating contemporaneous values of the six determinants along with their lagged values in the exchange rate equation before simulation. ${ }^{40}$

Selection of an ordering for the equations of a VAR model is simply the econometric identification procedure in another guise. Choosing an ordering is equivalent to imposing enough identifying restrictions to achieve a recursive system in the classical econometric framework. It is not surprising, then, that the ordering has important implications for the allocation of explanatory power among the individual determinants, just as the selection of exclusion restrictions influences simulation results in a classical econometric framework. The primary conclusions highlighted below, however, are not a product of the ordering selected for the six determinants.

VAR simulations are generally used to decompose the variance of the forecast error of the dependent variable at different forecast horizons into the percentages of the variance attributable to each of the explanatory variables. ${ }^{41}$ Decompositions of the forecast error variance of the change in exchange rates are provided in figure 4 for the dollar-mark, dollar-yen, and dollar-pound rates. The percentage that is attributable to disturbances to each of the explanatory variables is plotted for forecasting horizons of one to thirty-six months. The part of the forecast error variance that is attributed to own disturbances is denoted by the line $s$.

39. The following considerations have guided the choice of ordering. Because exchange rates and interest rates react strongly to contemporaneous events, they are placed at the end of the ordering. The placement of the price and output variables before the monetary variable reflects the desire to allow for a reaction function of the monetary authorities. Placement of trade and current accounts near the end of the ordering is consistent with the view that they have little effect on relative prices and output in the current period but that they may be somewhat sensitive to contemporaneous disturbances in these variables.

40. More precisely, the covariance matrix of estimated residuals is lower triangularized. See the discussion of VAR simulation methodology in Robert J. Gordon and Stephen R. King, "The Output Cost of Disinflation in Traditional and Vector Autoregressive Models,"' BPEA, 1:1982, especially pp. 207-15.

41. For other examples of this type of simulation-based variance decomposition, see Christopher Sims, "Macroeconomics and Reality," Econometrica, vol. 48 (January 1980), pp. 1-48; and Stanley Fischer, "Relative Shocks, Relative Price Variability, and Inflation," BPEA, 2:1981, pp. 381-431. 
Figure 4. Decomposition of the Variance in the Forecast Error for the Change in the Exchange Rate ${ }^{\mathrm{a}}$

Percent of the variance in the forecast error

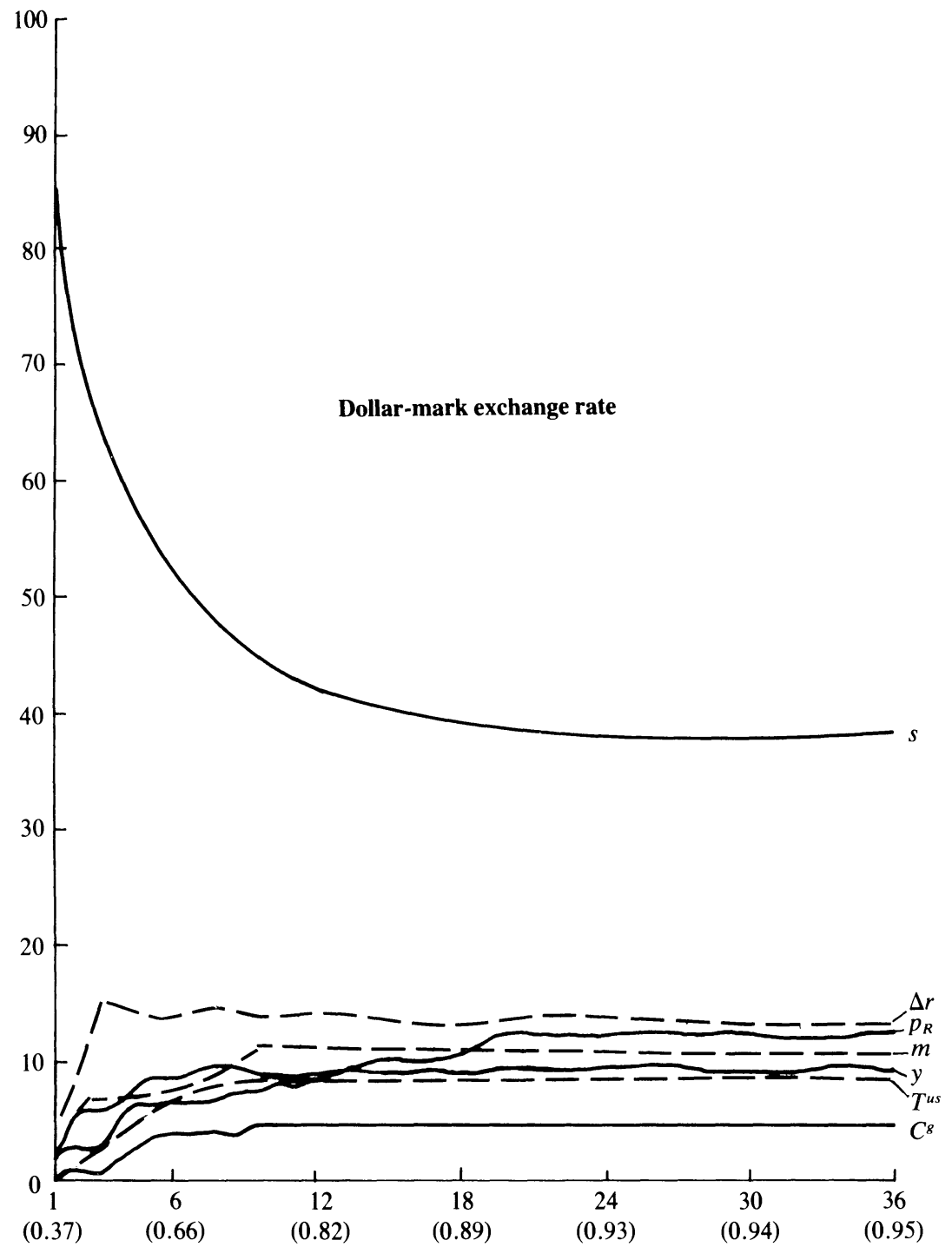

Months ahead ( $V^{*}$ in parentheses) 


\section{Figure 4 (continued)}

Percent of the variance in the forecast error

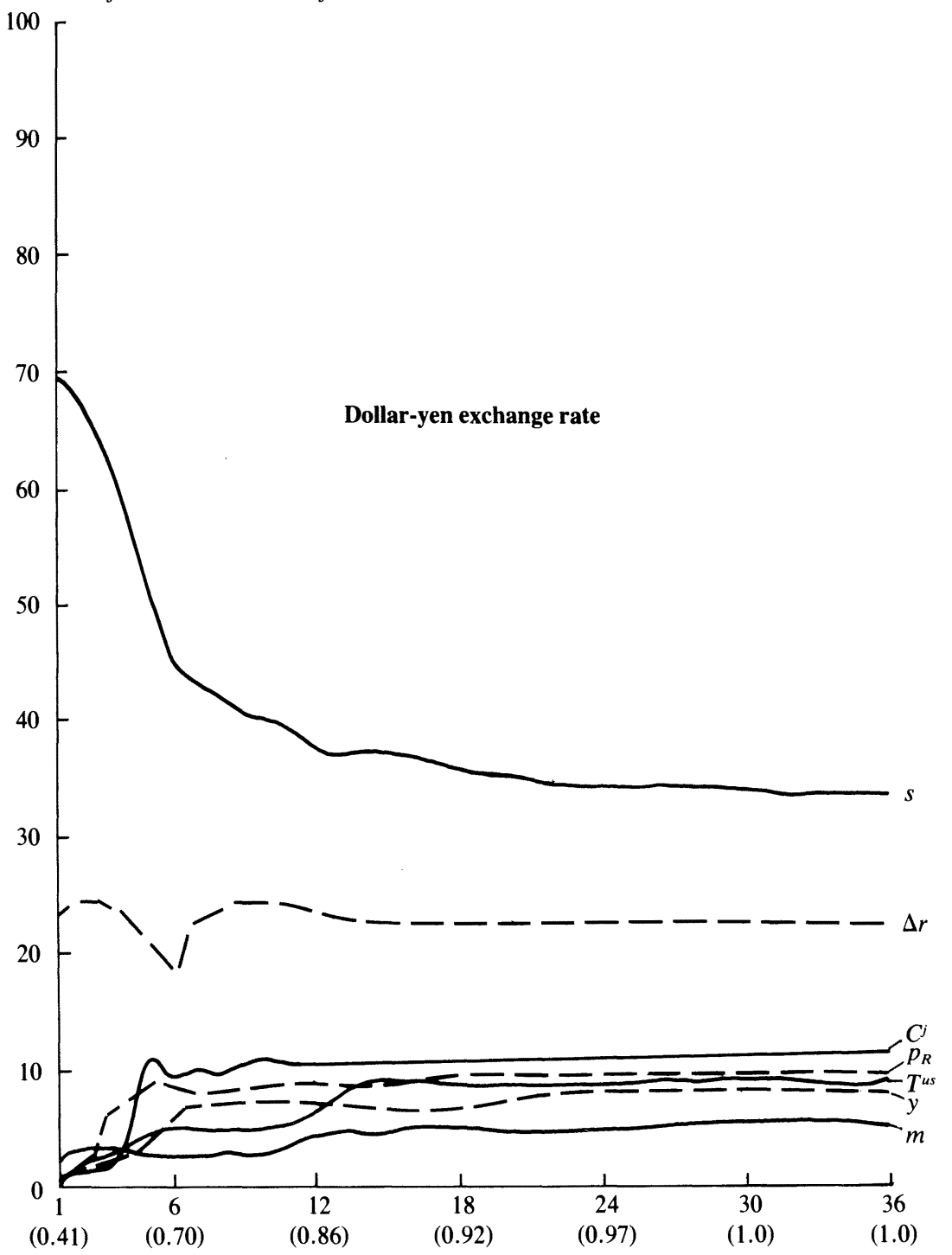

Months ahead ( $V^{*}$ in parentheses)

Source: Authors' calculations based on data from the Board of Governors of the Federal Reserve System.

a. The decomposition is explained by orthogonalized disturbances to the explanatory variables. The variables are $s$, percentage change in the dollar-foreign currency exchange rate; $\Delta r$, the change in the short-run interest differential; $m$, the percentage change in the relative money supply; $y$, the percentage change in relative output; $p_{R}$, the percentage 


\section{Figure 4 (continued)}

Percent of the variance in the forecast error

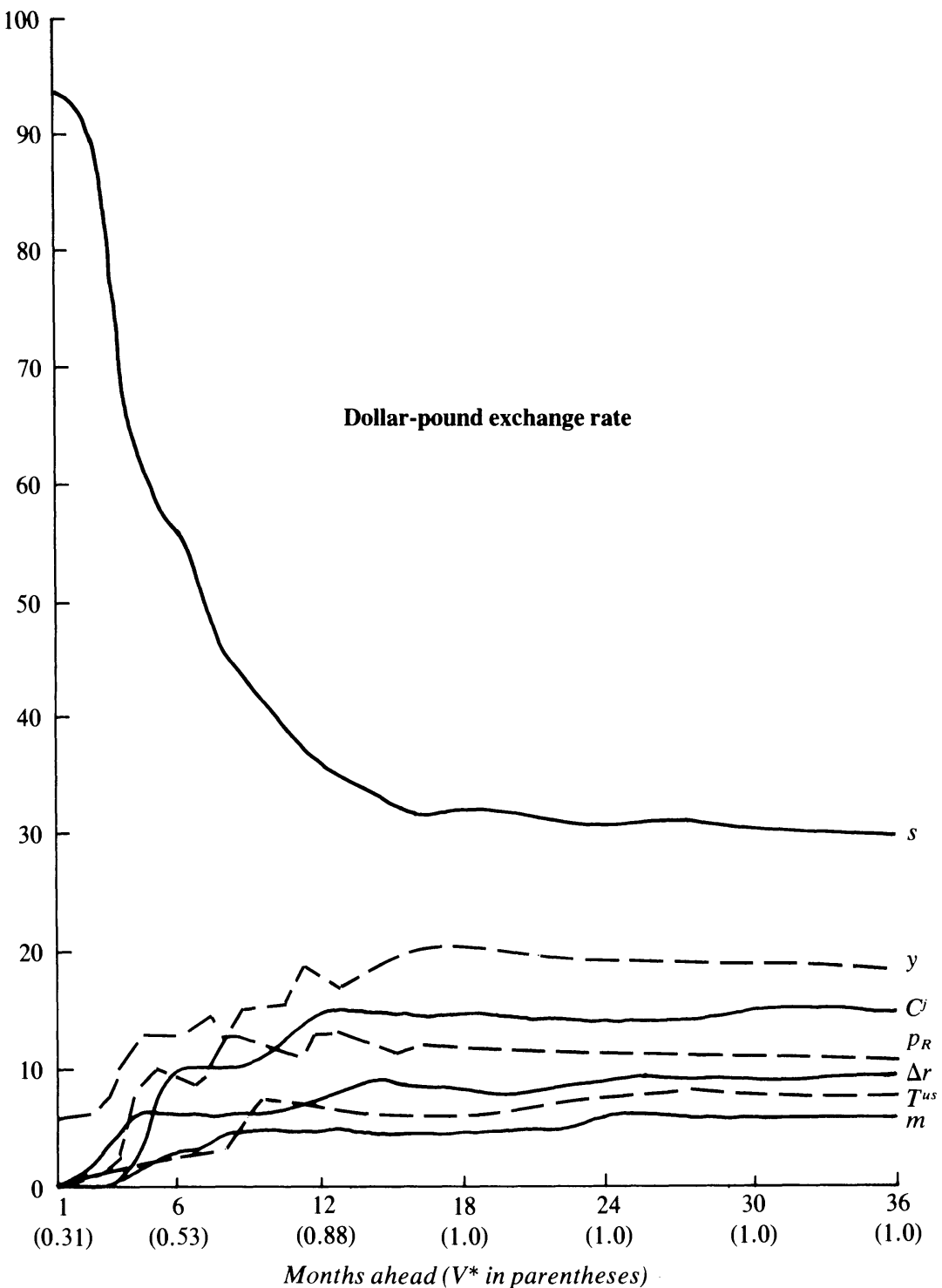

change in relative prices; $C_{g}$, the German current account; $T^{u s}$, the U.S. trade balance; $C_{j}$, the Japanese current account; and $T^{u k}$, the U.K. trade balance. The $V^{*}$ is the ratio of the variance in the forecast error to the variance of the dependent variable. When $V^{*}$ is close to 1.0 , the variance in the forecast error approximately equals the variance of the dependent variable. 
An intuitive interpretation can be given to these figures: they tell what types of (orthogonalized) disturbances have caused the change in exchange rates to deviate from its predicted value at various forecasting horizons. The in-sample simulation evidence in figure 4 reinforces the out-of-sample fit results reported by Meese and Rogoff that fundamentals help very little in forecasting exchange rates over short horizons. ${ }^{42}$ This is evident from the high percentage of the forecast error variance that is not explained by disturbances to the fundamentals (denoted by $s$ ) at horizons of less than six months. At longer horizons, disturbances to fundamentals account for more of the deviation of the change in exchange rates from its predicted level.

A more important issue is whether the high volatility of exchange rates during the past decade can be related to movements in the theoretically suggested determinants. To address this issue, it is necessary to obtain a decomposition of the variance of the exchange rate change itself, rather than of its forecast error. An approximation to this variance can also be obtained from the above simulations. The one-stepahead forecast error based on the MA system is simply the contemporaneous disturbance appearing in the MA representation; the two-stepahead forecast error incorporates contemporaneous and first-lag values of disturbances; and so on. ${ }^{43}$ As we use the MA representation to forecast further into the future, each successive forecast error incorporates progressively more terms of the MA representation. In this way, the

42. Meese and Rogoff, "Empirical Exchange Rate Models."

43. To see this, consider the following MA equation from a two-variable system consisting of variables $x_{1 t}$ and $x_{2 t}$ :

$$
\begin{aligned}
x_{1 t}=u_{t} & +a_{11} u_{t-1}+a_{12} u_{t-2}+\cdots \\
& +a_{21} v_{t-1}+a_{22} v_{t-2}+\cdots,
\end{aligned}
$$

where $u$ and $v$ are the disturbance terms from the first and second equations, respectively. The one-step-ahead forecast error is then

$$
x_{1, t+1}-E_{t} x_{1, t+1}=u_{t+1} .
$$

From the assumption of stationarity, $\operatorname{var}\left(u_{t+1}\right)=\operatorname{var}\left(u_{t}\right)=\sigma_{u}^{2}$. Thus the one-step-ahead forecast-error variance involves the variance of the contemporaneous term of the MA representation. Similarly, the two-step-ahead forecast error is

$$
x_{1, t+2}-E_{t} x_{1, t+2}=u_{t+2}+a_{11} u_{t+1}+a_{21} v_{t+1},
$$

so that its variance is calculated from terms involving contemporaneous and lagged disturbances from the two equations. 
forecast error at very long horizons yields a good approximation of the entire MA representation of the dependent variable itself. ${ }^{44}$

In figure 4 the $V^{*}$ value reported in parentheses beneath each forecast horizon is the ratio of the forecast error variance at that horizon to the total variance of the change in exchange rate. At forecast horizons for which $V^{*}$ is close to 1.0 , the forecast error variance closely approximates the variance of the exchange rate change itself. A horizon of thirty-six months proved sufficient in all cases to obtain a value of $V^{*}$ close to 1.0.

Variance decompositions are reported in table 3 for percentage changes in the dollar-mark, dollar-yen, and dollar-pound exchange rates from March 1973 to August 1982. The last row of the table indicates the part of the variance of the change in exchange rates that cannot be attributed to (orthogonalized) innovations in the six explanatory variables and is ascribed to own disturbances. This part of the variance amounts to 30 to 40 percent and is invariant with respect to the ordering selected for the six other equations placed before the exchange rate in the simulations. ${ }^{45}$

A common criticism of the VAR methodology is that it only provides evidence on the importance of reduced-form disturbance terms (forecast

44. Because MA coefficients further in the past become progressively smaller in a stable system, ignoring the distant past of the theoretically infinite, moving-average representation may not entail much loss of information.

45. Given that the exchange rate is placed last in the ordering for simulations, the ordering of the remaining six equations has no effect on the simple dichotomy of the variance of the exchange rate change into the part attributable to VAR disturbances in the six fundamentals taken together, and the part explained by own disturbances. To see this, consider a trivariate VAR system of equations for variables $x, y$, and $z$ that has been ordered for simulations and whose estimated residuals are (from first to last) $u_{x t}, u_{y t}$, and $u_{z l}$. These disturbances are serially uncorrelated, i.i.d. disturbance terms that may, however, be correlated with each other. When the covariance matrix of the estimated residuals is orthogonalized before simulation, it is equivalent to a redefinition of the residuals using the following hypothetical regressions:

$$
\begin{aligned}
& u_{x t}=e_{x t}, \\
& u_{y t}=d_{1} u_{x t}+e_{y t}, \\
& u_{z t}=d_{2} u_{x t}+d_{3} u_{y t}+e_{z t} .
\end{aligned}
$$

The resulting residuals $-e_{x t}, e_{y t}$, and $e_{z t}-$ are uncorrelated with each other by construction. The redefined residual for the last equation, $e_{z}$, is clearly not influenced by the ordering of the two other equations. Hence when the MA equation for $z$ is used in simulations to split the explanatory power between contemporaneous and lagged values of $e_{z t}$ on the one hand, and of $e_{x t}$ and $e_{y t}$ on the other, the division is invariant with respect to the ordering of the two top equations. 
Table 3. Variance Decomposition of the Change in Exchange Rates, March 1973 to August 1982a

\begin{tabular}{lccc}
\hline & \multicolumn{3}{c}{ Percentage of variance accounted for } \\
\cline { 2 - 4 } Orthogonalized innovation & $\begin{array}{c}\text { Dollar-mark } \\
\text { rate }\end{array}$ & $\begin{array}{c}\text { Dollar-yen } \\
\text { rate }\end{array}$ & $\begin{array}{c}\text { Dollar-pound } \\
\text { rate }\end{array}$ \\
\hline Relative output & 9.1 & 8.6 & 19.4 \\
Relative prices & 13.5 & 9.5 & 10.7 \\
Relative money & 11.2 & 5.5 & 6.3 \\
U.S. trade balance & 9.1 & 9.0 & 8.4 \\
Other country's current account ${ }^{\mathrm{b}}$ & 4.9 & 11.5 & 15.4 \\
Short-term interest differential & 13.8 & 22.1 & 9.7 \\
Unexplained (spot rate) & 38.3 & 33.9 & 30.1 \\
\hline
\end{tabular}

Sources: All U.S. data except for the trade balance are from the Board of Governors of the Federal Reserve System. Exchange rates are noon New York spot bid market rates, aligned at end-of-month dates with the interest rates and money supplies. Output variables are industrial production indexes from OECD, Main Economic Indicators. Consumer price indexes for Germany, Japan, and the United Kingdom are from the Monthly Report of the Deutsche Bundesbank, table VIII-7; Bank of Japan, Economic Statistics Monthly, table 119(1); and Department of Employment, Employment Gazette, table 6.4, respectively. The M1 series for the same countries are from the Monthly Report of the Deutsche Bundesbank, table I-2; the Bank of Japan, Economic Statistics Monthly, table 4; and the Bank of England Quarterly Bulletin, table 1. Data on trade balances are from OECD, Main Economic Indicators, for the United Kingdom; and from U.S. Bureau of the Census, Highlights of U.S. Export and Import Trade, tables E-1 and I-1 through 1978, and Summary of U.S. Export and Import Merchandise Trade through 1982 for the United States. Current account data for Germany and Japan are from OECD, Main Economic Indicators. Interest rates for Germany, Japan, and the United Kingdom are, respectively, the three-month interbank rate from the Frankfurter Allegemeine Zeitung; the "over two-month ends" bill discount rate (Tokyo Stock Exchange) from the Federal Reserve Board data base; and the three-month deposit rate for the local authority from the London Financial Times. The threemonth Treasury bill rate is from the Board of Governors of the Federal Reserve System.

a. The entries in the table are the percentages of the variance of the exchange rate change that can be attributed to orthogonalized VAR disturbances to each of the explanatory variables shown. The last row reports the percent of the variance not ascribable to disturbances to any of the six explanatory variables, which is then residually attributed to exchange rate disturbances. The variables are presented above in the order in which they were placed for simulation (see the text for a discussion of the importance of the ordering for simulation).

b. Trade balance for the United Kingdom.

errors from the VAR equations), while the interesting economic issues relate to the importance of structural disturbance terms such as money demand or aggregate demand shocks. The VAR model can be viewed as the reduced-form representation of one or more structural exchange rate models, so that each VAR disturbance term is a linear combination of a number of structural disturbance terms. ${ }^{46}$ Then, unless the underlying structural model is identified, it is not possible to unscramble the structural disturbances from the estimated VAR disturbances.

Although results on the importance of VAR innovations cannot generally be translated into evidence on the importance of structural

46. John Taylor discusses this point in his comments on a paper by Stanley Fischer in BPEA, 2:1981, pp. 434-38. 
disturbances, some qualitative conclusions concerning the latter issue may be inferred if additional identifying assumptions are made. If, as in single-equation exchange rate models, it is assumed that the regressors in the exchange rate equation of the structural model underlying the VAR model are predetermined, that structural model must be block recursive. Then the exchange rate will not affect contemporaneously any of the other variables in the associated VAR system, and the disturbance term in the VAR exchange rate equation will be independent of any of the other disturbance terms. In this case, the structural and reduced-form interpretations of the VAR exchange-rate innovation coincide: the innovation represents disturbances to the exchange rate equation that are not due to structural disturbances to any of the other variables in the model. Under these assumptions, the results in table 3 may be interpreted as evidence that 60 to 70 percent of exchange rate volatility can be ascribed to (structural or VAR) disturbances to the theoretically suggested explanatory variables.

Further inferences from the VAR evidence require even stronger identifying assumptions. As noted earlier, in the presence of contemporaneous correlation among the estimated VAR disturbance terms, the allocation of explanatory power among the individual disturbances is influenced by the ordering, so this decomposition must be interpreted with more caution. In particular, the allocation of the variance among reduced-form innovations using VAR-based simulations will only correspond to the more meaningful allocation of the variance among the structural disturbances if the system is fully recursive (and not just block recursive). These results are summarized briefly here. For the dollarmark rate, disturbances to relative prices, the interest differential, and relative money account for about 40 percent of the variance of changes in exchange rates. This evidence suggests the relative importance of asset market variables and price developments. In addition to relative price and interest rate disturbances, disturbances in the current account are important in explaining the forecast error variance of the dollar-yen rate, despite having been placed below the other determinants in the ordering of equations. Disturbances in the U.S. trade balance are also an important source of volatility of the dollar-pound rate. The possible channels through which the current account or trade balance could influence the exchange rate are discussed below. 


\section{RANDOM DATA EXPERIMENTS}

From the above evidence it appears that a substantial proportion of the volatility of exchange rates can be related to unanticipated movements in the theoretically predicted determinants. One drawback of the VAR methodology, however, is that it requires estimation of a large number of coefficients relative to the small number of monthly observations since the advent of floating. Together with the likely collinearity among the many regressors, this implies that few of the coefficients are very precisely estimated.

To illuminate the empirical importance of this problem, an experiment was conducted for comparison. In the experiment the rate of change of the exchange rate was regressed on its own past values and on past values of six series that were created using a random number generator. The same number of variables, lags, and seasonal dummies as in the VAR simulations were included in the experiments to closely mirror the conditions for VAR estimation using actual data.

Table 4 compares the percentage of the variance of the change in exchange rates explained by orthogonalized innovations in the six explanatory variables in the earlier VAR simulations with that explained by innovations in the six randomly generated data series in the experiments. Based on evidence from five repetitions of the random data experiments, it appears that, on average, the model based on the actual data explains the variance of the exchange rate change only about 8 to 16 percent better than the models with purely randomly generated data. Thus one must conclude that much of the short-run volatility of exchange rates over the past decade remains unexplained by the variables emphasized in the models of the 1970s. These results reinforce those from outof-sample tests and indicate that one can neither explain nor predict with any confidence a substantial portion of month-to-month exchange rate volatility using even a very unrestricted representation of the asset market models.

\section{MODEL RESTRICTIONS}

While the VAR technique provides a way to assess whether the variables suggested by the asset market models can explain exchange rates, it does not provide tests of the restrictions imposed by these 
Table 4. Variance Decomposition of the Change in Exchange Rates, Actual Data versus Randomly Generated Data, March 1973 to August 1982a

\begin{tabular}{|c|c|c|c|}
\hline \multirow[b]{2}{*}{ Item } & \multicolumn{3}{|c|}{ Percentage of variance accounted for } \\
\hline & $\begin{array}{c}\text { Dollar-mark } \\
\text { rate }\end{array}$ & $\begin{array}{l}\text { Dollar-yen } \\
\text { rate }\end{array}$ & $\begin{array}{c}\text { Dollar-pound } \\
\text { rate }\end{array}$ \\
\hline Simulations based on actual data & 61.7 & 66.1 & 69.9 \\
\hline Average for random data experiments & 53.4 & 52.9 & 53.9 \\
\hline Range for the experiments & 48.4-59.5 & $49.7-58.1$ & $43.5-67.5$ \\
\hline Improvement gained by using actual rather & & & \\
\hline than random data ${ }^{\mathrm{b}}$ & 8.3 & 13.2 & 16.0 \\
\hline
\end{tabular}

Sources: Same as table 3.

a. Entries show the percentage of the variance of the exchange rate change explained jointly by orthogonalized innovations in the six explanatory variables (not including own innovations) for two data sets: actual data - the six variables suggested by the theoretical models (the same variables as in table 3); and random data-six randomly generated series.

b. Difference between the first two rows.

models. These restrictions are at the heart of the policy debate. They determine what influence policies can have on the exchange rate, and they are an important part of the cases for and against resisting changes in exchange rates.

For example, the purchasing power parity assumption of the flexibleprice monetary model leads to the conclusions that financial policies do not affect the real exchange rate and that there is no need for authorities to be concerned about the exchange rate anyway. Authorities can and should focus their attention on pursuing a monetary policy consistent with domestic price stability. The model, which assumes a stable demand for money and rational expectations, suggests that the right way to do this is to follow a policy of constant money growth equal to the trend rate of growth of real economic activity. If the demand for money moves erratically, the problem of finding the optimal monetary policy is more complicated. But the essential insight of the flexible-price monetary model from an international perspective is unaffected. The best policy for each country and for the world as a whole is for authorities to stabilize prices in their own economies as best they can.

In the sticky-price monetary model, the uncovered interest parity condition, which follows from the assumptions of perfect asset substitutability and rational expectations, is the central relation yielding international policy implications. Recall that uncovered interest rate parity implies that the nominal interest rate differential exactly equals the expected percentage change in exchange rates. If interest-bearing 
assets are perfect substitutes, authorities cannot expect to influence the exchange rate by intervening in the foreign exchange market if the intervention is sterilized-that is, if the stock of money is not allowed to change. Sales of interest-bearing assets denominated in one currency for nonmoney assets denominated in another have no effect on assetmarket equilibrium. Moreover, intervention that is not sterilized is equivalent to a domestic open-market operation because it makes no difference whether an increase in money is accomplished by purchasing assets denominated in domestic or foreign currency. Policies pursued abroad also influence macroeconomic conditions at home through their effects on the real exchange rate and interest rate. So economies are not insulated, and there are potential advantages to coordinating domestic stabilization policies among countries. ${ }^{47}$

If the uncovered interest parity condition holds, unstable currency preference can be ruled out as an important influence on exchange rates, and this reason for intervention to stabilize exchange rates can be rejected. Shifts in preferences by some portfolio holders would then be absorbed by other portfolio holders with no net effect on nominal or real exchange rates. Similarly, wealth redistributions would not affect exchange rates. The market would be self-stabilizing with respect to disturbances of this type. At the same time, the case for allowing exchange rates to influence domestic macroeconomic policies would be strengthened. The exchange rate might then provide a useful indicator of economic conditions and prospects at home relative to those in foreign economies.

In the portfolio-balance model, uncovered interest rate parity will not hold exactly. Imperfect asset substitutability implies that interest-bearing assets denominated in different currencies are perceived to have different risk characteristics. The existence of differential risk-reflected in risk premiums or discounts-allows scope for sterilized exchange market intervention to influence exchange rates, although its impact is less powerful dollar-for-dollar than that of unsterilized intervention.

47. The model as presented incorporates a role only for monetary policies. But in an elaborated model, which incorporates the influence of fiscal policy on aggregate demand, varying the mix of monetary and fiscal policy leads to different real interest rates and real exchange rates for a given level of aggregate demand. See the analysis within the context of a sticky-wage monetary framework by André Burgstaller, "Flexible Exchange Rates, Rational Expectations, and the Trade-off between Inflation and Unemployment," Discussion Paper 85 (Columbia University, 1980). 
This model also incorporates additional determinants of changes in exchange rates, including the wealth redistribution associated with a current account imbalance. The exchange rate response tends to reduce the current account imbalances and foster external balance. But if current accounts are most susceptible to transitory disturbances and respond slowly to changes in exchange rates, this adjustment mechanism would contribute little to damping current account imbalances.

Tests of uncovered parity are tests of the joint hypothesis that assets denominated in domestic and foreign currency are perfect substitutes (the absence of a risk premium) and that expectations are rational. It is important for policy purposes to determine which part of the joint hypothesis accounts for the failure of uncovered parity to hold. If, on the one hand, the failure indicates the existence of a risk factor consistent with the portfolio-balance model, it implies a channel through which sterilized intervention could affect the exchange rate. The inability of researchers to relate the observed deviations from uncovered parity to the variables that the portfolio-balance model suggests makes it more difficult to interpret the results as evidence supporting the existence of a risk premium. ${ }^{48}$ Even if the failure of uncovered parity could be interpreted in this way, the question would still remain whether intervention could improve the allocation of risk and resources achieved by the free market.

If, on the other hand, the failure of the tests is a reflection of expectations that do not fully and immediately incorporate new developments or overreact (or underreact) to them, it would still be necessary to understand how expectations behave and how they might be influenced by official actions in order to determine whether intervention could improve the situation. Also, from the basic principle that it is best for policies aimed at eliminating market imperfections to act directly at their source, information about the source of any inefficiency is essential to determining if intervention is in fact the optimal corrective strategy. Thus if there is a case for intervention based on the uncovered interest parity tests, it is predicated on knowledge of the source of the rejection of the condition. There has been little research along these lines.

We have already called attention to the failure of purchasing power

48. See Jeffrey A. Frankel, "In Search of the Exchange Risk Premium: A Six-Currency Test Assuming Mean-Variance Optimization," Journal of International Money and Finance, vol. 1 (December 1982), pp. 255-74. 
parity to provide an accurate short-run characterization of the behavior of exchange rates and relative prices. Fluctuations in real exchange rates during the past decade have been large and cumulative. Evidence has also been cited from the literature indicating statistically significant deviations from the uncovered interest rate parity condition. Failure of this condition to hold is commonly interpreted as evidence supporting the portfolio-balance model and contradicting the sticky-price monetary model. But tests of uncovered parity do not shed light on how well the central insight of the sticky-price monetary model-that real interest rate differentials have an important influence on the real exchange rateaccounts for the broad sweep of real exchange rate movements over the floating rate period. If this mechanism leaves much unexplained over the past decade, it suggests a role for the additional factors incorporated in the portfolio-balance model to explain sustained and systematic deviations from uncovered interest parity. To look at this question, evidence is provided below on how well real interest rate differentials explain the broad movements of real exchange rates.

UNCOVERED INTEREST PARITY IN THE LONG TERM

It was noted earlier that the uncovered interest parity condition implies that the expected percentage change in the real exchange rate will equal the real interest rate differential observed across countries. Thus the uncovered interest rate parity condition is expressed as

$$
r_{t}=r_{t}^{*}+s_{t}^{e},
$$

where, as before, $r$ is the nominal interest rate; $s$ is the change (over the same horizon as the interest rate) in the logarithm of the exchange rate; $e$ denotes an expected value conditional on information available at time $t$; and ${ }^{*}$ denotes a foreign variable. Let $Q$ denote the real exchange rate. By definition,

$$
\ln Q_{t}^{e}=\ln S_{t}^{e}+\ln P_{t}^{e *}-\ln P_{t}^{e},
$$

where, as before, $P$ is the price level. This relation holds for any horizon of expectations.

From these relations, the following association can be derived between the real interest rate differential across countries and the expected 
percentage change in the real exchange rate (where again a lowercase level variable indicates a percentage change):

$$
q_{t}^{e}=\left(r_{t}-p_{t}^{e}\right)-\left(r_{t}^{*}-p_{t}^{e *}\right) .
$$

If equilibrium is expected to be restored by some date $T$ periods in the future, the deviation of the logarithm of the real exchange rate today from its equilibrium value, $\ln \bar{Q}$, must equal the compounded real return differential from now to date $T$ (or any period, $N$, further in the future than $T$ ). In logarithmic form, ${ }^{49}$

$$
\ln \left(Q_{t} / \bar{Q}\right)=-\sum_{k=\mathrm{o}}^{N-1}\left[\left(r_{t+k}-p_{t+k}^{e}\right)-\left(r_{t+k}^{*}-p_{t+k}^{e *}\right)\right] \text { for } \quad(N \geq T),
$$

where $r_{t+k}$ is the expected one-period nominal interest rate for period $t+k$. If the expectations theory of the term structure holds, the average expected nominal interest rate over $N$ years can be proxied by the $N$ period bond rate. The deviation from the equilibrium exchange rate can be written as $N$ times the average real interest differential over $N$ years,

$$
\ln \left(Q_{t} / \bar{Q}\right)=-N\left[\left(\bar{r}_{t}-\bar{p}_{t}^{e}\right)-\left(\bar{r}_{t}^{*}-\bar{p}_{t}^{e *}\right)\right],
$$

where $\bar{r}_{t}$ is the average nominal interest rate on an $N$-period bond with no coupon, and $\bar{p}_{t}^{e}$ is the average expected inflation rate over $N$ periods.

This relation is examined below using interest rates on U.S. bonds of ten years' maturity and foreign bonds of about the same maturity. It seems unlikely that portfolio managers project current monetary disequilibriums further into the future than this, so that one can reasonably assume that equilibrium is expected to be restored within ten years. Predicted values for the real exchange rate are generated from nominal interest rates and measures of expected inflation rates under the assumptions that the long-run equilibrium real exchange rate, $\bar{Q}$, has been constant and that the uncovered interest parity condition has held over the past decade. A comparison of the actual and predicted values of the real exchange rate provides an indication of how well the exchange rate mechanism in the sticky-price monetary model accounts for the broad swings in real exchange rates over the floating rate period.

49. This equation uses the approximation $x \cong \ln (1+x)$ for a value of $x$ of the order of magnitude of interest rates and inflation rates. 
We tested two proxies for expected inflation. First, a centered twelvemonth moving average of actual inflation-that is, the inflation occurring at about the time expectations were formed-provides a "myopic" measure of long-term inflationary expectations. This measure works well if investors simply project current inflation experience far into the future. In contrast, an inflation forecast based on rational expectations weights all relevant available information on the basis of its historical power to predict future inflation. The second proxy is a rational inflation expectations series provided by the VAR model described above. A tenyear average inflation series is constructed as the simple average of inflation forecasts provided by the VAR system for the subsequent 120 months. ${ }^{50}$

Table 5 shows the regression results and the percentage of variation in the real exchange rate accounted for by variation in real interest rate differentials, $R^{2}$, using each of the expected inflation proxies. Real interest differentials calculated using the myopic expected inflation proxy explain a substantial part of the variation in the dollar-mark and dollar-yen real exchange rates, but the rational expectations proxy has virtually no explanatory power. Moreover, both proxies have the wrong sign for the dollar-pound real exchange rate, and the rational expectations proxy apparently explains a substantial share of the variation in the real exchange rate.

The empirical results clearly do not strongly support an explanation for changes in exchange rates that depends on uncovered interest rate parity with rational expectations. The substantial explanatory power of half of the bivariate regressions reported does, however, confirm an important connection between interest rates and exchange rates even if that connection is very different for the pound than for the mark and the yen.

Figure 5 shows how movements of real exchange rates correspond to movements of real interest rate differentials based on the myopic proxy for inflation expectations. The real exchange rates are shown together with the regression predictions and a priori predictions that are calculated using a value of $\ln \bar{Q}$ equal to the sample mean of $\ln Q$ and a coefficient of 10 on the real interest rate differential, corresponding to the approxi-

50. An alternative approach would be to estimate the long-run expected real interest rate differential using the observed time-series process for short-run real differentials. 
Table 5. The Relation between the Long-Term Real Interest Rate and the Real Exchange Rate, August 1973 to March 1982a

\begin{tabular}{|c|c|c|c|c|c|c|}
\hline \multirow[b]{2}{*}{$\begin{array}{c}\text { Dependent } \\
\text { variable }\end{array}$} & \multicolumn{3}{|c|}{ Myopic inflation expectations } & \multicolumn{3}{|c|}{ Rational inflation expectations } \\
\hline & Constant & $\begin{array}{c}\text { Real } \\
\text { interest } \\
\text { rate } \\
\text { differential }\end{array}$ & $R^{2}$ & Constant & $\begin{array}{c}\text { Real } \\
\text { interest } \\
\text { rate } \\
\text { differential }\end{array}$ & $R^{2}$ \\
\hline Dollar-mark rate & $\begin{array}{l}-1.49 \\
(0.013)\end{array}$ & $\begin{array}{c}-2.74 \\
(0.321)\end{array}$ & 0.42 & $\begin{array}{l}-1.46 \\
(0.022)\end{array}$ & $\begin{array}{l}-1.20 \\
(0.563)\end{array}$ & 0.04 \\
\hline Dollar-yen rate & $\begin{array}{c}-6.04 \\
(0.009)\end{array}$ & $\begin{array}{c}-2.19 \\
(0.212)\end{array}$ & 0.51 & $\begin{array}{c}-6.04 \\
(0.019)\end{array}$ & $\begin{array}{r}0.72^{\mathrm{b}} \\
(0.74)\end{array}$ & 0.01 \\
\hline Dollar-pound rate & $\begin{array}{c}0.66 \\
(0.017)\end{array}$ & $\begin{array}{c}0.35^{\mathrm{b}} \\
(0.421)\end{array}$ & 0.01 & $\begin{array}{l}0.64 \\
(0.008)\end{array}$ & $\begin{array}{l}4.93^{\mathrm{b}} \\
(0.397)\end{array}$ & 0.59 \\
\hline
\end{tabular}

Source: Authors' least-squares regression, $\ln Q=a+b\left[\left(r_{t}-\ln p_{t}^{e^{*}}\right)-\left(r_{t}^{*}-\ln p_{t}^{e^{*}}\right)\right]$. Results are reported for real interest rate differentials constructed using the myopic and rational expected inflation proxies described in the text.

a. Standard errors are reported in parentheses.

b. The regression coefficients are of the wrong sign.

mate ten-year maturity of the interest rates. ${ }^{51}$ The figure shows no correspondence between real exchange rates and real interest differentials for 1973-74, the period of initial adjustment to floating exchange rates and the first oil shock. But after 1975, and particularly since 1979, the actual and predicted series for the dollar-mark and dollar-yen real exchange rates correspond more closely. The a priori predictions suggest that the very large real depreciations of the mark and yen against the dollar in recent years are roughly commensurate with movements of interest rates and inflation rates if one is prepared to entertain the hypothesis of myopic inflation expectations.

The question remains, why do the rational expectations proxies give poor results? These proxies for inflation over ten years are relatively insensitive to current inflation or to disturbances in the other variablesthe proxies for the inflation differential range over an interval of less

51. The estimated coefficients reported in table 5 are considerably smaller than the a priori value of 10 , but considerable deviations of the estimated coefficients from their a priori values should not be surprising given: (1) coupon payments on bonds for which market interest rates are available that give more weight to near-term interest rates in the yield to maturity calculation of the geometrical average interest rate over the life of the bond; (2) tax considerations, which are ignored; (3) measurement error in the differential for the real interest rate-especially in the expected inflation component; and (4) the longrun equilibrium real exchange rate, $\bar{Q}$, which may not be constant. 
Figure 5. Long-Run Uncovered Interest Rate Parity under Myopic Inflation Expectations

In (dollars per mark) ${ }^{\mathrm{a}}$

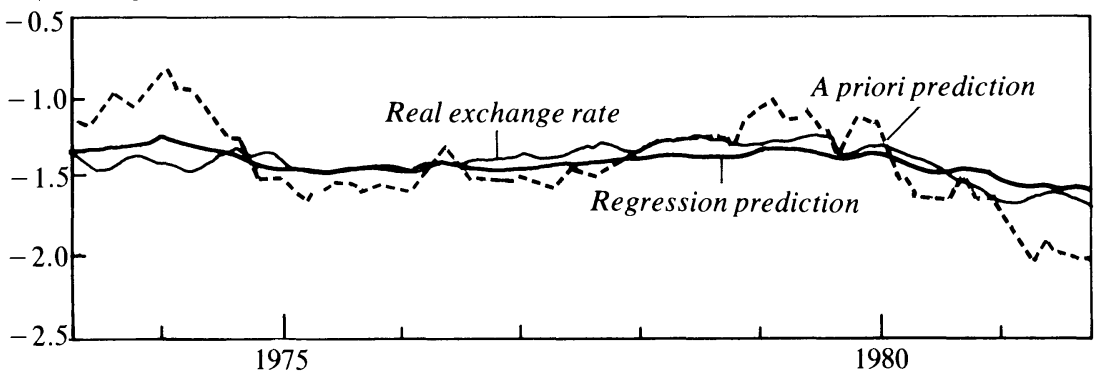

$\ln (\text { dollars per yen })^{\mathrm{a}}$
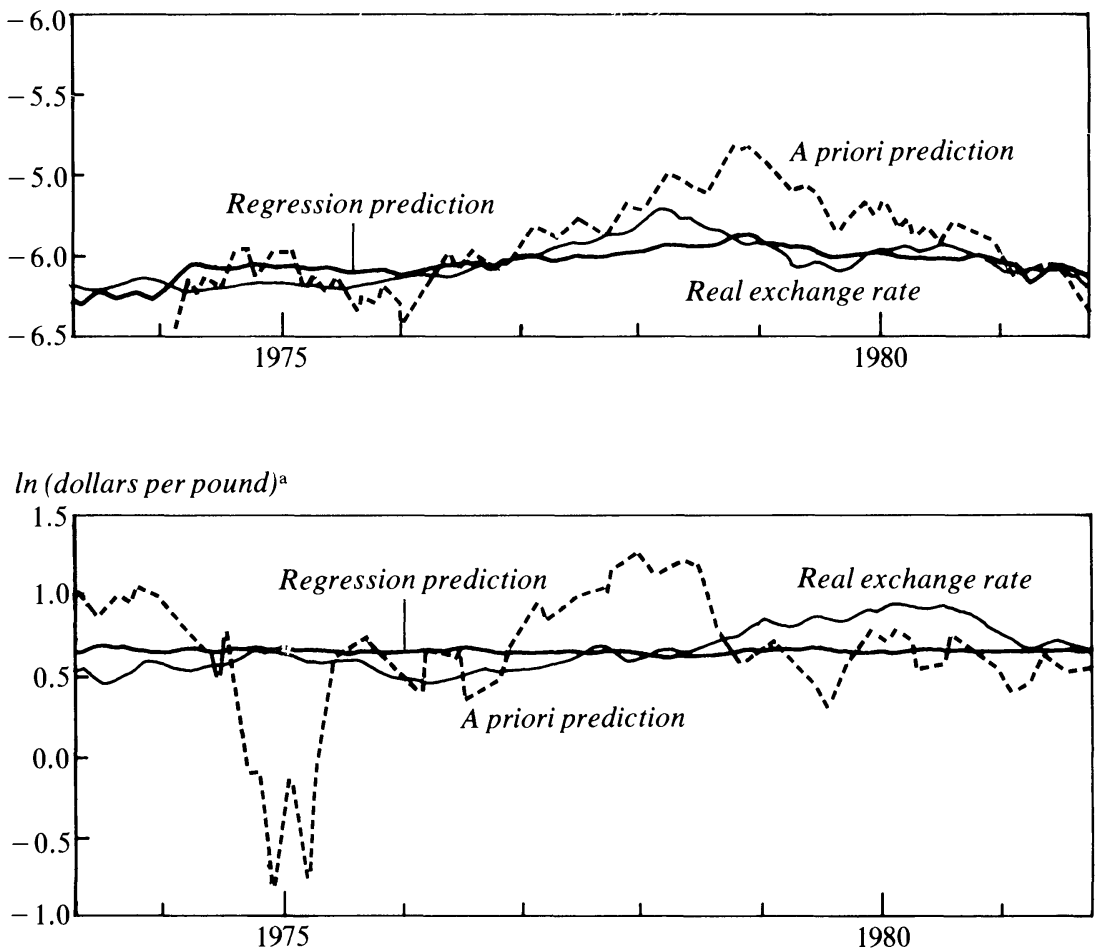

Source: Authors' calculations as described in the text, based on data from Federal Reserve Bank of New York, international macro data base.

a. Both currencies were deflated by the CPI index in which $1976=100$. 
than 4 percent. This flatness may be largely a consequence of the way the proxies were calculated-forecasts for monthly inflation differentials tend to converge to their mean values in the first few years so that the ten-year average forecasts remain near their average values. Ideally one would prefer to have long-run inflation forecasts that give more weight to longer-run developments, but with a sample period of less than ten years, there are few observations on lower-frequency phenomena. Still, the rational forecasts seem justified on two grounds. First, diagnostic tests did not suggest that longer lags should be included. Second, one could reasonably expect average inflation differentials over a period as long as ten years to correspond more closely to average inflation over a comparably long past period than to current inflation. Nevertheless, the evidence suggests that the markets for the yen and mark may have been heavily influenced by near-term inflation experience. ${ }^{52}$

Uncovered interest parity does not seem to offer an explanation for movements in the dollar-pound exchange rate. A number of explanations come immediately to mind, including the phasing out of the reserve role of the pound for the first half of the period, capital controls in the United Kingdom before 1979, and the effect of oil prices and North Sea oil developments on market assessments of the competitive position of the United Kingdom's economy. But a priori one would have had little reason to expect these factors to be more important for the pound than similar factors would be for the other currencies.

The strong perverse relation for the dollar-pound exchange rate based on the rational inflation expectations proxy also calls for explanation. As for the other currencies, the time series for this proxy is essentially flat. Thus the perverse relation is primarily one between the nominal interest rate differential and the exchange rate. This may well reflect a greater tendency of the authorities in the United Kingdom to move interest rates in response to pressures in the exchange market. Such behavior was most evident in 1976 and 1977 as authorities in the United

52. Steve Golub, "International Financial Markets, Oil Prices, and Exchange Rates" (Ph.D. dissertation, Yale University, 1983), has also explored the relation between interest rates and inflation by taking cumulative ex post realized real inflation differentials as a proxy for rational expectations. He finds, as we do with our rational expectations proxy, that persistent differentials cannot explain exchange rates very well. See also Peter Isard, "An Accounting Framework and Some Issues for Modelling How Exchange Rates Respond to the News," in Jacob A. Frenkel, ed., Exchange Rates and International Macroeconomics (University of Chicago Press, forthcoming). 
Kingdom raised interest rates sharply when the pound weakened and moved them down again when it recovered.

This analysis of interest rates, inflation, and real exchange rates provides some evidence supporting the sticky-price monetary model's predicted relation between the real interest differential across countries and changes in the real exchange rate. But the results are not robust, and the relation fits best under a myopic view of expectations that seems inconsistent with rationality. This latter result suggests a need for further study to determine whether the apparent expectational anomalies do in fact exist. If they do, are they specific to exchange markets or can they be related to behavior in other asset markets, particularly to the term structure of interest rates and capital investment markets?

THE ROLE OF THE CURRENT ACCOUNT AND TRADE BALANCE

While the VAR evidence (including the results in the appendix) provides some support for the relative importance of the trade balance or current account in explaining fluctuations in some exchange rates, that effect has not been constrained in estimation to pass through a portfolio-balance channel. There are other hypotheses indicating that current accounts should influence the path of the exchange rate. It seems unlikely that the portfolio-balance channel can explain the strength of the often-noted association between current account deficits and depreciation or current account surpluses and appreciation. It is implausible, for example, that the portfolio-balance mechanism was the cause of the pronounced dollar depreciation accompanying the U.S. current account deficit pattern in 1977 and 1978. The effect of the $\$ 28$ billion cumulative U.S. current account deficit on net U.S. private sector holdings of foreign assets was swamped by concurrent intervention of more than double that amount. ${ }^{53}$ Moreover, in many years, the effect of government deficit financing operations on wealth and relative domestic and foreign asset stocks far outweighs that of current account imbalances. Current account imbalances could also have an impact on goods market equilibrium. But the wealth effect of government deficits again can more than offset wealth transfers induced by the current account, so that any potential

53. See Peter Hooper and John Morton, "Fluctuations in the Dollar: A Model of Nominal and Real Exchange Rate Determination," Journal of International Money and Finance, vol. 1 (April 1982), pp. 39-56. 
effects of current accounts on goods markets might easily be offset by other forms of asset accumulation. ${ }^{54}$

This leads one to suspect that forces other than the portfolio balance mechanism may be at work. One possibility that has been explored in recent work is that unanticipated developments in the current account or trade balance provide new information about a country's evolving competitive position and hence about the exchange rate level consistent with long-run current account balance. ${ }^{55}$ Thus the current account may signal required long-run exchange rate adjustments and so have a significant short-run influence on the exchange rate. The practical limitation of this version of the current account-exchange rate nexus is that it provides little guidance on the difficult empirical question of how best to model the expected long-run equilibrium exchange rate.

This signaling hypothesis, favored by proponents of the monetary model, provides no direct channel through which the current account can affect the exchange rate and thus suggests that it is only current account innovations that affect the exchange rate. ${ }^{56}$ Some findings have indicated the importance of current account news, although there is also evidence indicating that anticipated changes in the current account matter. ${ }^{57}$

54. The impact of wealth transfers induced by the current account on the goods market has been explored by Rudiger Dornbusch and Stanley Fischer in "Exchange Rates and the Current Account," American Economic Review, vol. 70 (December 1980), pp. 960-71; and Guillermo A. Calvo and Carlos Alfredo Rodriguez, "A Model of Exchange Rate Determination under Currency Substitution and Rational Expectations," Journal of Political Economy, vol. 85 (June 1977), pp. 617-25.

55. See Hooper and Morton, "A Model"; Isard, "An Accounting Framework"; or Michael Mussa, "The Role of the Current Account in Exchange Rate Dynamics," Discussion Paper (University of Chicago, June 1980).

56. Unless wealth is incorporated in the money demand function. See Pentti J. K. Kouri, "The Exchange Rate and the Balance of Payments in the Short Run and in the Long Run: A Monetary Approach," Scandinavian Journal of Economics, vol. 78, no. 2 (1976), pp. 280-304; or Jeffrey A. Frankel, "The Mystery of the Multiplying Marks: A Modification of the Monetary Model," Review of Economics and Statistics, vol. 64 (August 1982), pp. 515-19.

57. For a theoretical model exploring the importance of the current account see Mussa, "The Role of the Current Account." Frenkel and Dornbusch provide empirical evidence on the role of news in exchange rate determination in Jacob A. Frenkel, "Flexible Exchange Rates, Prices and the Role of 'News': Lessons from the 1970s," Journal of Political Economy, vol. 89 (August 1981), pp. 665-705; and Dornbusch, "Exchange Rate Economics." Dornbusch modeled current account news as the difference between the actual value and the value predicted by the OECD. Evidence is provided in Bonnie E. Loopesko, "The Role of Current Account Imbalances in Exchange Rate Determination: 


\section{ARE EXCHANGE RATE RESPONSES NONLINEAR?}

A number of observers of exchange markets have suggested that exchange rates overreact to some new information relative to what would be expected under rational expectations. Overreaction could take many forms. Testing for it depends on having a model that places bounds on the appropriate response. Here we simply examined whether large changes in fundamentals are associated with more than proportionately large changes in exchange rates, behavior that would be inconsistent with linear models.

To see whether the market responds more strongly to large changes in other economic indicators, the change in the log of the exchange rate was regressed on the same variables as in the earlier VAR system, and on squared values of the first two lags of the determinants. The signs of the original observations were preserved, so that these terms represent disproportionately large or small changes in the same direction (positive or negative). If the true model were linear in all the determinants, the finding that the squared terms are significant could indicate a market overreaction to recent information.

The results in table 6 indicate that there is some evidence of a disproportionate response by the market to large recent developments in the determinants of the exchange rate. There is no evidence of nonlinear response for the dollar-pound rate, but some significant nonlinear response terms are found for the dollar-mark and dollar-yen rates. There is no well-defined pattern to the results. All that can be concluded is that these two exchange rates react more strongly to large changes in some of their determinants than would be predicted by simple linear models.

At best, these results suggest an avenue for further research. More generally, further empirical research is required into other theoretically suggested sources of market inefficiency such as bubbles, bandwagons, and extraneous beliefs about the determinants of exchange rates. ${ }^{58} \mathrm{It}$ is

Competing Hypotheses and Empirical Evidence," Research Paper 8236 (Federal Reserve Bank of New York, December 1982), indicating that it is not just news, but also anticipated current accounts, that affect the exchange rate.

58. For a discussion of these phenomena in the context of rational expectations models, see Oliver Jean Blanchard, "Speculative Bubbles, Crashes and Rational Expectations," Economics Letters, vol. 3, no. 4 (1979), pp. 387-89; Oliver Jean Blanchard and Mark Watson, "Bubbles, Rational Expectations and Financial Markets"' (Harvard University, January 1982); and Robert P. Flood and Peter M. Garber, "Market Fundamentals versus 
Table 6. Nonlinearity Tests, March 1973 to August 1982a

\begin{tabular}{|c|c|c|c|}
\hline \multirow[b]{2}{*}{ Variable } & \multicolumn{3}{|c|}{ Significance level of squared variables } \\
\hline & $\begin{array}{l}\text { Dollar-mark } \\
\text { rate }\end{array}$ & $\begin{array}{l}\text { Dollar-yen } \\
\text { rate }\end{array}$ & $\begin{array}{c}\text { Dollar-pound } \\
\text { rate }\end{array}$ \\
\hline Relative outputs & $8.7^{*}$ & 90.0 & 14.1 \\
\hline Relative prices & 62.2 & $8.5^{*}$ & 44.2 \\
\hline Relative money & 55.6 & 44.4 & 28.7 \\
\hline U.S. trade balance & 56.8 & 64.5 & 70.0 \\
\hline $\begin{array}{l}\text { Other country's current } \\
\text { account }^{\mathrm{b}}\end{array}$ & 60.2 & 79.2 & 19.1 \\
\hline Short-term interest differential & 76.0 & $5.1^{*}$ & 70.0 \\
\hline Exchange rate & $0.6^{* *}$ & $6.6^{*}$ & 91.7 \\
\hline $\begin{array}{l}\text { All nonlinearity terms taken } \\
\text { together }\end{array}$ & 15.7 & 18.4 & 48.4 \\
\hline
\end{tabular}

Source: Authors' calculations based on data from sources in table 3.

* Marginal significance of at least 10 percent.

** Marginal significance of at least 5 percent.

a. Marginal significance levels are reported above for $F$-tests of the joint significance of two lags of squared values of the explanatory variables, with original signs of the observations preserved. The equation also includes six lagged values of each explanatory variable (unsquared), so that the squared values are rough indicators of the nonlinear response of the exchange rate to movements in its determinants.

b. Trade balance for the United Kingdom.

not only important to determine whether the exchange rate moves too much in relation to economic variables but also why it may overreact, in order to determine whether intervention provides the most direct means to eliminate the problem. Attempts to address the latter issue will most likely have to focus on the microeconomic decision process in exchange markets.

\section{Exchange Rate Behavior and Policy}

What can be said about exchange rate policy when no existing model is strongly supported by the data? Should exchange rates be managed

Price Level Bubbles: The First Tests," Journal of Political Economy, vol. 88 (August 1980), pp. 745-70. Obstfeld and Rogoff show that even minimal government interventions can prevent speculative price bubbles in Maurice Obstfeld and Kenneth Rogoff, "Speculative Hyperinflations in Maximizing Models: Can We Rule Them Out?' Journal of Political Economy, vol. 91 (August 1983), pp. 675-87. McKinnon and also Dornbusch relate the discussion to the foreign exchange market. See Ronald I. McKinnon, "Floating Foreign Exchange Rates 1973-74: The Emperor's New Clothes," in Karl Brunner and Allan H. Meltzer, eds., Institutional Arrangements and the Inflation Problem, CarnegieRochester Conference Series on Public Policy, vol. 3 (Amsterdam: North Holland, 1976), pp. 79-114; and Rudiger Dornbusch, "Equilibrium and Disequilibrium Exchange Rates," Zeitschrift für Wirtschafts- und Sozialwissenschaften, vol. 102, no. 6 (1982), pp. 573-99. 
more heavily or even fixed once again? And, if so, how should this policy be carried out? Policymakers must choose exchange rate and macroeconomic policies despite the absence of clear answers to theoretical and empirical questions. What is more, there is little reason to expect that the fog of uncertainty will be dissipated soon.

The very fact of uncertainty-about economic behavior and about future shocks-needs to be kept at the center of policy discussions. With considerable uncertainty about key structural relations, policies that avoid disastrous consequences under a broad range of models are preferable to policies that are optimal for a strict interpretation of one model but would serve very badly for other plausible models. In addition, flexibility of policies is desirable when the world economy seems vulnerable to large shocks, both real and monetary.

One positive conclusion seems well established after ten years of experience with floating exchange rates: countries are not insulated from disturbances or policies in other countries by a strong purchasing power parity relation between exchange rates and relative prices. At a minimum, the interdependence of macroeconomic developments indicates a need to take external developments into account when developing strategies for domestic macroeconomic policy.

To carry the policy discussion further than these general considerations, one must go well beyond what can be established about exchange rate determination on the basis of strong statistical evidence concerning aggregative relations. In this section more concrete views are offered on policy issues that reflect a plausible, but not strictly empirically proven, interpretation of the evidence. These views also reflect judgments on a number of issues not addressed in the paper. Three should be made clear at the outset. First, it is taken for granted that cumulative fluctuations of the real exchange rate on the order of 10 or 20 percent that are sustained for six months or more have important effects on trade flows, domestic economic activity, and inflationary processes, even in an economy as large and relatively self-contained as that of the United States. It is less clear, however, that exchange rate volatility over shorter periods has large real effects. Second, responsibility and accountability for macroeconomic performance are viewed as unlikely to be shifted from national governments to some international body. Policy proposals have little chance of practical implementation if they require authorities to subordinate national goals to international ones. Third, it is doubtful that 
controls on capital flows or the use of trade restrictions and trade subsidies would be desirable or even effective in managing exchange rates. We draw a sharp distinction between these policies, which seek to supplant or frustrate market processes, and central bank intervention in the foreign exchange market, which seeks to influence markets through the management of the government's own assets and liabilities such as foreign currency reserves, high-powered money, and nonmonetary debt.

The major policy issues can be grouped into four categories: exchange rates and monetary policy, the monetary and fiscal policy mix with floating exchange rates, international coordination of macroeconomic policies, and sterilized intervention in the exchange market. After discussing each of these, we conclude with our views on the desirability of returning to fixed exchange rates.

\section{EXCHANGE RATES AND MONETARY POLICY}

To the extent that exchange rates reflect real interest rates, they could be a useful guide to monetary policy when money demand is unstable and inflation expectations cannot be observed with much precision. Using the exchange rate in this way would involve, in effect, inverting the argument underlying our predictions of exchange rates from nominal interest rates and expected inflation rates. Some inferences about inflation expectations relative to interest rates could be made from exchange rate movements, although a rigid response of monetary policy to exchange rate developments would presume a tighter relation than seems to exist. The evidence on the relation between real interest rates and exchange rates from our crude experiments is mixed. Monetary factors do not seem to provide the entire story of exchange rates. And, even if they did, allowance would have to be made for developments in other countries.

A second reason for using the exchange rate as an indicator of monetary policy is that the deviations of real exchange rates from their long-run values, owing to disturbances in a world with sticky prices, will affect export- and import-competing sectors and hence aggregate demand and inflation with a lag. Thus a given monetary growth rate or interest rate may be more or less restrictive depending on whether the currency is strong or weak.

These considerations suggest a supplemental and judgmental role for 
the exchange rate in monetary policy rather than a central or mechanical role. But its potential value as an indicator warrants closer study.

\section{MONETARY AND FISCAL POLICY MIX UNDER FLOATING \\ EXCHANGE RATES}

The greater freedom of monetary policy under flexible exchange rates can easily contribute to a neglect of the stabilization role of fiscal policy. A balance of monetary and fiscal policy is important, however, to avoid cumulative distortions in trade and investment. There is a risk that budget imbalances will go unchecked long enough to alter international competitive positions and to affect capital formation. The greatest difficulty results from persistent budget deficits. The inflationary pressures created by the fiscal impetus will need to be contained by greater monetary restraint and higher real interest rates and the currency will appreciate. Higher real interest rates will reduce domestic capital investment, while a stronger currency will reduce the current account balance and generate a corresponding shift toward an inflow of funds from abroad on the capital account of the balance of payments. Because of the real interest rate sensitivity of domestic saving and investment, a capital inflow smaller than the government deficit will balance supply and demand for funds in domestic markets. Thus net capital inflows cannot prevent domestic capital formation from being crowded out even if international capital flows are perfectly elastic with respect to the expected rate of return. Moreover, any net flow of funds from abroad entails an erosion of the competitive positions of exporters and those competing with imports.

\section{INTERNATIONAL POLICY COORDINATION}

The large fluctuations in real exchange rates over the floating rate period, interpreted within a sticky-price monetary or portfolio-balance model, suggest strongly that economies are not insulated from what happens abroad. Consequently, even governments that pursue purely national objectives should seek close consultation and exchange of information on economic developments. Such consultations would be essential, for example, to the informed use of the exchange rate as an indicator for monetary policy.

In principle, macroeconomic interdependence among a relatively 
small number of large countries means that cooperative policies involving international quid pro quo or the acceptance of international constraints on policies should be superior to unilateral national policies, even if these are informed by international consultation on economic developments and intentions. But it is not obvious that the major macroeconomic problems of the past ten years could have been solved simply by more cooperative policies. Large shocks in the world economy and the breakdown of economic relations that had guided policy in the $1960 \mathrm{~s}$ overwhelmed policymakers. Ad hoc cooperative policy packages, which are seen by all parties to offer near-term advantages, can be put together within the existing international consultative framework of summit meetings and many lower-level meetings. Still, examples of agreement on substantive policy trade-offs are rare, presumably because cases in which all parties expect net benefits are unusual.

Adding more structure to policy coordination seems politically impractical and of questionable economic advantage. The uncertainty surrounding the effects of policies and the risk of shocks make the longterm benefits of a systematic exercise of cooperation doubtful. Under these conditions, governments can hardly be expected to accept even short-term constraints on policies.

\section{STERILIZED EXCHANGE MARKET INTERVENTION}

Exchange market intervention that is divorced from domestic monetary policy has been advocated by many as a policy instrument. Indeed, considerable intervention, much of it sterilized, has been undertaken during the floating rate period. The effects of sterilized intervention have not been explicitly analyzed in this paper, but the analysis presented bears indirectly on this issue..$^{59}$

59. We have not explored here directly the question of the effects of foreign exchange market intervention using publicly available data on official foreign exchange market transactions. A multinational study of the effects of intervention, in which the authors participated, has recently been completed using, in part, data unavailable to outside researchers. The results of this study indicate that the effect of sterilized intervention will be short-lived; sterilized intervention cannot reverse the exchange rate effects of divergent policies across countries; and the effect of coordinated intervention by several central banks will be greater than the same volume of intervention by a single central bank. See "The Report of the Working Group on Exchange Market Intervention" from the Working Group on Exchange Market Intervention, a group established at the Versailles Summit of the Heads of State and Government in March 1983. 
The current state of understanding of exchange rate behavior (or lack thereof) argues for a flexible and exploratory intervention policy. The evidence on deviations from covered interest parity points to the possibility that sterilized intervention could have an influence on exchange rates, although competing explanations for these deviations would suggest different channels through which intervention would affect exchange rates. The strong case for not intervening is based on the view that changes in the exchange rate reflect current and rationally forecasted future economic developments and policies. We find a large component of exchange rate volatility that cannot be related to the variables included in the VAR model. The possibility that exchange rates are excessively volatile because of unstable portfolio demands for assets denominated in different currencies, or because of volatile market psychology and bandwagons, must be taken seriously. The issue becomes a question of whether authorities are wise enough to sort out exchange rate changes attributable to these largely unobservable factors from more fundamental developments, which may also be difficult to observe except with a long lag. An additional case can be made that sterilized intervention should also be used to moderate deviations of real exchange rates from long-run equilibrium values caused by disparities in monetary conditions across countries. But such a policy would carry great risk of treating one symptom while leaving the underlying problem unresolved. It would seem better to attack such problems at their source-that is, by giving some weight to exchange rates in monetary and fiscal policy.

Balancing the possible benefits and risks of sterilized intervention, we advocate a cautious approach. Where there is strong corroborating evidence that shifts in portfolio demand are occurring relatively independently of expectations, their effects on exchange rates might be neutralized. One example would be an announced shift of asset preferences motivated by political considerations, although such events are likely to be rare.

Intervention that has as its objective reducing intraday and day-today fluctuations in exchange markets also warrants serious consideration. Its justification is not that short-run volatility is very costly, but that by reducing short-run volatility, the longer-run unexplained swings in rates might be moderated. Most active participants in foreign exchange markets say that when rates exhibit great short-run volatility, longer- 
run considerations have little or no weight in formulating their strategies. High volatility engenders more myopic behavior in market participants, perhaps because it causes longer-term expectations to be more loosely held. With longer-term volatility roughly proportional to day-to-day volatility, the possibility must be taken seriously that rates fluctuate for little or no economic reason far enough and long enough to have important macroeconomic, microeconomic, and random income-redistributive effects. Official action to reduce short-run volatility could then contribute to more stable long-run behavior and a more stable world economy. Such an intervention policy would not involve a cumulative buildup of large official foreign currency positions, nor would it attempt to maintain exchange rates at unsustainable levels. Thus the risks would be small.

\section{Fixed Exchange Rates for the Major Industrial Countries?}

Should the exchange rates of major industrial countries be fixed? Implicitly a negative answer has already been given to this question. Maintaining fixed exchange rates necessitates a level of macroeconomic policy coordination that was never achieved on a sustained basis, even under the Bretton Woods system. National authorities could not place the maintenance of the system above national economic goals. Only if political mechanisms evolved that provided for supernational responsibility and accountability for the conduct of macroeconomic policy and for international transfer payments to balance national interests would a truly fixed exchange rate system be likely to endure. Once par value changes become an accepted way of relieving pressures that build up in a fixed-rate system, currencies are susceptible to speculative attack. This was evident in the final years of Bretton Woods and more recently within the European Monetary System. Domestic policies are then deflected from course in efforts to maintain the system, with little if any long-run gain in exchange rate stability. A flexible exchange rate regime does not prevent authorities from giving weight to an exchange rate objective in the conduct of policy. It only dispenses with a rigid commitment to a particular rate, which has never been more than a contingent one for sovereign governments. The episodes of most extreme fluctuations of exchange rates during the floating rate period occurred when exchange rate and other external considerations had virtually no 
weight in monetary and fiscal policy, even so far as their effects on the domestic economy were concerned. Moreover, policies to reduce volatility through coordinated intervention have not been pursued with enough continuity to develop mature strategies. Before exchanging one extreme policy for another, it makes sense to explore the middle ground more thoroughly.

\section{APPENDIX}

\section{Results of VAR Estimation}

TESTS OF SIGNIFICANCE are reported below for the VAR exchange rate equation underlying the simulations discussed in the text.

Table A-1. Determinants of Changes in Exchange Rates, March 1973 to August 1982a

\begin{tabular}{lccc}
\hline & \multicolumn{3}{c}{ Significance level } \\
\cline { 2 - 4 } \multicolumn{1}{c}{ Lagged variable } & $\begin{array}{c}\text { Dollar-mark } \\
\text { rate }\end{array}$ & $\begin{array}{c}\text { Dollar-yen } \\
\text { rate }\end{array}$ & $\begin{array}{c}\text { Dollar-pound } \\
\text { rate }\end{array}$ \\
\hline Relative output & 77.4 & 55.6 & 42.2 \\
Relative prices & 17.7 & 80.1 & 40.7 \\
Relative money & 44.0 & 67.0 & 90.0 \\
U.S. trade balance & $3.7^{*}$ & 62.3 & 30.6 \\
Other country's current & & & \\
$\quad$ account & $0.3^{\mathrm{b}}$ & 44.7 & $0.2^{*}$ \\
Short-term interest differential & $4.8^{*}$ & 28.8 & 36.0 \\
Own lags & $0.7^{*}$ & 78.6 & 67.6 \\
Statistic & & & \\
$\quad R^{2}$ & 0.62 & 0.59 & 0.69 \\
Corrected $R^{2}$ & 0.25 & 0.07 & 0.17 \\
$Q(30)^{c}$ & 23.4 & 18.9 & 21.0 \\
\hline
\end{tabular}

Source: Authors' calculations, based on data cited in table 3 .

* Marginal significance of at least 5 percent.

a. Marginal significance levels of the $F$-statistics for null hypothesis that, conditional on lags of the other variables being included in the equation, coefficients on lagged values of the variable considered are not jointly significant (a low marginal significance level implies the variable is a highly significant determinant of the exchange rate change). Using a likelihood ratio test, lag lengths of 6,7 , and 8 were selected for the dollar-mark, dollar-yen, and dollarpound exchange rates, respectively.

b. Trade balance for the United Kingdom.

c. The $Q(k)$ is the Box-Pierce $Q$ statistic, which indicates whether the first $k$ autocorrelations of the residuals are significantly different from zero. Marginal significance levels for $Q(30)$ are 80 percent for the dollar-mark rate, 89 percent for the dollar-pound rate, and 94 percent for the dollar-yen rate. A high marginal significance level indicates that there is little evidence of serial correlation. It is the probability that the $Q$ statistic is at least as large as shown if the first $k$ residuals are, in fact, not autocorrelated. 


\section{Comments and Discussion}

Ralph C. Bryant: This paper contains many perceptive observations about the variability of exchange rates and does a good job of summarizing the recent literature. It is thus a welcome addition to the papers presented at earlier meetings of the Brookings Panel that focus on the international aspects of macroeconomic behavior and policy.

The first half of the paper is a skillful exposition of the evolution of theoretical analysis and actual experience. The authors strain a bit to force the chronology of the theory to fit the chronology of actual developments. (It is misleading, for example, to portray the portfoliobalance strand of the literature as developing after the flex-price and sticky-price monetary models and as a response to awkward facts that were not analyzed satisfactorily in those models.) As the authors themselves point out, the assumptions of purchasing power parity and uncovered interest rate parity have been shown not to hold in actual practice. By now, therefore, it is time to retire the flex-price and stickyprice monetary models and give them less time on the stage. These minor criticisms notwithstanding, the first half of the paper is insightful and should be useful background for a variety of readers of this journal.

The second half of the paper is the more important. In that part, in which the authors use VAR analysis to try to "explain" exchange-rate movements, I am skeptical of their empirical generalizations. The discussion of policy issues at the end of the paper is sound, but somewhat too agnostic. My comments thus focus on these two areas. I summarize my doubts about the authors' VAR analysis and then offer, less cautiously than the paper, some conclusions about policy attitudes to exchange-rate variability. 
How does an analyst "explain" the movement of an economic variable? At a proximate level, explanation relies on causal premises embedded in a single behavioral relation of a structural model. For example, changes in bank borrowing at the Federal Reserve discount window are typically explained by changes in the federal funds rate, the discount rate, and a scale variable for the aggregate size of bank balance sheets. For a deeper explanation, however, one cannot restrict attention to any single behavioral relation. In the case of discount-window borrowing, for example, one wants to know why the federal funds rate and the size of bank balance sheets behaved as they did, not merely that borrowing is proximately dependent on those variables. One is thus frequently driven to consider an entire structural model, or at least major blocks of an entire model, in which many variables are treated as jointly endogenous. To explain at that level, one must derive the reduced-form and final-form versions of the structural model.

Where do exchange rates appear in structural models? If a model is specified according to today's best-practice macroeconomic theory for open economies, exchange rates (or a weighted-average exchange rate serving as a proxy for all the bilateral rates) appear as arguments in many behavioral functions-in equations for asset demand and liability supply that serve as components of variables for expected returns, as a component of many price variables, and hence in demand and supply functions for goods. Exchange rates are also present in income-statement and balance-sheet identities. Generally speaking, the exchange rate appears throughout the structural equations as a variable on the righthand side. The exchange rate itself, however, is not a left-hand variable in any structural equation. The exchange rate is like goods prices and interest rates-quintessentially endogenous in the system of structural equations as a whole but not proximately "determined" in any single equation or small subset of equations.

In particular, it is wrong to characterize the exchange rate as just a component of goods prices, or just an asset price (even though it has many of the attributes of an asset price). The exchange rate is not merely the relative price of home and foreign goods. It is not merely the relative price of home and foreign monies. It is not merely the relative price of home and foreign securities. It is all these, and more.

To "explain" exchange rates in a meaningful way, therefore, there is 
in principle no choice but to obtain the reduced-form or final-form equations of some structural model. ${ }^{1}$

Each behavioral equation in a structural model typically includes a stochastic error term to allow for unexpected disturbances in the behavior approximated by that equation. Such disturbances ("shocks") have a clear conceptual interpretation. In a structural equation for discount-window borrowing, for example, one can interpret the error term as an unexpected shift in bank demand; with clarity, one can say such a shock "originates" in the market for immediately available funds.

On the other hand, interpretation of the error terms in the reducedform equations of a model is not conceptually straightforward, as the authors recognize. In the typical case, each reduced-form error is a complex combination of many structural errors. Only if one knows the structure of the model is it possible to unscramble the reduced-form errors into their complex, structural components. And of course even when the structural errors are contemporaneously uncorrelated, the reduced-form errors will be correlated. In the typical case, it is not possible to speak of a composite, reduced-form error term as originating in some one sector or market in the model.

It is true that if the structural model happens to be recursive in a convenient way, one can more easily derive the reduced-form equations of the model and find that some of the reduced-form errors are a less complex composite of the underlying structural errors. For example, if the matrix of structural coefficients associated with the contemporaneous values of the endogenous variables can be written in a lower triangular form, the reduced-form errors will have a correspondingly recursive structure. For structural models of open economies in which the exchange rate appears throughout the behavioral equations as an argument, however, this convenient recursiveness property will not exist. The theory alone is sufficient to discount that possibility.

Suppose an analyst had available a plausible structural model and had derived its reduced-form and final-form equations. He would then be

1. It is instructive to ask which economic variables in a structural model are not capable of significantly influencing the exchange rate (that is, given best-practice theory, do not appear, contemporaneously or as lagged values, in a reduced-form equation for the exchange rate). As a matter of theory, the list of such variables is quite short, perhaps even nonexistent. 
able to offer a straightforward explanation of exchange-rate changes. Ex post he could identify unexpected disturbances in the structural equations and interpret them unambiguously. He could study the relative frequencies and intensities of those shocks. And he could thereby identify the "causes" of exchange-rate changes and unambiguously parcel out the variance of the exchange rate among them.

With these points as background, now consider the VAR systems estimated and used by Shafer and Loopesko. Is it possible to use such systems to assess whether the variables featured in asset market models can "explain" changes in the exchange rate? Can calculations such as those in figure 4 and in table 3 of the paper indicate which types of unexpected disturbances cause the exchange rate to deviate from its predicted value? Is it valid to make inferences about the proportion of the variance of the exchange rate attributable to disturbances originating in the foreign exchange market itself rather than being transmitted from other sectors of the economy? I believe the answer to all these questions is negative.

If a nonstructural VAR system is correctly to subsume a class of structural models containing the true model, at least two necessary conditions must be met. The VAR system must include all the variables appearing in the true model (with as many lagged values of all the variables as appear in the true model). And the true structural model must contain a recursive pattern in the contemporaneous interactions among its endogenous variables. The VAR systems studied by the authors are quite unlikely to satisfy either of those conditions.

First, the authors' VAR systems omit a number of variables likely to be important. For example, they contain no variable genuinely representing monetary policy. "Money," as conventionally defined, does not qualify. Even the theory in the simplified models discussed in the first half of the paper, at least when presented carefully, makes it clear that the relevant money is central-bank, high-powered money. The VAR systems have no variables representing fiscal policy. Perhaps the most puzzling omission of all is a variable representing the quantity of intervention in the exchange market, the stock of international reserves, or some other type of asset stock. Even the simplest and least adequate of the portfolio-balance theories asserts that wealth, at home and abroad, belongs in the VAR systems. But the authors include only changes in wealth coming from imbalances in the current account. 
If many variables are included in a VAR system, the problems with degrees of freedom tend quickly to become unmanageable. But that is a difficulty with the technique, not a valid analytical reason for excluding the additional variables.

Another difficulty with the Shafer-Loopesko VAR systems is their treatment of all home and foreign variables as relative values. The practice of using variables that are ratios, or differences, of home and foreign variables is typical of the literature; the authors have plenty of company. Nonetheless, a chief argument used to justify VAR analysis is its avoidance of arbitrary restrictions. It is difficult to imagine a more arbitrary assumption, which is what this practice comes down to, than presuming that the behavior parameters in the home and foreign structural equations are of the same magnitude.

Still another weakness of the VAR systems in this paper is their ruthlessly bilateral approach. In the mark-dollar system, for example, only German and U.S. variables are included. Nothing that happens in the rest of Europe or in the rest of the world can influence the markdollar exchange rate except by sneaking into one or more of the VAR residuals.

The second necessary condition for a VAR system to be valid, that the contemporaneous interactions among endogenous variables follow a recursive pattern, seems also quite unlikely to hold. As noted above, carefully specified models of an open economy with the exchange rate as an endogenous variable are even less likely than models of a domestic economy to satisfy this condition. Certainly for quarterly data, and probably for monthly data, most theories suggest that a contemporaneous, two-way correlation will exist between many pairs of variables. For example, exchange rates influence interest rates and interest rates influence exchange rates. Goods prices influence exchange rates, but exchange rates probably also influence goods prices.

Shafer and Loopesko acknowledge that the disturbances to which they refer in figure 4 and in table 3 are essentially reduced-form errors, not structural errors. They note that the reduced-form errors, or "VAR innovations," cannot be given a structural interpretation unless a pattern of block or full recursivity exists in the underlying structural model. But these conditions are quite implausible, as noted above. Yet it is a structural interpretation, and only a structural interpretation, that is of analytical interest. 
To the authors' credit, they report a set of random-data experiments in the paper. The results in table 4 strongly reinforce my reasons for discounting the results in table 3 and figure 4 .

Just as I doubt that the authors' VAR analysis helps to explain exchange rates in a meaningful way, I doubt that it can help in assessing whether exchange rates move "too much." With a structural model in hand, an analyst can either refute or support assertions that exchange rates move too much or are out of alignment. Doing so requires specification of a counterfactual scenario and of normative criteria for ranking actual and counterfactual outcomes. But the analytical procedures are conceptually straightforward.

With only a VAR system of the sort estimated in this paper, however, one cannot get a genuine handle on such questions. The authors themselves acknowledge this difficulty at one point in their discussion. Later in their paper, however, when they ask specifically whether exchange rates move disproportionately in response to large changes in economic variables, they are tempted to revert to their VAR systems and to report a rough test for nonlinear response (table 6). The same basic difficulties exist with this rough test, and it is no more revealing than the underlying VAR results.

I reluctantly conclude that in the VAR section of their paper the authors have not provided any dependable evidence on why exchange rates move as they do and whether they move excessively. What is needed is evidence on determinants of exchange rates in a structural sense. Despite an apparent appeal as a method of avoiding the difficulties of an old-fashioned structural approach, VAR systems are not capable of yielding something for nothing. If we want to make structural inferences, as we clearly do, there is no easy shortcut. ${ }^{2}$

Shafer and Loopesko are understandably constrained from advancing policy views very different from those of the Federal Reserve and the Reagan administration. Not being subject to such constraints, I want to state-incautiously-several propositions about the implications of exchange-rate variability for policy. These propositions seem to me a reliable anchor for more detailed recommendations.

There are two widely held, somewhat ideological views about changes

2. The criticisms of VAR analysis made here are developed more systematically in a recent paper by Thomas F. Cooley and Stephen F. LeRoy, "Atheoretical Macroeconometrics: A Critique"' (University of California at Santa Barbara, March 1983). 
in exchange rates. The first, most often encountered in Europe but also increasingly popular elsewhere, is the minimum-variance position. Those holding this view emphasize the uncertainty and disruption that may be associated with fluctuations in exchange rates and argue that governments should act to maintain as much stability in exchange rates as possible. The second view, the untrammeled-market position, holds that every nation should pursue appropriate domestic macroeconomic policies and then permit currency values to be freely determined in the exchange market without any intervention by central banks and governments.

Both of these traditional positions are analytically deficient. Variability in exchange rates is neither good nor bad in itself. And its presence or absence should not be a goal of national macroeconomic policy.

The traditional debate between the minimum-variance and the untrammeled-market positions has a polarized character that is misleading. Policymakers have no compelling reason to choose between fixed or flexible exchange rates. Since they do not have to make that choice, furthermore, they should not make it. When discussing domestic monetary policy, economists do not have analogously polarized debates about interest-rate variability-at least not to the same unfortunate degree. There is little pressure on policymakers to choose between minimum variability in interest rates and completely untrammeled variability. Nor should there be. When debate occurs about excessive interest-rate volatility, there are few if any who challenge the basic case for managed variability of some sort.

A third view about exchange-rate variability, the insulation position, was once very popular among economists. According to that view, "flexible exchange rates are a means of combining interdependence among countries through trade with a maximum of internal monetary independence" and are a "means of permitting each country to seek for monetary stability according to its own lights, without either imposing its mistakes on its neighbors or having their mistakes imposed on it." A sweeping version of that view asserted that flexibility in exchange rates bottles up policy actions and nonpolicy disturbances within the nation where they originate, thereby insulating other nations from their consequences. A more cautious version asserted only that flexible rates insulate nations from each other's "monetary" disturbances. ${ }^{3}$

3. Milton Friedman, "The Case for Flexible Exchange Rates," Essays in Positive Economics (University of Chicago Press, 1953), p. 200. 
As is now fairly widely recognized, and as Shafer and Loopekso note, this third view is also analytically deficient. It is simply not correct, in theory or practice, that flexible exchange rates can insulate an economy from disturbances originating abroad, even from monetary disturbances.

There is an element of truth in the conventional view about the insulating properties of flexible rates. For most if not all domestic macroeconomic policy actions taken abroad and for many types of nonpolicy disturbances, the effects spill over less into the home nation if the home currency is permitted to appreciate in response to external stimuli that are expansionary and to depreciate in response to those that are contractionary. But this element of truth does not constitute an unqualified recommendation in favor of more rather than less variability in exchange rates. For one thing, the buffering tendencies of variability do not apply to all types of disturbances originating abroad. Even more important, the buffering tendencies associated with exchange rate variability are not always beneficial. (For example, policymakers should not want to be insulated from the rest of the world in periods dominated by disturbances originating within the real sectors of their own economy.)

Still another common attitude about exchange rate arrangements has been to assert that one or another type of exchange rate system imposes constraints on policy decisions. Before 1973 it was widely believed that the obligation of maintaining a par value tends to "discipline" policymakers and constructively constrain their choices about domestic policies. The advocates of floating, using a similar argument to advance an opposite policy recommendation, claimed that the decision to float would provide independence for domestic policies. More recently, one frequently hears the assertion that a system of flexible exchange rates is a major constraint on domestic policies.

All these assertions and counterassertions, however, tend to be misleading. It is neither fixed exchange rates nor flexibility of those rates that impose constraints on domestic policies. Exchange rates per se are not the central influence. Rather, it is the openness of the economythe magnitude and pattern of international transactions-that puts genuine constraints on what can be done with domestic policies. The autonomy of national policies, furthermore, is undermined by the openness of the economy no matter what happens to exchange rates.

Shafer and Loopesko observe that the past ten years would have been difficult to live through under any exchange rate arrangements. I would state the point more strongly. There is no set of exchange rate arrange- 
ments under which the 1973-75 and 1979-80 oil shocks would not have had traumatic consequences. It is impossible to imagine any arrangements that would not have transmitted major inflationary and contractionary impetuses back and forth among the major economies. I doubt that the competence and appropriateness of domestic macroeconomic policies in the past ten years was much influenced, positively or negatively, by the exchange rate arrangements that actually existed, or that those policies would have been greatly improved under any other arrangements. For the same reasons, the next ten years in the world economy are likely to be difficult no matter what exchange rate arrangements are in place.

Intervention in the exchange market is not an unimportant issue, despite the points just made. Current U.S. policy about intervention is rigid and verges on a theological adherence to the untrammeled-market position. It would be preferable for the United States to take a more eclectic stance toward intervention for U.S. account and to adopt a more forthcoming position about cooperative intervention with foreign governments. (The discussion of intervention by Shafer and Loopesko is consistent with this recommendation, but they refrain from openly criticizing current U.S. policy.)

Even though U.S. intervention policy needs to be modified, it would be wrong to expect a great deal from that change alone. Indeed, the most important modification in policy that is needed is for the United States and foreign governments to refine their overly simple attitudes. Intervention policy and exchange rate arrangements are secondary rather than primary issues. The basic macroeconomic problems troubling the United States will remain, and cause headaches of roughly comparable intensity, regardless of what is done with intervention policy and exchange rate arrangements. It is thus a mistake to allow the manner and degree of variability in exchange rates to be seen as, in itself, an issue of overriding importance.

Rudiger Dornbusch: Various studies that have appeared in the past year, in particular the work of Meese and Rogoff, have documented the failure of structural macroeconomic models to explain the facts about exchange rates in a satisfactory manner. ${ }^{1}$ Indeed, a random walk is

1. Richard A. Meese and Kenneth Rogoff, "Empirical Exchange Rate Models of the Seventies: Do They Fit Out of Sample?" Journal of International Economics, vol. 14 (February 1983), pp. 3-24. 
shown to be preferable to structural models in predicting rates. In the field of exchange rate economics analysts have reached the point at which the stock market literature arrived some years earlier. Against this background, Shafer and Loopesko set out to investigate what is left of exchange rate economics and to determine what inferences can be made for exchange rate policy.

The paper presents a refreshing approach that blends market commentary and the centerpieces of exchange rate models. It studies episodes rather than trying to explain (where others had already failed) all the evidence in a uniform way. The authors immediately dismiss purchasing power parity as a plausible model to explain short-run developments in exchange rates and appropriately give emphasis to the difference in adjustment speeds between goods markets and asset markets, to the risk premium, and to the current account.

The dismissal of purchasing power parity that now has become well established is one of the important insights we have gained from the tenyear experience with floating rates and from a more thoughtful review of earlier episodes. It was believed that exchange rates might not follow purchasing power parity except during periods dominated by monetary disturbances. Now the evidence leads to a much stronger argument: in the case of monetary disturbances in particular, large systematic deviations from purchasing power parity are observed. This was dramatically illustrated during the German hyperinflation after World War I. And it appears whenever monetary instability dominates: for instance, in the experience of the United Kingdom or in the U.S. real exchange rate since 1979. The prices of U.S. manufactured goods relative to the dollar prices of other nations are today 20 to 30 percent higher than the 197382 average. That represents a very striking departure from purchasing power parity, the reason for which is to be found in the monetary-fiscal policy mix.

There are two central conclusions of the paper. First, the sticky-price asset-market model provides a relatively satisfactory framework to explain the broad pattern of exchange rate movements, at least in the cases of the dollar-yen and the dollar-mark. Second, there is no striking evidence of exchange rate effects through risk premiums and the current account, although on occasion these factors may have residually accounted for some of the experience. The combination of these two conclusions leads to a third, this one directed to policy: there is no 
presumption that exchange rates have moved in an unaccountable way, and for that reason an active exchange rate policy does not appear imperative. However, because there is some evidence that sterilized intervention might work and that deviations from equilibrium real exchange rates persist, the issue of whether to pursue a more active exchange market policy remains open.

Shafer and Loopesko offer two kinds of evidence on the success of structural models in explaining exchange rate developments. One is evidence from a vector autoregressive (VAR) representation of the exchange rate focused on the macroeconomy. The VARs are estimated for seven variables, with exchange rates placed last, and the results are used to determine the role of the "fundamentals" from popular models in accounting for the variance in the forecast error. The exercise shows that the fundamentals-innovations in money, prices, output, interest rates, and trade balances-account for only a small portion of the forecast-error variance for the short-term horizon, with the portion accounted for reaching 60 percent only after two years or more.

The variance decomposition that the authors show is interesting, but their interpretation is misleading. VARs cannot help, except by assumption, to identify the structural errors that give rise to exchange rate innovations. From the VAR estimation procedure it is clear that the innovation in the exchange rate equation is an amalgam of the error terms in all the structural regressions representing the news. ${ }^{2}$ Innovations in prices, output, or money are simply responses to combinations of these primitive innovations. The decomposition of the variance in the forecast error therefore does not help to allocate forecast error variance to such phenomena as shifts in money demand, transitory fiscal expansion, strikes, a blip in the wage equation, or an oil price shock. Because most of the variables used in the VAR representation (certainly the trade balance, for example) cannot be thought of as predetermined, the analysis really does not succeed in linking changes in exchange rates to news.

The authors conclude from their VAR analysis that fundamentals account for only about 60 percent of exchange rate movements. That conclusion is certainly not warranted. Forward-looking models of the exchange rate based on rational expectations show that anticipated

2. See Thomas F. Cooley and Stephen F. LeRoy, "Atheoretical Macroeconomics: A Critique" (University of California at Santa Barbara, March 1983). 
future movements in fundamentals affect the current exchange rate. News relevant to these future values of the fundamentals need not be correlated with the current realizations of the particular regressors that are used. The failure to explain exchange rates by structural models or by VAR analysis thus comes down to our inability to track these expectations, not necessarily to a failure of the models.

There are other reasons why I view this particular VAR approach with reservations. First, the entire analysis is excessively bilateral. It focuses only on two countries at a time and assumes implicitly that there are no important multilateral interactions through trade flows or through the world capital market. Data scarcity may have precluded a more generous specification, but that only means the exercise cannot be conducted meaningfully. The same is true for other important omitted variables such as wealth. It would be interesting to know, for example, whether stock market prices play an important role in exchange rate determination, as one would expect from portfolio models. I also discount the empirical results because, if there are important linkages between the interest rate and exchange rate, the 1979 change in Federal Reserve operating procedures is certain to have affected the relations among innovations, interest rates, and exchange rates, which makes the assumption of an unchanging stochastic process hard to accept.

The second kind of empirical evidence supporting structural models concerns the link between real interest rate differentials and the real exchange rate. The authors note that the real interest differential, $\left(r-r^{*}\right)$, is equal to the expected rate of change of the real exchange rate,

$$
r=r^{*}+\Delta q,
$$

where $q=p^{*}+e-p$ is the log of the real exchange rate and $p$ and $e$ are the logs of the price level and the nominal exchange rate, respectively. Assuming now that the real exchange rate, following a disturbance, converges asymptotically to its long-run equilibrium, $\bar{q}$, yields

$$
\Delta q=v(\bar{q}-q),
$$

or, combining equations 1 and 2 ,

$$
q=\bar{q}-\left(r-r^{*}\right) / v .
$$

The model therefore predicts that, when there is a real interest differential 
with foreign rates exceeding those at home, the relative price of foreign goods will be high and falling. The model carries the assumption of perfect asset substitution, and the evidence is offered in figure 5 .

The authors express qualified satisfaction with the findings for the case of the dollar-mark and the dollar-yen exchange rates, though not with the dollar-pound sterling rate. I am not certain by what criterion they judge their success, except to note that in the regression for the first two cases the linkage between interest differentials and the real exchange rate is indeed significant and of the sign indicated by the theory. But it is also true that these regressions perform well only if the 1980-82 period is included and that they show little stability in a sample for a longer period. It is also worth noting that the coefficients of the interest differential reported in the regressions show values of 2 to 3 for $1 / v$. Thus the mean lag, $(1-v) / v$, would be of the order of one and one-half years. These results are certainly out of line with the conjecture that disequilibriums in real exchange rates that persist for long periods, say ten years, account for the patterns in the real exchange rate and real interest rate.

The model for the real interest rate does well in explaining that a rise in U.S. interest rates should lead to an appreciation of the real exchange rate. But it fails when it predicts that the real exchange rate should also be depreciating. That has not in fact been happening, and a theory is needed that will explain why the dollar-real or nominal-is both high and stuck. I believe fiscal policy may provide an answer. In the United States the prospective full-employment deficits have increased greatly; abroad they remain unchanged or even decline. The effect is a rise in world aggregate demand at full employment. Moreover, although world aggregate demand has increased, there has also been a relative rise in the demand for U.S. goods because the fiscal expansion that has occurred in the United States has led to relatively larger increases in spending on U.S. goods, though of course there are also spillover effects abroad. One thus expects the full-employment real interest rate-the long-term rate-to increase in the world to restore the balance between world spending and world full-employment income. At the same time the real exchange rate of the dollar will appreciate to eliminate the relative excess demand for U.S. goods.

The diagram below illustrates these points. On the axes I show the world real interest rate, $r$, and the relative price of U.S. goods (the real exchange rate), $q$. Along line $I$ the world demand for U.S. goods is equal 


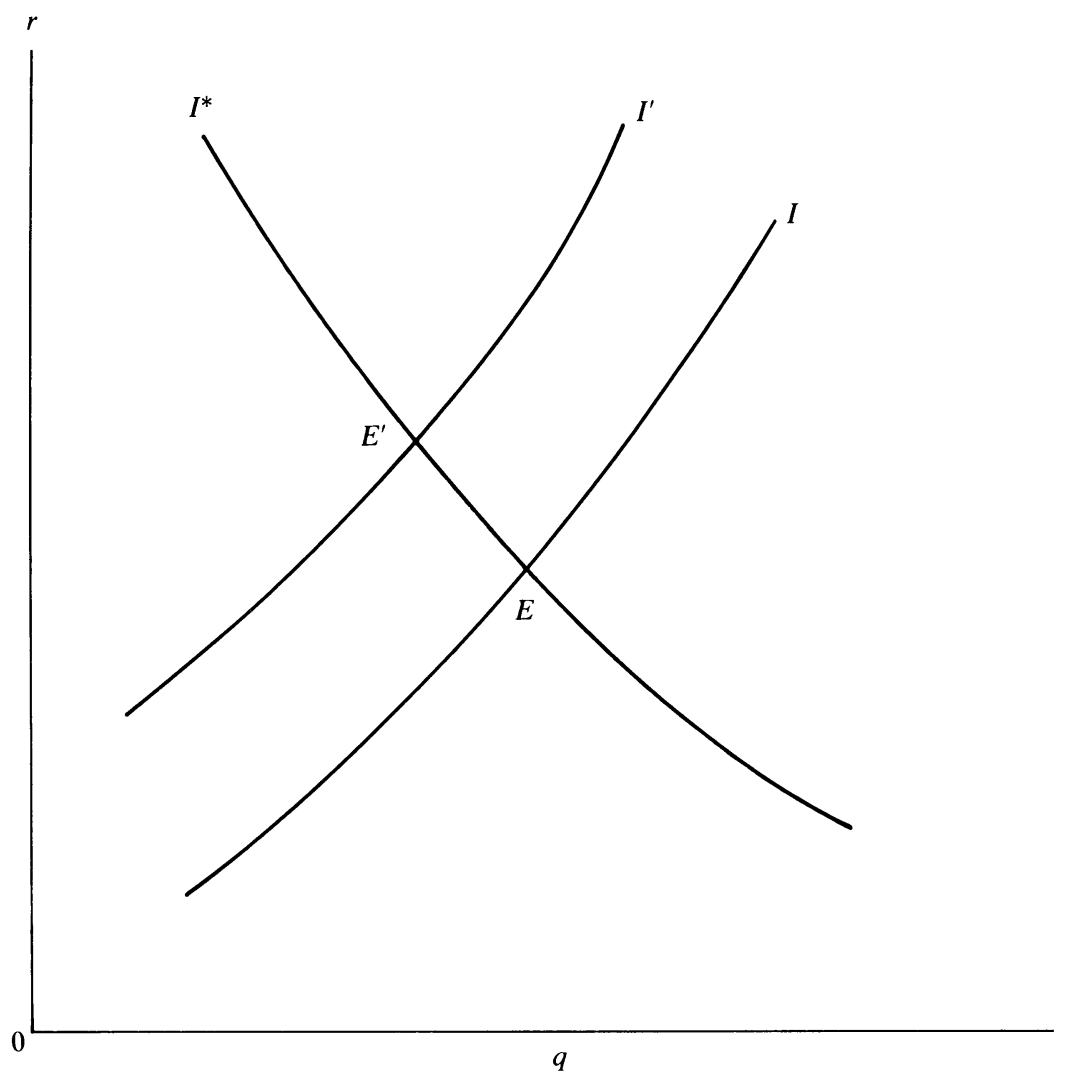

to the full-employment supply. Higher real interest rates depress demand and therefore require an offsetting real depreciation to maintain full employment. Similarly, along $I^{*}$ there is full employment abroad. Higher interest rates reduce demand and require a real appreciation of the dollar to maintain full employment abroad. A U.S. fiscal expansion, by raising the demand for U.S. goods, shifts the equilibrium schedule of the goods market upward and to the left. A new equilibrium obtains at point $E^{\prime}$ with a higher world interest rate and a real appreciation of the dollar.

These prospective changes in interest rates and exchange rates are anticipated under rational expectations and show up in higher long-term real interest rates and in dollar appreciation. The forward-looking nature 
of assets markets, however, makes recovery much more difficult. If this analysis is correct, a move toward smaller long-run, not cyclical, deficits would lead to a collapse of the dollar. The analysis emphasizes the peculiar and central effects of fiscal policy under flexible exchange rates. This is a point Shafer and Loopesko indeed recognize, although they do not go beyond sketching an interesting framework for a more complete investigation of fiscal policy.

The authors are cautious in their assessment of the experience with floating exchange rates, and they are equally cautious in offering policy advice. They do not conclude, for example, that flexible rates played an important part in the deterioration of macroeconomic performance and in the growth of protectionism. Nor do they argue forcefully either for intervention or against it. Now only few fully committed supporters of floating rates remain. But criteria are still lacking by which to form the judgment that flexible rates have been a bad experience, just as we confidently announce that the Bretton Woods system was poor.

Shafer and Loopesko do not express a strong view on intervention. They believe some intervention may be desirable in some circumstances. But, for instance, would they advocate using it to alter the present dollar exchange rate?

\section{General Discussion}

C. Fred Bergsten pointed out that, while much of the attention in the paper and comments was devoted to the possibility of excess volatility in exchange rates, the possible misalignment of exchange rates was of greater concern. These two issues are frequently mixed up in formal discussions, though they are conceptually quite distinct. In current policy discussions much of the present rationale for intervention in exchange markets has to do with maintaining relative stability of exchange rates, or what is usually referred to as "leaning against the wind." Yet often such intervention results in slowing down the required adjustment process as rates head toward their equilibrium values. $\mathrm{He}$ noted that the Germans had intervened in January 1983 to slow the appreciation of their currency against the dollar. This intervention was in keeping with the accepted international practice of leaning against the wind but was the opposite of what was required to achieve a fundamental realignment of currency levels. 
George von Furstenberg responded that we may know less than some people think about what alignment of exchange rates is appropriate. The German election results in early 1983 would appear to have removed uncertainty about the future of German policy, yet the deutsche mark subsequently fell against other currencies. Relatively high real interest rates, which were presumed to have overvalued the dollar, have melted away, but the dollar stubbornly persists in being "overvalued." U.S. budget deficits are presumed to contribute to the strong dollar, but even larger deficits in Japan apparently have no similar effect on the yen. Robert Lawrence disagreed with the statement that even well-informed specialists could not predict the impact of fiscal policy on exchange rates. He observed that Japan and the United Kingdom have actually tightened their fiscal policies, while the United States has loosened its policies. The consequences on the relative values of the yen, pound sterling, and dollar have been the expected ones. Edmund Phelps also commented on the relation between fiscal policy and exchange rates. An anticipated increase in future government expenditure will raise the anticipated future value of the local currency and thus strengthen the currency immediately. He reasoned that this effect, together with tax liberalizations that have raised the real rate of interest, may help explain the current strength of the dollar.

Even assuming that the authorities knew in what direction they wanted to move exchange rates, William Nordhaus noted that recent studies cast doubt on the feasibility of sterilized intervention-buying or selling foreign exchange without affecting either country's money supply. He argued that evidence suggests the effect of such intervention is exceedingly small. This result parallels the historical experience with "Operation Twist" under the regime of fixed exchange rates in the 1960s. Operation Twist represented an attempt to alter the term structure of interest rates so that short-term rates would be high, to attract funds to the United States, while long-term rates would be kept low so as to stimulate investment. However, the scale of the required intervention, even to change relative interest rates by a few basis points, discouraged authorities from a large-scale Operation Twist. 